\title{
Partitiv und Inkongruenz beim Subjekt des Finnischen.
}

Den Ausländer, der sich in den Bau der finnischen Sprache hineinzuarbeiten versucht, überkommt angesichts des Partitivs ein Gefühl der Hilflosigkeit, so wie einem Stosstruppführer vor einem feindlichen Minenfeld zumute sein mag: bei jedem Schritt lauern Gefahren, und selbst der guten, verlässlichen Mutter Erde, die uns allen einen festen Standort gibt, darf er nicht mehr trauen. Die mit viel Sorgfalt und Scharfsinn erarbeiteten Regeln, die uns durch das Gewirr der Einzelerscheinungen hindurchleiten sollen, sind teilweise bis zu einem bemerkenswerten Grad von Einfachheit vorgetrieben worden; aber derjenige, der die Regeln wirklich b r a u c ht, sieht sehr bald, dass diese Einfachheit trügt. Wer viel mit fremden Sprachen zu tun hat, weiss - entgegen allen Versicherungen der Lehrpraktiken -, dass es nur sehr wenig Einfaches in der Sprache gibt. Dem, der die Sprache von Kindheit an spricht, wird das freilich nur selten bewusst ${ }^{1}$. Für ihn sind die Regeln ein vergnüglicher Luxus: sind sie gut, dann zeigen sie ihm in handlichen, klaren Formulierungen, was er doch alles weiss; sind sie aber schlecht, dann stellt er voll befriedigter Eitelkeit fest, dass er es besser weiss als die Lehrer. Für uns Lernende aber sind die Regeln der Schlüssel zu einem unverständlichen Zeichensystem; wir sind in jedem Anwendungsfall auf ihre unbedingte Zuverlässigkeit und Eindentigkeit angewiesen, da wir ihn ja noch nicht aus dem Gesamtsystem heraus beurteilen können. Bei einem Phänomen von der Kompliziertheit des finnischen Partitivs

1 Vgl. auch. N. Denison, The Partitive in Finnish (Hels. 1957) S. 15. Leider erhielt ich das Buch erst nach Abschluss dieser Arbeit. 
aber sind die Regeln - um zu dem eingangs gebrauchten Bild zurückzukehren - wie ein Orientierungsplan über das Minenfeld ohne Zeichenerklärung.

Auf diesem Hintergrund wird es wohl verständlich, dass ich den Beginn der Aufsatzreihe über unser Thema im "Virittäjä» freudig begrüsste und den Gedankengängen der vorzüglichen Sachkenner mit wachsendem Interesse folgte. Aber schon bald blieb es nicht mehr beim blossen Zuhören. Nicht als ob ich mir angemasst hätte, einen besseren Weg durch das "Minenfeld" zu kennen; aber die Verschiedenheit der Standpunkte und der Anforderungen, von denen aus der Muttersprachler und der Lernende an die Probleme herantreten, führte mich bald zu der Einsicht, dass die normativen Regeln, um die sich die Aufsätze bemühten, vielleicht dem Wissenden oder gut Orientierten zur Stütze dienen, aber nicht dem Lernenden aus seinen Schwierigkeiten heraushelfen können. Das liegt zwar zum Teil, wie erwähnt, an der Beschaffenheit der Materie. Hinzukommt aber, wie ich immer wieder an mir selbst erfahren habe, eine gewisse Einseitigkeit in der Methode, die neuerdings auch den Diskussionspartnern bereits aufgefallen ist, vgl. O. Ikola, Vir. ${ }^{1} 60$, 350 ff. und Siro, 61, 184 ff. Seine Hilfsbedürftigkeit gibt dem Lernenden in gewissen Fällen einen Vorteil vor dem Muttersprachler, und eben hieraus leite ich für mich die Berechtigung $\mathrm{ab}$, in dieser schwierigen Diskussion das Wort zu ergreifen. Den Herausgebern der Zeitschrift danke ich herzlich für ihre Bereitwilligkeit, ihren Teil an dem Wagnis mitzutragen. und hoffe, dass infolge der ungewohnten Perspektive im Leser die von Penttilä bereits befürchtete Langeweile nicht aufkommen wird.

Wie u.a. Ravila betont hat (zitiert bei Siro S. 184), lässt sich die Vielfalt der Erscheinungen wissenschaftlich niemals vollständig und endgültig beschreiben. Dass die Regeln über den Partitiv nicht allen Anwendungsfällen gerecht werden können,

1 Die Diskussionsbeiträge aus den Jahrgängen 58-61 des "Virittäjä» werden nur mit der Nummer des betr. Jahrgangs bezeichnet. Bei SADENiEm und Siro, die beide nur einen Beitrag lieferten (Jahrg. 59 bzw .61) bleibt auch diese fort. - 
ist selbstverständlich. Wenn auch die Verfasser den Anspruch auf Vollständigkeit aufrecht erhalten müssen, so sind sie sich doch der Grenzen der von ihnen gewählten Methode bewusst. So schreibt z.B. Siro S. 185: »Toinen asia on yrittää etukäteen ratkaista, voiko se ja se verbi tällaisessa lauseessa (sc. mit Existentialverb) predikaattina esiintyä. Voimme oikeastaan vain käytännöstä todeta, että sitä voidaan tällaisessa yhteydessä käyttää eli että sen jokin esiintymä on eksistentiaalinen». Ikola $(60,351)$ : „Lauseita ei juuri voida ryhmitellä lajeihin, joita jyrkät raja-aidat erottaisivat toisistaan, vaan tavallisesti on olemassa monenlaisia väliasteita... On paljon lauseita, jotka jokseenkin yhtä hyvällä syyllä voidaan rinnastaa nominatiivisubjektillisiin kuin partitiivisubjektillisiinkin malleihin. Valinnan ratkaisee tällöin se, kumpaan suuntaan viittaava seikka on puhujan kielitajussa etualalla, kummasta näkökulmasta hän asian näkee» ${ }^{2}$. An den dann folgenden Beispielsätzen zeigt Ikola, wie nicht-existentiale Verba existential aufgefasst werden können.

Der Spielraum in der Verwendung des Partitivs erschwert natürlich in hohem Grade die Formulierung der Regeln und die schon vorher zu leistende Klärung des sprachlichen Tatbestandes. Ein grosser Teil unserer Diskussion ist ja nur deshalb notwendig geworden, weil die Verfasser, obwohl alle Finnen und gewiss mit feinem Gefühl für ihre Sprache begabt, nicht imstande waren, im Augenblick der Formulierung die ganze Vielfalt der einschlägigen Fälle zu übersehen - ein besonders aus der Erforschung der Muttersprache sattsam bekanntes Phänomen. So änderte z.B. Ikola seine Auffassung vom Begriff der Teilbarkeit unter dem Einfluss von Penttiläs und Sadeniemis Einwänden $(59,319)$, und auch die Bedingtheit der Partialität durch den Kontext sowie das Verhältnis der Existentialität zur Partialität ist anfangs noch nicht klar gesehen $(58,225 \mathrm{f}$ ); Penttilä wiederum korrigiert seine Auffassung von der Teilbarkeit (vgl. z.B. 60, 34) und der halbdefiniten Spezies $(59,396)$ usw. Dabei ist es interessant zu beobachten, wie jeweils die neue These möglichst auf $10 \mathrm{~g}$ is c h e m Grund entwickelt

Vgl. noch dens., 61, 295. 
wird, die Kritik aber von sprachlichen Feinheiten ausgeht und die Schärfe der logischen Definition durch sprachliche Interpretation abzuschwächen oder überhaupt zu beseitigen sucht. So lockert Ikola 58, 226 die Koppelung von Teilbarkeit und Partitiv für die negierten Sätze auf; Sadeniemi schränkt 59, 14 Ikolas Feststellung ein, dass ein Subjekt, dessen Vorstellung bestimmt und teilbar ist, total sei; Penttilä mildert dann den scharfen logischen Gegensatz von definiter und indefiniter Spezies durch Einführung der "halbdefiniten" Spezies, die dann Siro $61,189 \mathrm{f}$. in eine "quantitativische" und eine "notivische" unterteilt. Die gegenteilige Tendenz zeigt sich in der bereits erwähnten Meinungsänderung Penttiläs gegenüber dem Begriff der Teilbarkeit: er wird extrem logizistisch und findet denn auch keine Zustimmung.

Die Bedeutung dieser anscheinend von der Sache selbst diktierten Richtungsänderung scheint mir darin zu liegen, dass alle Verfasser, obwohl sie ihre Aufgabe im Bemühen um leicht fassliche, für die praktische Grammatik brauchbare Regeln angriffen, sich in steigendem Masse genötigt sahen, die logischformalistische Betrachtungsweise durch die psychologischinterpretierende zu ergänzen und teilweise sogar zu ersetzen. Logisch gesehen, sind die Begriffe der bestimmten und unbestimmten Spezies konträr; eine »halb bestimmte" ist nur akzeptabel, wenn unan vom begrifflichen zum Stoffdenken, von der Logik zu den Verstehensvoraussetzungen des Sprechers übergeht. Die Begriffe der Teilbarkeit und Unteilbarkeit wurden weitgehend aus ihrer engen Bindung an die Gegenstände und die an diesen orientierte Logik befreit und zu Funktionen der Verbbedeutung entwickelt. Der scharfe Gegensatz zwischen Singular und Plural wurde durch Einführung des Begriffes der "pluralischen Individualität” gemildert - analog zur Kategorie der "Halbbestimmtheit". Damit näherte man sich wieder einer Anschauungsweise, mit deren Hilfe Airila schon 1924 (MSFOu. 52, 17 f.) m.E. bis zum Kern des Problems vorgedrungen war.

Die genannte Umorientierung führt zu der Folgerung, dass rein grammatische Kategorien zur Lösung der Schwierigkeiten nicht ausreichen. Die Kategorien sind nur der Niederschlag gewisser Kennzeichen der Sätze mit partitivischem oder in- 
kongruentem Subjekt; nur selten reicht eine allein zu dessen Motivierung aus (so etwa die Teilbarkeit der Subjektvorstellung ${ }^{1}$ ), d.h., nur selten ist sie zureichender Grund für dessen Anwendung und ist also kein fester Bestandteil des finnischen Sprachsystems. Weder erhalten Teilbarkeit und Spezies im Finnischen einen einheitlichen formalen Ausdruck, noch haben umgekehrt die partitivischen und die inkongruenten Fügungen eine einheitliche Funktion. Dieser Sachverhalt ist m.E. der sprachliche Ausdruck dafür, dass zwischen den Sätzen mit nominativischem Subjekt und Kongruenz einerseits und denen mit partitivischem Subjekt und Inkongruenz andererseits keine scharfen Grenzen bestehen, dass m.a.W. diese Doppelheit zur subjektiven Interpretation gegebener Sachverhalte benutzt und damit zu einem der Mittel ausgestaltet wird, die jede Sprache entwickeln muss, um das ungeheure Missverhältnis zwischen der Unendlichkeit des sprachlich zu Bewältigenden und den beschränkten Möglichkeiten der Einzelsprache tragbar zu machen.

Logische Definition sprachlicher Tatbestände erhebt ja den Anspruch, dass auch derjenige sie versteht, der die betr. Sprache nicht kennt. Sie müsste also für den Lernenden vollauf genügen. Welche Schwierigkeiten dessen ungeachtet dem Aussenstehenden aus der Beschäftigung mit unseren Problemen erwachsen, wieviel Unklarheit trotz oder vielleicht wegen der einseitig logischen Behandlung übrig bleiben ${ }^{2}$, soll jetzt anhand der Diskussion im "Virittäjä» veranschaulicht werden.

\section{Zur Existentialität.}

Wenn der Lernende die in Setälä-Sadeniemis Finnischer Satzlehre genannten Bedingungen für das partitivische Subjekt liest (zitiert 58, 224 f.), erhebt sich sogleich die Frage nach der Rangordnung der Bedingungen. Hierüber finden sich zwar

1 Vgl. Sadenieurs Bemerkung zu dem Satz Sukulaisiani ei asu Haminassa S. 13.

2 Auch Ikola ist sich dessen bewusst: vgl. $61,294 \mathrm{f}$. 
in den einzelnen Diskussionsbeiträgen mancherlei verstreute Angaben, aber im Zusammenhang ist der Gegenstand nicht behandelt worden. Dadurch wird die Übersicht über das komplizierte Zusammenspiel der einzelnen Faktoren ausserordentlich erschwert.

Ikola stellt zwar a.a.O. sogleich fest, dass die semologische Beschaffenheit des Prädikatsverbs die allgemeine notwendige Bedingung sei und zitiert Airilas sehr interessante Ausführungen SUST 52, 17 ff. Aber hier tritt sofort die Schwierigkeit hervor, die das Verständnis der ganzen Diskussion stark behindert: die Regeln sind deskriptiv abgefasst, sollen aber doch mit Hilfe der Interpretation im Grundsätzlichen verankert werden. Wenn der Begriff des Intransitivs so eingeschränkt wird, dass es »olemista, olemaan tulemista, olemasta lakkaamista tai liikettä, joskus tilanmuutosta» bedeutet, und wenn diese Feststellung in Airilas Erläuterung durch den Zusatz "ainakin pääosaltaan" weiter eingeschränkt wird, dann ist dem Lernenden gerade das nicht in die Hand gegeben, was er braucht, ein zuverlässiger Führer in der Praxis. Um den verwickelten Tatbestand "logisch» zu beschreiben, musste man die einschlägigen Verba unter einem so vagen Oberbegriff subsumieren (und dann noch mit Einschränkungen), dass der Lernende nicht mehr weiss, worin denn nun das entscheidende Kriterium besteht. Was ist das Gemeinsame bei "Sein, sein werden, aufhören zu sein, Bewegung, Lageänderung»!1 Und was hat das mit dem Partitiv zu tun? Da das sprachliche System nicht logisch sondern von eigener, gestalthafter Art ist, kann man solche Regeln nur dann anwenden, wenn man ihren Sinn versteht, d.h. den inneren Zusammenhang zwischen ihren Bestimmungen und dem zu regelnden Tatbestand. Airila macht - wie mir scheint, als Einziger - einen Versuch hierzu. Er sieht den Zusammenhang darin, wettä, predikaatin täytyy jättää subjektin epämääräisyys niin sanoakseni koskemattomaksi, se ei saa ilmaista subjektin toimintaa, ei mikä tai millainen se on ..., ja samalla kuin sen toiminnasta tai laadusta. jotakin sanotaan, se siirtỵ partiaalisesta totaaliseksi». Er meint

1 Vgl. Penttilä, 60, $31 \mathrm{f}$. 
also, das Subjekt stehe im Partitiv, weil es unbestimmit sei, und der Charakter der Unbestimmtheit lasse nur Verben der genannten Art zu, weil die übrigen Aussagen über Tätigkeit oder Beschaffenheit des Subjekts enthielten. Hier wäre also die später sogenannte Existentialität F o l g e, nicht Voraussetzung der Partialität ${ }^{1}$, d.h. sie könnte bestenfalls die Richtigkeit des Partitivs bestätigen, nicht aber als sicheres Kennzeichen seiner Anwendung gelten. Eine weitere Schwäche dieser Erklärung in unserem Zusammenhang besteht darin, das sie zu unscharf ist und dadurch den Lernenden in Unklarheit lässt, wann ein Regelfall gegeben ist. Wenn z.B. Verba wie tulla, juosta existential sind, so muss man siclı fragen, warum das nicht "toimintaa" ist, und warum sie dem blossen Existieren näherstehen als etwa "schreien». Zwischen "kommen» und "existieren" ist kaum eine andere Verbindung denkbar als die, dass der Kommende eben auch existiert, und diese gilt, wie die Kritik auch geltend gemacht hat, für alle Verba. Und selbst Angaben über die Beschaffenheit des Subjekts, die an sich eine sicherere Anleitung zu enthalten scheinen, schliessen die Existentialität nicht aus, wie Ikolas Beispiel a.a.O. Talonkin tyttäriä on palvelijoina beweist. Wenn es dann zu allem Überfluss noch, wie wir im Laufe der Diskussion erfahren, auch zahlreiche Existentialsätze mit nominativischem Subjekt gibt, so bleibt von diesem Teil der Erklärung Airilas in der Tat kaum mehr als ein nützlicher Fingerzeig übrig ${ }^{2}$. Auf ihren grossen Wert für unsere Betrachtungsweise werden wir unten zurückkommen. Wenn nun die finnische Forschung die Charakterisierung der zulässigen Verben als »existential» u.ä. durchweg als richtig anerkennt - auch Ravila Vir. 1944, 122 f., obwohl er dort gegen Siro ähnliche Einwände erhebt wie wir oben gegen Airila - , so ersieht man daraus, wie weitgehend der

1 Umgekehrt z.B. Sadeniemi s. 10.

2 Auch Denison sieht keinen Grund, am Begriff "Existentialität» zu rütteln. Sie ist für ihm eine Art Schwäche des Verbs, ein Mangel an Aktivität. Existentialität ist nach ihn Voraussetzung für den sunpersönlichen» Gebrauch, der für das Verb neben partitivischem Subjekt typisch ist (a.O. S. 11f f.). Vgl. u.S. 
Muttersprachler seine Sprache kraft seines vorgegebenen Wissens um ihren Bau beurteilt.

Ikola führt Airilas Gedanken insofern erfolgreich fort, als er versucht, die Existentialität mit Hilfe des Kontexts näher zu präzisieren $(58,225)$ : sie ergibt sich nicht allein aus der Bedeutung des Verbs, sondern ausserdem non kysymy̧s jostakin . . lokaliteetista tai olotilasta, jonka sisällöstä lause ilmoittaa jotakin (mitä se sisältää, rupeaa sisältämään, lakkaa sisältämästä jne.)». Die Möglichkeit, Ikolas Ausführungen im Sinne Sadeniemis misszurerstehen (die Partitivform ist psychologisches Prädikat: 59, 10), war zwar gegeben. aber im Grunde schon in Frage gestellt durch Ikolas Beispiele kirjeitä oli tullut, ihmisiä syntyy $(58,266)$; aber andererseits schwächen diese Beispiele die Gültigkeit ron Ikolas Formulierung wieder ab, da der Nichtfinne nicht weiss, in welchen Fällen man die Lokalität "hinzudenken» darf, und erwecken gewisse Bedenken, ob es wirklich die Aufgabe solcher Sätze ist nilmoittaa jotakin lokaliteetin tai olotilan sisällöstä», wenn in dem Satz kirjeitä oli tullut ein tänne 0.ä. unausgedrückt bleibt, weil es nach dem Zusammenhang selbstrerständlich ist, so ist es doch fraglich, oh Schwerpunkt der Mitteilung wirklich das Ankommen von Briefen zum Inhalt des Ortes Hier wird. Das liesse sich doch nur sagen, wenn andere Orte ausgeschlossen werden. Das aber ist in vorliegendem Satz, soweit ich rerstehe, nicht der Fall, und dann hätte die Ortsangabe wohl auch nicht fehlen dürfen. Eine Folge der begrifflichen Verschwommenheit ist es zweifellos, wenn Sadeniemi der Existentialität einen von Ikola nicht gemeinten Sinn beilegen kann: für ihn ist der Satz ${ }^{*}$ Pihalla juoksee Niemelän lapset existential $(59,13)$, für Ikola nicht $(59,326)$. So kann auch Ikola Sadeniemis Feststellung nicht gutheissen, dass im Existentialsatz die Inkongruenz geringeren Umfang hat als das partitivische Subjekt, d.h. dass die Inkongruenz keine $\mathrm{z}$ u r e i c h e n d e Bedingung für den Partitiv ist. Dagegen arbeitet Sadeniemis scharfsinnige Interpretation der verneinten Sätze (a.0. 12 f., vgl. auch Siro, 61, 186) mit einem viel wirklichkeitsnäheren, sprachgerechteren und daher leichter anwendbaren Begriff der Existentialität, der freilich Ikolas Konzeption stört (vgl. Ikolas etwas zu formalistische Entgegnung 59, 324; 328). 
Penttilä beteiligt sich zunächst nicht an der Diskussion um die Existentialsätze $(59,153)$. Er fasst sie wie Sadeniemi auf und hält die Voraussetzung, dass das Subjekt psỵchologisches Prädikat ist, für notwendig. Für ihn ist somit der Existentialsatz eine rein formale Grösse, und er bemüht sich um die Lösung mit Hilfe der Halbbestimmtheit.

Durch die Missdeutung und Linterbewertung seiner Existentialsätze wird Ikola genötigt. seine Auffassung weiter zu verdeutlichen $(59,319$ ff.). Er zeigt, dass der Begriff des psychologischen Prädikats hier entbehrlich ist und schiebt zwei Bestimmungen des Existentialsatzes in den Vordergrund, die wiederum die Logik auf Kosten der Sprachtatsachen zu stark hervortreten lassen. Obwohl sie wieder an Airila anknüpfen, führen sie nicht das weiter, was m.E. für die Forschung am wesentlichsten gewesen wäre. Er sagt nun, es komme ihm weniger auf das Verhältnis von Lokalität und deren Inhalt an als darauf, »että lause ilmaisee olemassa olemista» und dass "sen olemassaoloa ei edellytetä" (59. 322 et passim). Auf das Existieren, nicht auf das Sein an einem (rte komme es an; daher seien auch folgende Sätze existential: On olemassa monenlaisia kasveja ja eläimiä. Ihmisiä ei silloin vielä ollut. Es folgt dann nähere Erklärung des Ausdrucks vilmaiseen, die auch für uns wichtigr ist: das Sein ist dann mausgedrückt", wenn Lokalität oder Zustand nur als solche mitgeteilt werden, ohne den Gegensatz zu anderen Lokalitäten oder Zuständen auszuschliessen. "Jos sanotaan, että lokaliteetissa $L$ on olio tai esine $a$, ei tällöin ed ellỵt e t ä $a$ :n olemassaoloa, ei lähdetä siitä, että a joka tapauksessa olisi jossakin .... (S. 322 f.). Die Bezeichnung medellỵttää", die schon Airila gebraucht hatte. ist deshalb nicht ganz glücklich, weil $\log$ i s c h ja auch bei blosser Mitteilung das Sein "vorausgesetzt" wird. Gemeint ist aber die Voraussetzung i in $\mathrm{K}$ o n t e $\mathrm{x} \mathrm{t}$ : der Existentialsat\% ist nicht eine inhaltliche Berichtigungr von etwas, was der Hörer vorher aufgenommen oder gedacht hat, sondern eine vom Stoff her gesehen - isolierte Information. Es sei schon hier darauf hingewiesen, dass bei entsprechender Verteilung der Schwerpunkte diese Anschauung die Art der sprachlichen Darstellung als entscheidenden Faktor einbezieht. Die Ablehnung des Begriffs "psychologisches Prädikat" und die neue 
Präzisierung der Existentialität zwingt allerdings, soweit ich sehe, ebenfalls zur Aufgabe der Bestimmung, der Satz sage etwas über den Inhalt der Lokalität aus. Das Musterbeispiel kattilassa on vettä sagt weder etwas über das Wasser aus noch darüber, dass das Wasser den Inhalt des Kessels ausmacht, sondern es teilt einfach mit, dass im Kessel Wasser vorhanden ist. $^{1}$ Dass das Entscheidende an der Vorstellung vettä nicht ihr Beinhaltetsein im Kessel ist, scheint mir ua. daraus zu erhellen, dass man den Satz fortsetzen kann ..., ei kahvia. Nur so ist Ikolas Forderung erfüllt, dass keine anderen Möglichkeiten ausgeschlossen sein dürfen: das Inhaltsverhältnis darf nicht als These sondern nur als Information ausgesagt werden. Weiteres hierüber s.u. S. 50. Die später von Penttilä bemängelte Schwierigkeit bei Ikolas Betrachtungsweise beruht ua. darin, dass Ikola einerseits zugibt, der Charakter der Existentialität resultiere aus dem "näkökulma" (S. 323), d.h. ja aber doch aus dem (gedanklichen oder sprachlichen) Zusammenhang, andererseits a.O. behauptet, das Wissen, das der Hörer über die Existenz des gemeinten Gegenstandes aus dem Zusammenhang oder sonst erworben habe, sei nicht entscheidend. Wenn es sich so verhält, dann wird diese Kategorie in der Tat zu einem schwer zu handhabenden Instrument für den Lernenden und verliert für ihn erheblich an Bedeutung.

Penttilä nimmt nun, nachdem Ikola den Begriff der Existentialität erment in den Mittelpunkt gerückt hat, ebenfalls dazu Stellung $(60,31$ ff.). Er treibt die oben bereits angegriffene Subsumption der neben Partialsubjekt auftretenden Verbvorstellungen noch erheblich weiter: die Aufzählung der wesentlichsten Verbkategorien in der Grammatik sei »eigentlich überflüssig” (S. 32), da sie alle ein Element des Seins enthielten also eine formale Vereinfachung der Regel auf Kosten der Verständlichkeit. So muss man z.B. hinnehmen, dass erehtÿ̈ in der Bedeutung "aus Versehen kommen, hingeraten" im Gegensatz zu "sich irren" das Seienselement enthält ${ }^{2}$, weil es semolo-

1 Sachlich besagen alle Varianten das Gleiche; aber der Aussagewert der einzelnen Vorstellungen ist jeweils verschieden.

2 Ikola äussert 61, 296 Bedenken. 
gisch tulla nahesteht. Aber für den Nichtfinnen liegt es zweifellos näher, das Verb nach derjenigen Bedeutungsnuance zu beurteilen, die es von tulla u $\mathrm{n}$ t e r s c h e i d e t; sonst könnte man ja auch tulla rerwenden. Da die Grammatik möglichst alle Missverständnisse ausschliessen sollte, ist das Verhalten des Fremden hier vielleicht nicht belanglos. Sehr instruktiv ist auch Penttiläs Gegenüberstellung Ihmiset juoksevat (: Ihmisiä juoksee) täällä asioimassa pyhinäkin, auf die wir unten näher eingehen wollen. Sie zeigt, dass formal die Bedingungen des Existentialsatzes erfüllt sein können, ohne dass ein solcher entsteht, weil der $\mathrm{K}$ o n t e x t es hindert. Ist es (für den Finnen, möchte ich hinzufügen) nach Penttilä noch ssuhteellisen helppon, in Verba wie vilahdella oder lymyillä ein existentiales Element zu entdecken, so bedürfen folgende Sätze bereits der Verteidigung: Leipiä paistuu uunissa ("on olemassa sellaisia leipiä, jotka (nyt) paistuvat uunissa") oder Susia ulvoo järven jäällä (ebenso interpretiert). Penttilä selbst zögert bei dem Beispiel (S. 33) Oravia on kesyyntynyt kaupunkimme puistoissa, da kesyyntyä "ei ole mikään nimenomainen olemisen verbi». Nicht der Umstand, dass zwischen den existentialen und nicht existentialen Verba keine scharfe Grenze zu ziehen ist, spricht gegen Penttiläs Verfahren - denn das ist typisch für sprachliche Tatbestände - sondern die ungewöhnliche Ausdehnung eines an sich leicht auffassbaren Begriffsumfangs. Wertvoll dagegen ist wieder die von Penttilä zitierte Bemerkung Airilas, dass man die Existentialverba nicht gut mit Bestimmungen versehen kann, "koska siten itse to i m in t a, sen laatu astuu etualalle». Im ganzen aber genügt für Penttiläs "eksistenssilause" das Vorhandensein einer Lokalität. Er übernimmt nicht die von Ikola erarbeiteten Einzelheiten, aber er erkennt auch den fraglichen Sätzen nicht die von Ikola behauptete Bedeutung zu. Hier handelt es sich jedoch nicht allein um Unterschiede der theoretischen Analyse sondern gelegentlich um ganz konkrete Interpretationsschwierigkeiten, in denen der Nichtfinne nicht entscheiden darf (vgl. z.B. S. 42 f.; $345^{1}$ ). Jedenfalls beweisen solche Differenzen, wie trügerisch

1 Vgl. auch Ikola, 61, 295 f. 
die angebliche Einfachheit der Regeln ist. Besonders umstritten wird Ikolas Kriterium der Existentialsätze natürlich, wenn sie negiert sind, weil die Feststellung, dass das Subjekt. nicht den Inhalt der Lokalität bildet, zwar logisch der konträre Sonderfall des positiven Satzes, sprachlich aber etwas ganz anderes ist und daher in andere Gedankenzusammenhänge hineingehören und einen anderen Aussagewert haben kann ${ }^{1}$. Auch ist, da nach Ikola der Kontext nicht befragt werden darf, oft schlechthin nicht zu entscheiden, ob die Existenz an einem anderen Ort vorausgesetzt wird oder nicht (vgl. auch Penttilä, 60, $361 \mathrm{f}$.). Sachlich stichhaltig scheint mir an Penttiläs Kritik auch nach Ikolas späteren Kommentaren noch der Einwand, den er a.O. S. 43 gegen das Satzpaar Oppilaamme erehtyiiät (: Oppilaitamme erehtyi) opettajainhuoneeseen erhebt und der sich grundsätzlich gegen die ganze Deutungsweise erheben lässt: "En voi ymmärtää, että esim. lauseissa [folgen die genannten Sätze] lauseiden eron painopiste olisi oppilaiden olemassaolon edellyttämisessä tai edellyttämättömyydessä». Die dann folgende Begründung wird zwar später von Ikola entkräftet; aber die Behauptung, es handle sich im 1. Satz um die ganze Studentengruppe, im 2. um einen Teil, nicht aber um die Existentialität, schєint mir berechtigt. Ikola könnte zwar mit Recht erwidern, die Existentialität solle nicht den Satzinhalt sondern die logische Ursache der Satzform liefern. Aber es ist immer misslich, wenn diese beiden Faktoren nicht in innerem Zusammenhang stehen; dann ist die logische Erklärung in Gefahr, ihre Stringenz und Evidenz zu verlieren und die Sprachtatsachen zu vergewaltigen. Unseren eigenen Standpunkt werden wir unten im Zusammenhang entwickeln.

Naturgemäss wird die Diskussion im weiteren Verlauf, da es eine endgültige Lösung offenbar nicht gibt, immer komplizierter. Aber für uns ist eben dies negative Ergebnis wichtiger als neue Einzelheiten, so dass wir uns mit der Betrachtung weniger Gesichtspunkte begnügen können. Ikola zeigt 60, 340 f., dass Penttiläs Begriff "Existenzsatz» für die Partitiv-

1 Ein anschauliches Beispiel geben Penttiläs Darlegungen 60, 362 (gegen Ikola, a.O. s. 342). - 
regreln zu weit gefasst ist, weil z.B. bei canhenen, das eine Lageveränderung bezeichnet, das Partitivsubjekt unmöglich ist. Das muss Penttilä a.0. $360 \mathrm{f}$. einräumen, weist aber seinerseits darauf hin, dass auch die Existentialsätze derlei Verben nicht deutlich ausschliessen ${ }^{1}$.

Methodisch wichtiger ist Ikolas neuerlicher Hinweis darauf, dass die Existenz der Subjektvorstellung im Einzelfall nicht absolut sondern im Vorstellungszusammenhang des betr. Satzes gemeint ist (S. 343 f.): "Samoin ei lauseen Kattilassa on veltä subjektin tarkoite ole vesi yleensä eikä mikä tahansa vesierä, vaan juuri kattilassa oleva konkreettinen vesierä, jonka olemassaolo ei ole ennestään ollut tiedossa, vaan jonka olemassaolon juuri tämä lause ilmaisee». Die Kompliziertheit des Credankenganges mag mich entschuldigen, wenn ich mit folgendem Einwand nicht im Recht bin: enthält die eben zitierte Begriffsumschreibung nicht wenigstens formal eine Tautologie? Besagt sie nicht in dürren Worten, dass der Satz die Existenz der Subjektrorstellung mitteilt, wenn er ausdrückt, was er ausdrückt? Wenn die durch eine gedachte oder bezeichnete Ortsangabe bewirkte Beschränkung der Satzaussage notwendige Voraussetzung für die Existentialität ist, dann darf sie nicht gleichzeitig als Beweis für ihr Vorhandensein benutzt werden. Die Begrenzung durch Ortsangaben geschieht ja auch in nicht existentialen Sätzen. In unserem Beispielsatz ist die Subjektrorstellung laut obigem Zitat "kattilassa oleva. konkreettinen vesierä». Diese Vorstellung schliesst aber einerseits zweifellos die Existenz an einem anderen Ort aus, andererseits enthielte der Satz dann keine Mitteilung mehr sondern eine Tautologie: kattilassa oleva vesierä on kattilassa. Wenn ich bei unserem Satztyp zur Konstituierung der Subjektrorstellung die Ortsbestimmung bereits benötige, dann ist diese keine echte Bestimmung mehr. Anders ausgedrückt: wenn ich bei dem fraglichen Satztyp in die Subjektvorstellung die Ortsbestimmung, die deren Sein zum So-sein umgestaltet und damit die Existentialität konstituiert, bereits mit einschliesse, dann kann ich nicht auf Grund des Satzganzen den Subjekt-

1 Weiteres zur Abgrenzung der Existentialsätze u. S. 56 ff. 
gegenstand als Inhalt des genannten Ortes bezeichnen - kurz, ich kann nicht gleichzeitig etwas als Bestandteil der Subjektvorstellung und als ihr durch den Satz neu beigelegte Bestimmung ausgeben.

Mir scheint, wir haben es hier mit drei verschiedenen Schichten der Wirklichkeit zu tun: mit der realen Wirklichkeit, die die Gegenstände der sprachlichen Mitteilung enthält, ferner mit dem logischen Bereich, der rein formaler Natur ist und unabhängig vom Sinn der Aussage nur die Beachtung der Denkgesetze erfordert. In ihm ist unser Pseudosatz kattilassa oleva vesierä on kattilassa unanfechtbar. Es ist natürlich logisch einwandfrei etwas zu prädizieren, was das Subjekt bereits enthält; Tautologien sind bekanntlich in der Logik ganz gewöhnlich. Aber solche Sätze haben keinen Erkenntniswert. Auf diesen aber ist die $\mathrm{sprachli} \mathrm{ch}$ e Wirklichkeit orientiert. Hier denkt man in sprachlichen Ganzheiten, deren Bestandteile oft in logisch falschen oder doch ungenauen Beziehungen zueinander stehen, ohne dass der Sinn dadurch verdunkelt zu werden braucht. Da auch die meisten Wörter in sich abgeschlossene Sinnträger sind, müssen die sprachlichen Ganzheiten durch Verbindung dieser selbständigen Sinnträger aufgebaut werden. Die U̇bersummativität des Gesamtsinnes kommt in der Art der Verbindung zum Ausdruck. Wenn ich den Gegenstand "Wasser" als Inhalt des Gegenstandes "Kessel" sprachlich bezeichnen will, dann muss ich infolge der Natur der Sprache zunächst die beiden Vorstellungen $\mathrm{t} r$ e $\mathrm{n} n \mathrm{e} \mathrm{n}$, um sie dann verbinden zu können. Ich muss zwar im Denken die Verbindung bereits mehr oder minder deutlich vollzogen haben, um den Satz bilden zu können; aber das enthebt mich nicht der Notwendigkeit, die Verbindung im autonomen sprachlichen Bereich nochmals und zwar so zu vollziehen, als ob sie hier zum ersten Mal geschähe. Denn sonst könnte der Hörer sie ja nicht nachschaffen. Daher darf der Umstand, dass die Verknüpfung der Einzelvorstellungen zu einem Ganzen den Sinnumfang des Einzelwortes nach Massgabe der Ganzheit beschränkt und spezialisiert, bei der Beurteilung des gedanklichen Verhältnisses zwischen den Einzelvorstellungen keine Rolle spielen, da sonst der Akt der sprachlichen Verbindung und damit das sprach- 
liche Leben selbst gegenstandslos würde. Da die Sprache ihrem Wesen nach Mitteilung von Bewusstseinszuständen zur Aufgabe hat, muss sich auch derjenige, der ein fertiges Sprachgebilde analysiert, so verhalten, als ob er Empfänger dieses ausgesendeten Gebildes wäre. Er darf zwar mit dem Wissen operieren, das ihm das Satzganze vermittelt, da erfahrungsgemäss dies Wissen oft schon vor Beendigung des Satzes aufgefasst ist, aber er darf m.E. nicht Einzelheiten der sprachlichen Struktur (also z.B. die Regelung des Partitivgebrauchs) in ursächliche Abhängigkeit zu logischen, im Sinn der sprachlichen Mitteilung nicht aktualisierten Beziehungen der Satzbestandteile bringen.

Die Wichtigkeit dieser grundsätzlichen Fragen wird sogleich anschaulich, wenn wir z.B. ins Finnische übersetzen wollen. Nehmen wir den deutschen Satz "Welche von unseren Studenten kamen ins Dozentenzimmer». Nach Ikolas 59, 327 formulierten Regeln ist hier für die Bestimmung des Subjektkasus zunächst die Frage zu entscheiden, ob der Satz existential ist. Die Frage nach Spezies oder Teilbarkeit muss beiseite bleiben, da sie ja erst auf Grund der Existentialität beantwortet werden kann. Bleiben also nur zwei Kriterien. 1. Wird der Subjektgegenstand zum Inhalt des Ortes? Das ist zwar der Fall; aber das Gleiche trifft m.E. für den Satz zu "Unsere Studenten kamen ins Dozentenzimmer". Wie soll ich unterscheiden, ob der Satz etwas über den Ort aussagt (der ja doch in jedem Fall P r ä d i k a t, also $\mathrm{S}$ a t $\mathrm{z}$ a u s s a g e ist) oder darüber, dass das Subjekt zum Inhalt des Ortes wird, was ja ebenfalls eine Aussage über den Ort bedeutet? Soweit ich sehe, kann man nicht-existentiale Deutung im Sinne Ikolas hier überhaupt nur auf logischem Wege gewinnen, insofern sich das SubjektPrädikatverhältnis umkehren lässt, u.zw. in b e i d e n Sätzen. Das Zeugnis der sprachlichen Form dagegen weist ebenso einheitlich auf existentialen Sinn, insofern die sprachliche Verbindung einer Subjektvorstellung mit einer Ortsvorstellung durch ein verbum existendi im hier gemeinten Sinn immer zugleich die Existenz des Subjektgegenstands ausdrückt. Dieser Umstand entwertet gleichzeitig unser $\mathrm{z}$ w e i t es Kriterium. Wenn Existentialität dann entsteht, wenn das absolute Sein 
des Subjektgegenstandes durch Lokalisierung an einem bestimmten Ort in ein individuelles so-sein verändert wird, dann wilt auch dies Kennzeichen für b e i d e obigen Varianten des deutschen Satzes. Denn auch für die Variante mit Artikel gilt, was Ikola 60,344 über die entsprechende finnische Variante mit existentialer Geltung ausführt: »Tietenkin edellytetään, että maailmassa on oppilaita, mutta tämä lause kuitenkin ilmaisee juuri n ä $m$ ä oppilaat (ts. subjektin tarkoitteen) olemassa oleviksi». Besonders aufschlussreich ist die Fortsetzung: "Asia ei muutu, jos lisäämme subjektiin possessiivisuffiksin: Opettajainhuoneeseen tuli oppilaitamme. Ehkä voidaan sanoa lauseen edellyttävän, että on olemassa moppilaitamme», nutta siitä huolimatta ei lause edellytä juuri n ä i d e n oppilaiden olemassaoloa, vaan i I m a is e e heidät olemassa oleviksi». Obwohl also die Subjektvorstellung durch das Possessivsuffix bestimmt ist, die Bestimmbarkeit aber doch die Existenz voraussetzt, soll der Satz die Existenz der ins Dozentenzimmer kommenden Studenten ausdrücken. Ich sehe keinen Unterschied zwischen Bestimmung durch ein finnisches Possessivsuffix und einen deutschen Artikel, und auch in der Variante mit Artikel, der im Finnischen die nicht-existentiale mit Nominativsubjekt entspricht, wird gerade die in Rede stehende Studentengruppe mit Hilfe des Dozentenzimmers als existierend bezeichnet. Einen Vorschlag zur Lösung der Schwierigkeit vom Sprachlichen her werden wir unten vorlegen. Auf Grund vorstehender Überlegungen gewinnt man doch den Eindruck, dass logische Analyse der Beziehungen zwischen den Satzteilen allein die Existentialität nicht zu erhärten vermag. Da dies aber Voraussetzung für Bestimmung des Subjektkasus ist, lässt sich die richtige Übersetzung unseres Satzes auf diesem Wege nicht ermitteln, d.h. die Regeln über den Gebrauch des Partitivs sind an dieser Stelle lückenhaft. Eine Bestätigung hierfür scheinen mir die Sätze mit "unteilbarem" Subjekt zu bieten, in denen die Existentialität, wenn sie hier auch keine praktische Bedeutung hat, ja ebenfalls feststellbar sein muss. Der von Ikola $60,343 \mathrm{f}$. behandelte Satz Kattilassa on kananmuna ist, wenn ich recht verstehe, bei definitem Subjekt nicht existential, bei indefinitem existential. Die Spezies des Subjekts aber geht nicht 
daraus hervor, "was der Satz sagt" (a.0. 342) sondern lediglich aus dem Kontext, den Ikola aus der Diskussion ausschliessen möchte. Ich kann mich daher des Eindrucks nicht erwehren, dass unbewusst das Vorhandensein eines partitivischen Subjekts bei der Frage nach der Existentialität den Ausschlag gibt, wodurch natürlich ein Zirkelschluss entsteht. Trotzdem halte ich die nachdrückliche Hervorhebung der Tatsache, dass die Existentialität nichts Absolutes sondern im Einzelfall jeweils durch die Umstände bestimmt sei, für einen klärenden Fortschritt, weil sie die Unterscheidung von logischer und sprachlicher Wirklichkeitsebene erleichtert.

In dieselbe Richtung wie der soeben vorgetragene Einwand zielt Penttiläs Entgegnung 60,357 f. Penttilä geht aus von dem Satz Vene näkyy jo und argumentiert: wenn der Inhalt dieses Satzes zu seiner sprachlichen Formulierung eines Existentialsatzes bedarf und wir dann festgestellt haben, dass die Vorstellung "Boot" vom Standpunkt des Erscheinens teilbar ist (diese Überlegung ist $\mathrm{S}$. $356 \mathrm{f}$. durchgeführt), dann wäre nach Ikola die einzige Form, in der der Satz erscheinen könnte, Venettä näkyy jo; die zuerst genannte, die gut finnisch ist, liesse sich nur unter der offenbar falschen Annahme rechtfertigen, dass der Satz nicht existential sei. Da Penttilä hier den Ausdruck veksistentiaalilause" gebraucht, erhebt er also den Anspruch dass die Satzvariante mit nominativischem Subjekt I k o las Forderungen an den Existentialsatz genügt. Ikola hatte seine Ansicht zum letzten Mal 60, 345 ff. dargelegt. Leider habe ich seime Dirlegungen nicht ganz verstanden. Er weist auf die Besonderheit von näkyä (und kuulua) hin und führt aus, dass es sich bei ihrem Subjekt nicht um materielle Existenz sondern die Existenz eines sinneseindrucks handelt. Kirlko ei näy tänne wird dementsprechend so interpretiert: "Kirkko kuitenkin n ä k y y jonnekin (ts. sen näkökuva on olemassa jossakin)». Die Variante mit partitivischen Subjekt dagegen »ei sano tästä mitään, vaan ilmoittaa vain, ettei kirkon näkökuva ole olemassa "täällä» (tai ei tule "tänne»)". Was die Unterscheidung von Gegenstand und Sibneseindruck angeht, so ist sie m.E. wiederum zu logisch, und man möchte an Ikolas, gegen Penttilä gerichteten Satz 60, 342 erinnern: "Eihän mi- 
kään elävä kieli ole muodostunut tällaisen tieteellisen katsomuksen pohjalta, vaan kielen lähtökohtana on yksinkertaisen kansanihmisen ajattelutapa ja maailmankäsitys». Auch leuchtet die Notwendigkeit einer solchen Unterscheidung nicht recht ein. ${ }^{1}$ Wenn man mit Ikola zugibt, settä mikä tahansa esineen nimi, joka muuten esiintyy jaottomana, kuitenkin on "näkymisen kannalta katsoen jaollinen" $(60,345)$, dann bedarf der Partitiv bei näkyä logisch keiner Rechtfertigung mehr. Die Schwierigkeit scheint auch hier rein logischer Art zu sein. Ikola bemerkt nämlich a.O. S. 346, dass das Verb näkyä der Definition der Existentialität nur genüge, wenn man vom Sinneseindruck ausgeht. Daraus folgt m.E. nur, dass die Definition nicht sprachgerecht ist. Da die Frage nach der Abgrenzung der Existentialverba noch nicht geklärt ist, muss die Diskussion hier einstweilen abgebrochen werden.

Die andere Frage aber, wegen deren uns näkyä hier interessiert, ist wieder die: wie erkennt man den Unterschied zwischen existential und nicht existential? Ikola behauptet 60, 377 und 347 ohne Kommentar, dass die Sätze Oksien välistä näkyi orava und Tuolla oksien välissä näkyi oravaa beide deutlich existential seien, dass aber das Subjekt im 1. Fall unteilbar, im 2. dagegen teilbar sei. In den oben zitierten verneinten Beispielen lässt sich noch ein Unterschied wahrnehmen, u.zw. deshalb, weil die Verneinung die Existenz des Subjektgegenstandes an sich (und damit natürlich auch an einem anderen Ort als dem im Satz genannten) in Frage stellt (vgl. Sadeniemi S. 12 f., Ikola 59, 323). Aus den Beispielen scheint hervorzugehen, dass nichtexistentiale Sätze bei den Verba für Sinneseindrücke nur in negierter Form vorkommen, womit dann also in diesen Fällen ein Unterschied gefunden wäre. Danach wäre also der Satz Vene nälkyy jo existential. Aber woraus sehe ich nun, dass »die Existenz des Subjektgegenstandes nicht vorausgesetzt wird»? Worin besteht der Unterschied etwa zu Kattilassa on kananmuna mit definitem Subjekt? Im Rahmen

1 Vgl. den von Ikola 60, 347 diskutierten, nicht zulässigen Satz *kirkko ei näy, in dem die Existenz des Gegenstandes mit der Nichtexistenz des Erscheinungsbildes in Kontrast steht. 
seiner Partitivregeln ist für Ikola unser Satz - im Gegensatz zu Penttiläs Behauptung - doch möglich unter der Voraussetzung, dass die Subjektvorstellung »vom Erscheinen aus betrachtet» unteilbar ist. Auf dieses Problem werden wir noch zu sprechen kommen. Jedenfalls handelt es sich hier nicht um echte Polemik, da Penttilä einfach seine Ansicht ron der Teilbarkeit gegen die Ikolas stellt. Im Abschnitt über die Existenzsätze (a.O. 359 ff.) hebt Penttilä, wie schon erwähnt, besonders den Umstand hervor, dass unter den Verben, die Bewegung bzw. Lageänderung ausdrücken (und also seit alters zu den Existenzverba gehören), solche sind, neben denen partitivisches Subjekt unmöglich ist. Für unseren Gedankengang wichtig ist, dass diese Ausnahmen sich da finden, wo der Begriffsumfang des Seins besonders deutlich zugunsten eines konkreteren Inhalts überschritten wird. Abschliessend weist er nochmals sehr klar darauf hin, dass seiner Ansicht nach im Existenzsatz der Subjektspartitiv dann möglich ist, wenn die Subjektvorstellung teilbar ist, während Ikola formuliert (vgl. a.O. S. 358):» . . . mutta jos tällaisessa lauseessa [sc. eksistentiaalilauseessa] on puhe jonkin kokonaisuuden epämääräisestä osasta, on subjekti jaollinen ja partitiivissa...". Penttilä fasst also den Begriff der Existenzsätze weiter, fügt aber als Bedingung für den Partitiv die Teilbarkeit der Subjektvorstellung hinzu; Ikola wieder fasst den Begriff der Existentialsätze enger und gibt als 2. Bedingung an, dass von einem unbestimmten Teil die Rede sein muss. In beiden Fällen ist die Aussage über die Existenz des Subjektgegenstandes nur notwendige, nicht zureichende Bedingung für den Partitiv; deshalb erscheint Penttiläs Auffassung, bei der diese Bedingung einfach hingestellt wird, natürlicher als diejenige Ikolas, dessen Begriff der Existentialität zugleich enger und verschwommener ist, und der sich um einen (logischen) Zusammenhang zwischen Existentialität und Partialität bemüht. Dies Bemühen an sich ist zwar sehr zu begrüssen; indessen dürften die fraglichen Erscheinungen für solches Unternehmen nicht geeignet sein ${ }^{1}$.

Siro ist $(61,184)$ der Ansicht, dass die Diskussion einen "toten

1 Vgl. u, S. 51 . 
Punkt» erreicht habe und erwägt, ob man sie nicht dadurch weiterführen könnte, dass man die umstrittenen Begriffe »tietyn synkronisen rakenteen osina» auffasst. Zur Erklärung dieses Gedankens sagt er: »Kielellisten muodosteiden kaikkia ominaisuuksia ehkä ei saisikaan niiden tarkoittamasta todellisuudestı tai kielellisten ainesten merkityssisällyksestä lähtien selitetyksi, vaan on mahdollista, että eräät niistä kävisivät helpommin ymmärrettäviksi kielen rakenteen erikoisuuksina”. Als ich diese Sätze las, hatte ich die Hauptgedanken vorliegender Arbeit bereits halböffentlich in Helsinki vorgetragen ${ }^{1}$ und war sehr erfreut darüber, dass die oben angedeutete Richtungsänderung in der finnischen Forschung sich fortsetzte. Konnte ich doch nun hoffen, dass mein Beitrag sich organischer in den Diskussionsverlauf einfügen werde. Bezüglich der Existentialität kommt Siro zu ganz ähnlichen Ergebnissen, wie ich sie dargelegt hatte: mit Ikolas und Penttiläs Mitteln lässt sich die Existentialität nicht zu einem für unseren Zweck brauchbaren Werkzeug machen. Siro betrachtet das Problem "systeemin kannalta" und umschreibt dann den Sachverhalt so: "Ei-eksistentiaaliset predikaatit ovat sellaisia, että ne ilmoittavat tapahtumista tai toimintaa niin intensiivisesti, että niiden luoma lausekokonaisuus edellyttää subjektin tarkoittaneen olemassaoloa». Das existentiale Verb dagegen ssisältää väitöksen jonkin olemassaolosta. Se jättää siten subjektin laatuun nähden paljon avoimeksi, joten myös subjektin partiaalisuus käy mahđolliseksi ..."(184) ${ }^{2}$. Siro gibt allerdings, wie schon erwähnt, zu, dass sich dieser Sachverhalt nicht in handliche Regeln fassen lasse (S. 185). Siro sieht somit die oben vermisste Beziehung zwischen Existentialität und Partialität darin, dass die geringere Intensität des Existentialverbs die Subjektvorstellung weniger bestimmt. Leider ist er den neuen Weg nicht zu Ende gegangen. Er belastet seine Charakteristik des sprachlichen Tatbestandes noch mit dem alten, aussersprachlichen Gegensatz "Voraussetzung" und "Ausdruck" der Existenz, der ja zu den von ihm kritisierten Schwierigkeiten geführt hatte,

1 im Oktober 1956.

$2 \mathrm{Vgl}$. Airilas o. S. 20 zitierten Gedanken. 
und lässt dadurch die andersartige Betrachtungsweise $\mathrm{zu}$ wenig zur Geltung kommen: auch er gewinnt ja seine Vorstellung von der Existentialität "kielellisten muodosteiden tarkoittamasta todellisuudesta tai kielellisten ainesten merkityssisällyksestä», während der »Systemstandpunkt» (das viel strapazierte Wort ist hier anscheinend im Sinne der Satzganzheit, des eine geschlossene Gestalt bildenden Satzes gemeint) erst dann wirklich fruchtbar wird, wenn die Untersuchung sich auf das Satzganze und die es zusammenhaltenden Kräfte, insbesondere auf Subjekt $\mathrm{u}$ n d Prädikat sowie auf die Art richtet, wie sie im Satz miteinander verbunden werden ${ }^{\mathbf{1}}$. Bevor wir uns jedoch dieser Aufgabe zuwenden, müssen wir noch einen Blick auf die übrigen Faktoren werfen, die das Auftreten des Partitivs und der Inkongruenz bestimmen.

2. Sonstige Vorbedingungen des Partitivgebrauchs und der Inkongruenz.

Da die Diskussion über Teilbarkeit, Spezies usw. für den vorliegenden Zusammenhang von geringerer Bedeutung ist, brauchen wir hier die Einzelheiten nicht so genau zu verfolgen, zumal Siro das Wichtigste in dankenswerter Weise übersichtlich zusammengestellt hat $(61,181 \mathrm{ff}$.). Uns soll u.a. die Rangordnung der Bedingungen interessieren.

Für den Nichtfinnen ist der Gedanke am natürlichsten, dass der Partitiv unabhängig von der Existentialität nur bei teilbaren, unbestimmten Vorstellungen in Frage kommt. Auch dass im verneinten Satz das Subjekt als unbestimmt betrachtet werden kann, ist leicht verständlich. Diese - wenn wir von der Existentialität absehen - "naive" Anschauung herrschte im ganzen auch in Finnland bis zum Beginn unserer Diskussion. Ikola beginnt damit, dass er die Brauchbarkeit der Spezieskategorie für die Regelung des Partitivgebrauchs untersucht (58, 219 ff.). Er stellt fest, dass die umfassendste (notwendige) Bedingung für den Partitir die Existentialität sei, während die

1 Weiteres zur Existentialität u. S. 49 ff. 
Teilbarkeit im verneinten Satz entbehrlich sei, die Unbestimmtheit auch im affirmativen Satz nicht den Partitiv erzwinge: Talossa ei ole isäntää (hier kann nach Hakulinen die Subjektvorstellung auch definit sein; Penttilä würde hier von "halbdefiniter", Siro von "notivischer» Spezies sprechen), Muutamat pojat juoksevat pihalla. Nach Ikolas 1 . Beitrag ist also im negierten Satz die Existentialität $\mathrm{zurcichcndc} \mathrm{Bc}^{-}$ dingung, im affirmativen Satz dagegen nur die der untereinander gleichwertigen Partialität und Unbestimmtheit übergeordnete not w e n d ig e Bedingung.

Auch für die Inkongruenz will Ikola in erster Linie die Existentialität verantwortlich machen (a.O. 227 f.). Zu seinen Beispielen S. 228 möchte ich bemerken, dass Fälle mit olla = "haben" von besonderer Art sind und daher besser beiseite bleiben, sowie dass diejenigen Belege, in denen das Subjekt nicht psychologisches Prädikat ist, deutlich Sonderfälle und daher wohl als Ausnahmen zu werten sind. Ikola kommt zu dem Ergebnis, dass bei unteilbarem pluralischem Subjekt die Inkongruenz von der Spezies unabhängig ist; bei teilbarem Subjekt aber ist Unbestimmtheit neben Existentialität Voraussetzung für den Partitiv, während ebensolche Voraussetzung für die Inkongruenz bei teilbarem pluralischen (Nominativ)-Subjekt die Bestimmtheit der Subjektvorstellung ist. Inkongruenz im engeren Sinne (also neben pluralischem Subjekt im Nominativ) erscheint also nur im affirmativen Existentialsatz, wenn die Subjektvorstellung entweder unteilbar ist (Spezies spielt hier keine Rolle) oder wenn sie teilbar und die Spezies definit ist (S. 230). Die Kategorie der Unteilbarkeit ist also an Umfang grösser als die der Inkongruenz, aber nur ausserhalb der affirmativen Existentialsätze, innerhalb dieser Gruppe dagegen kleiner (weil es auch Inkongruenz bei teilbarem Subjekt gibt). Die Kategorie des teilbaren Subjekts ist auch innerhalb der affirmativen Existentialsätze grösser als die der Inkongruenz. Von den Spezies endlich trifft nur die bestimmte mit Inkongruenz zusammen; bei teilbarem Subjekt deckt sich ihr Bereich mit dem des Subjekts, bei unteilbarem ist er kleiner. Demnach wäre der Gegensatz Nom.: Part. auf affirmative Existentialsätze beschränkt und mit dem von def. 
und indef. Spezies gekoppelt; Subjekt beidemal teilbar. Das unteilbare Nominativsubjekt kann beide Spezies umfassen, das teilbare nur die bestimmte.

Diese Regeln werden nun im Laufe der Diskussion immer verwickelter und undurchsichtiger; nun erst beginnen für den Nichtfinnen die eigentlichen Schwierigkeiten. Sadeniemi hebt $(59,11 \mathrm{f}$.) zunächst einen nicht allein für den Nichtfinnen sondern auch grundsätzlich wichtigen Gesichtspunkt hervor, der m.E. von den übrigen Forschern zu wenig berücksichtigt wird, nämlich dass ein Satztỵp, der zwar vorkommt, aber deutlich als stärker bedingt, als Besonderheit empfunden wird, nicht ohne weiteres als mit dem Normaltyp gleichwertig behandelt werden darf. Er stellt fest, dass nominativisches Subjekt gewöhnlich definit ist, wenn es psychologisches Subjekt ist, wïhrend das unteilbare psychologische Prädikat indefinit, wenn teilbar, immer definit ist; bei Unbestimmtheit der Vorstellung tritt Partitiv ein - ein durchaus einleuchtendes Ergebnis, aus dem sich ganz klar die Bedeutung der Satzstruktur für unsere Frage ergibt. Bei seinem Versuch, den Geltungsbereich der Existentialität im verneinten Satz anders zu fassen (vgl. o. S. 21 ), weist Sadeniemi u.a. auf die Mehrdeutigkeit des verneinten Satzes hin (S. 13). Die in diesem Zusammenhang gemachte historische Bemerkung gehört zwar nicht in unseren Fragenkomplex, warnt aber zur Vorsicht bei dem Bemühen, alle einschlägigen Begriffe als homogen behandeln zu wollen.

Eine wirkliche Störung in der Symmetrie von Ikolas Regeln bedeutet Sadeniemis Feststellung, dass es auch unteilbare, unbestimmte, der Form nach pluralische Subjekte mit Inkongruenz gibt (Tỵp Siihen on olemassa hyvät edellytykset) (S. 14). Zwar kaun Ikola, der sich 59, 319 dieser Auffassung anschliesst, zunächst seine Regel sogar vereinfachen (S. 327: «sisällykseltään myöntävän eksistentiaalilauseen jaollinen subjekti on aina partitiivissa (ja indefiniittinen)». Aber dieser Fortschritt ist mit dem Nachteil erkauft, dass nun der Begriff der Teilbarkeit weiter belastet wird: pluralische Form ist nun weit häufiger als früher kein Kriterium der Teilbarkeit mehr. Schon Sadeniemi selbst weist auf die neuen Komplikationen hin in 
der Diskussion des später noch viel behandelten Satzes Miehillä oli mukanaan kirveet. Er sieht die Unteilbarkeit darin, dass die Äxte, die jeweils einem der Männer gehören, eine Gruppe bilden. Dass sie dadurch nicht allein "luvultaan", wie er meint, sondern überhaupt bestimmt sind (denn nach dem auch sonst in unserer Diskussion bevorzugten logischen Verfahren ist die Vorstellung kirveet ebenso possessivisch bestimmt wie in dem Beispiel Poikien paidat olivat puhtaat.), will er nicht zugeben. Penttiläs Ausführungen 59, 150 f. zeigen, dass man den Gruppencharakter der Vorstellung auch anders fassen kann (die durch die Situation geforderten Äxte). Siro neigt $(61,189)$ dieser Auffassung zu. Dass derlei Subjekte irgendwie bestimmt sind, dürfte damit erwiesen sein. Die hier angewandte Methode ist die gleiche, mit deren Hilfe Ikola seine Existentialität als in Bezug auf die genannte Lokalität definiert hatte, nur dass hier keine logischen Unklarheiten entstehen. Damit sind nach Ikolas Auffassung alle derartigen Sätze nicht existential; aber es gibt nun, entgegen seiner Regel, auch inkongruente nichtexistentiale Sätze. Für den Nichtfinnen entsteht die weitere Schwierigkeit, dass die unbestimmte Spezies im Finnischen offenbar einen anderen Umfang hat als etwa im Schwedischen (und Deutschen), wie Sadeniemi bemerkt. Dadurch dass sie nicht ins finnische Sprachsystem gehört, muss der Sprecher im Einzelfall nicht die Wahl zwischen den beiden Möglichkeiten treffen, sondern das Ergebnis folgt "zufällig", d.h. aus dem Zusammenhang. Sadeniemi führt als weiteren Faktor bei der Beurteilung der Inkongruenz den schon von Ahlman bemerkten Unterschied in der Zusammengehörigkeit ron Subjekt und Prädikatsergänzung ins Feld (S. 15 f.), der bezeichnenderweise von den übrigen Diskussionspartnern abgelehnt wird, weil er ihnen zu vage ist. Dieser echt sprachliche Gesichtspunkt ist indessen m.E. von grosser Bedeutung, weil er die sprachliche Form unmittelbar zum Abbild des sachlichen Zusammenhanges zwischen den Vorstellungen macht und sie dadurch weitgehend von den Zufälligkeiten des finnischen Sprachsystems befreit. Dass auch hier keine schematischen Regeln zu gewinnen sind, hat das Verfahren, wie Sadeniemi bemerkt und wohl aus den vorstehenden Ausführungen zu ersehen ist, mit den übrigen 
Methoden gemeinsam. Diese stecken aber überdies noch tief in speziell finnischer Anschauungsweise und erschweren nicht nur dem Nichtfinnen das Verständnis sondern können auch den Niederschlag dieses Denkens im Finnischen, das sie ja voraussetzen, nicht erklären. Logische Interpretation ist weder ein sicherer noch ein leichterer Ausweg. In eine ähnliche Richtung wie Ahlmans Bemerkung weist die ron Sadeniemi S. 16 angeführte Angabe aus dem Wörterbuch der Schwedischen Akademie über die Beschaffenheit der Sätze mit Scheinsubjekt det, die weitgehend den finnischen Existentialsätzen (in Sadeniemis Sinne) entsprechen. Für solche Sätze ist charakteristisch, dass "på grund af predikatets 1 . subjektets beskaffenhet det senare för tanken föga framträder såsom ett handlande subjekt". Hätte Sadeniemi sich die Mühe gemacht, diese Beobachtung für die finnischen Sätze fruchtbar zu machen, so wäre er wahrscheinlich zu der von Siro geforderten Betrachtungsweise vom Standpunkt des Systems aus vorgedrungen. So aber kommen wir nur zu der Regel a.O. S. 16, die durch das Schema auf S. 15 veranschaulicht wird. Zı diesem Schema kann der Ausländer nicht viel sagen, da er den Grad seiner repräsentativen Geltung nicht beurteilen kann. Nur ein Vorschlag sei erlaubt: wenn man Satz 3, den Ikola 59, 326 Fussn. 7 m.E. mit Recht als nicht hergehörig bezeichnet, ausschliesst, dann hätten wir in der 1. Gruppe nur inkongruente Beispiele, in der 2. dagegen nur einen mit dem plurale tantum kasiot als Subjekt; wenn das gleiche Wort in Satz 6 kongruiert, so beruht das auf der Bestimmtheit der Subjektvorstellung. Dann liesse sich die Inkongruenz ziemlich gut mit Siros "quantitativer Spezies" zur Deckung bringen. - In der abschliessenden Regel erscheint, den Rahmen des Existentialsatzes rorausgesetzt, für die Inkongruenz als zureichende Bedingung die feste Zusammengehörigkeit der Satzglieder oder das Nebeneinander von Unteilbarkeit und Unbestimmtheit (Ikola hatte auch bestimmte Vorstellungen zugelassen).

Bei diesem Stand der Forschung liesse sich also das Verhältnis der einzelnen Faktoren etwa so umschreiben: wenn die Subjektvorstellung unteilbar ist, kann der Partitiv nur im negierten Satz erscheinen; im affirmativen Satz kamn (ein geringerer 
Grad ron) Unbestimmtheit nur durch Inkongruenz bezeichnet werden, oder die Unbestimmtheit ergibt sich aus der syntaktischen Funktion (psychologisches Prädikat). Ist die Subjektvorstellung teilbar, dann kann an ihr die Alternative "bestimmt: unbestimmt» in Erscheinung treten, daher bezeichnet der Nominativ Bestimmtheit, der Partitiv Unbestimmtheit. Ob hier Inkongruenz auftreten kann, ist nicht sicher: Sadeniemis Satz 4 enthält die Verbindung Minulla on mukanani, die das Sprachgefühl vermutlich mit der Formel minulla on verbindet. ${ }^{1}$

Die durch Sadeniemis Beitrag ans Licht gekommene Problematik im Gegensatz "teilbar: unteilbar" veranlasst Penttilä 59, $148 \mathrm{ff}$. zu einer ausführlichen Analyse. Er wendet sich mit Recht gegen einseitig logische Interpretation (als Rückfall erscheint allerdings die Behandlung ron poikaa und poikia; sie sind ja nur Kasusformen, die von jedem Stamm ohne Rücksicht auf die Teilbarkeit bildbar sind) und kommt auf dem Boden von Siros Definition (Vir. 1943, 284) zu Sadeniemis Ergebnis (S. $151 \mathrm{f}$.). Auch er muss also den Gegenstand der Vorstellung als Masstab zugunsten des Kontexts aufgeben: Wenn man in dem Satz Miehillä oli mukanaan kirveet, führt er aus, die Axte in Gruppen teilt, so sind das immer noch Axtgruppen oder einzelne Äxte, "mutta $m$ i k ä ä n syntyvistä ryhmistä . . . ei ole tarittarien kirveiden ryhmä,... (152). Denlentsprechend die Definition: "voisimme sanoa jaollisuussaneeksi vain sellaista sanetta, jonka tarkoite voidaan jakaa . . . sellaisiin osiin, joilla ei ole mihinkään kokonaisuuteen kuuluran osan luonnetta». Im Interesse der Eindeutigkeit hätte erwähnt werden können. dass das "Ganze» entweder durch den Gegenstand oder im Kontext gegeben ist. Was der $\mathrm{B}$ e g r i f f der Teilbarkeit an Klarheit so verloren hat, soll die g r a $\mathrm{m}$ m at ische Kategorie durch Einführung der Halbbestimmtheit gewinnen, insofern dann, wie gesagt, teilbares Subjekt immer unbestimmt und partial ist (S. 154). Da Penttilä seinen Standpunkt bald änderte, soll dies Ergebnis nicht weiter behandelt werden. Von Interesse ist jedoch noch der Hinweis, dass die "halbbestimmten" Torstellungen "psycholo-

1 Vgl. Penttilä, 59, 159 f. 
gische Singulare" seien und daher Inkongruenz bedingen (158); hier wird also ein syntaktischer Tatbestand psychologisch gedeutet. Ferner werden mit Recht aus der Diskussion diejenigen Fälle ausgeschieden. wo die Bestimmtheit mit lexikalischen Mitteln erreicht ist. Ferner werden die Beispiele mit olla $=$ »haben» auf Grund ron Setäläs einleuchtender Erklärung für sich gestellt: hier herrscht immer Inkongruenz (gebilligt von Ikola, a.O. S. 329). Ebenfalls eine Sondergruppe bilden die pluralia tantum, bei denen der Nominativ nichts über die Spezies aussagt (159 f.). Dagegen führt m.E. die Interpretation solcher Begriffe wie korvat, vanhemmat wieder zu weit ins Aussersprachliche und verwirrt unnötigerweise das Bild. Siros Deutung als "quantitativ bestimmt» ermöglicht die Koppelung von Kongruenz und voll bestimmter Spezies, und die Fälle rücken in die Nähe der pluralia tantum.

Wäre Penttiläs Schlussregel (S. 160) aufrecht zu erhalten, dann hätte sie den grossen Vorteil, dass der unklar gewordene Begriff der Teilbarkeit für die Bestimmung des Subjektkasus entbehrlich wäre. Ausserdem träte die Funktion der Inkongruenz, einen mittleren Grad von Bestimmtheit zu bezeichnen, anschaulich hervor. Doch auch diese Symmetrie wird alsbald wieder zerstört.

Ikola zerfasert in seiner Antwort (59, 319 ff.) Penttiläs Speziesbegriffe ebenso wie Sadeniemi und Penttilä den Begriff der Teilbarkeit angegriffen hatten. Nach Ikolas Meinung stellen die von Penttilä genannten Sonderfälle eine zu schwere Belastung dar, so dass die Spezies für die Regelung nicht der richtige Ausgangspunkt sei. Der Satz Akkunaan ilmestyi pienet kädet erhält seine Form wegen der Halbbestimmtheit des Subjekts, bei $A k$ kunaan ilmestyi kalpeat kasvot beruht die gleiche Form auf Unbestimmtheit, bei Mieheltä paleltui korvat auf Bestimmtheit. Ikola dagegen sieht als Ursache in allen drei Fällen die Unteilbarkeit der Subjektvorstellung.

Die Erklärung der Inkongruenz als Folge des "psychologischen Singulars" greift Ikola mit dem Hinweis an, dass dieselben Wortformen, wenn definit verwendet, Kongruenz fordern (Saappaat ovat säkissä) und bemerkt dazu: "Yleensähän kongruenssi seuraa kieliopillista muotoa eikä merkitystä» (321). 
Dis trifft zwar zu. Immerhin sei etwa an den ron Ikola 58, 222 behandelten Fall Kolme ahselivaltaa olivat jo ratkaisseet lantansa erinnert, wo die Bestimmtheit des Subjekts eine Art Inkongruenz erzeugt, jedenfalls aber den Plural des Prädikats. Der Gedanke, dass dies Zusammentreffen nicht ganz zufällig ist, soll unten begründet werden. Ikola selbst hat 58, $232 \mathrm{f}$. eine eigene Erklärung der Inkongruenz rorgelegt. Ravilas Deutung (Ausgangspunkt on <oma: Vir. 1944, 125-7) zieht er in Zweifel, da die Entwicklungsbasis zu schmal sei und die Beschränkung der Inkongruenz auf die Existentialsätze nicht einsichtig werde. Dieser letzte Umstand führt ihn dazu, auf die schon von Ravila erwähnte ähnliche Situation in den idg. Sprachen zu verweisen. Diese Parallele erscheint mir indessen, wie so viele solcher Art, nicht zwingend. Die aus den idg. Sprachen angeführten Beispiele sind deutlich Sonderfälle oder Augenblicksbildungen und nehmen deshalb im system der Satzstrukturen einen anderen Platz ein als die finnischen. Die Nachstellung des Subjekts beruht nicht so sehr auf seiner Funktion als psychologisches Prädikat sondern "sozusagen" auf veiner Pause des Besinnens» und, da es sich meist um "Aufzählung" handelt, auf dem Gesetz der wachsenden Glieder, also auf der Schwere der Subjektgruppe. Derlei Sätze sind deshalb entweder anakoluthisch (wenn nämlich zu Beginn das Subjekt noch nicht klar ist) oder von vornherein auf die okkasionelle Heraushebung des Subjektworts angelegt. Die finnischen Sätze dagegen stellen die einzig zulässige Realisation des Existentialsatztyps dar und sind in ihrer Konzeption durchaus einheitlich. Das gilt - besonders vom idg. Standpunkt - vornehmlich von den Entsprechungen der whaben»-Konstruktion, wo der Besitzer, obwohl de facto "Subjekt», d.h. der, von dem etwas ausgesagt wird, regelmässig in einem Adverbialkasus am Satzbeginn steht. Dass allerdings die sprachpsychologischen Ursachen der an sich verschiedenen Erscheinungen ähnlich sind, darauf soll unten noch näher eingegangen werden.

Aus Ikolas Interpretation des Beispielmaterials ist für uns die Bemerkung wichtig, dass die Subjektvorstellung unteilbar wird, wenn sie mit der Prädikatsvorstellung eng zusammengehört (S. 326). Dadurch wird auch Sadeniemis Gegensatz 
"kiinteys: löyhyys" auf den von Teilbarkeit und Unteilbarkeit zurückgeführt. Dadurch gewinnt Ikolas Konstruktion zweifellos an logischer Geschlossenheit, verliert jedoch an sprachpsychologischer Durchsichtigkeit, wie z.B. das a.O. S. 327 behandelte Satzpaar Koulussa on huonoja opetusvälineitä: Koulussa on huonot opetusvälineet zeigt. Wenn uns nicht der Subjektkasus einen Hinweis gäbe, dürfte es schwer fallen, sich hier über die Existentialität klar zu werden. Das beruht einmal auf der Zweidentigkeit des finnischen koulussa on $(=$ »die Schule hat" und "in der Schule befinden sich»). Zweitens sagen ja beide Sätze nichts über die Lokalisierung des Subjekts aus sondern teilen mit, dass sich an einem Ort gewisse Gegenstände befinden; es wird also nicht die Existenz ausgedrückt. Und weiter: wenn wir die Frage lösen wollen, ob in einem der beiden Sätze die Existenz des Subjektgegenstandes vorausgesetzt wird, und beachten Ikolas (60, 343 nochmals präzisierte) Vorschrift, dass nur die Existenz an dem im Satz genannten Ort gemeint ist, dann sind beide Sätze existential, da die Existenz des Subjektgegenstandes in beiden Fällen nur im Hinblick anf die Schule betrachtet wird; ob es schlechtes Lehrmaterial auch anderswo gibt, darüber sagt der Satz nichts. So ist es vielleicht auch kein Zufall, dass Ikola es S. 329 vorzieht, den nicht-existentialen Charakter des Satzes Minulla on mukanani ne mitalit, joita . . . auf dem Umweg über die Teilbarkeit der Subjektvorstellung zu konstatieren. Im vorliegenden Falle wird das zwar aus dem Kontext klar; aber oft lässt sich bei der "haben"-Konstruktion diesbezüglich keine sichere Entscheidung treffen. Auch Ikola beurteilt diesen Typ als Ausnahme und erklärt ihn wie schon 58, 213 ff. (vgl. Hakulinen, Vir. 1926, $91 \mathrm{f}$.) daraus, wettä omistettua tarkoittava sana on osittain saanut objektin funktion» (329). Die als Beispiele genannten Sätze Minulla on sinut und Äidillä on teidät möchte Ravila Vir. 1944, 125 Fussn. lieber als Kontamination mit Sätzen mit saada u.ä. verstehen. Zu den zitierten Beispielsätzen darf ich bemerken, dass sie ihr Personalpronomen zu Sonderfällen stempelt. Der fragliche Satztyp ist unleugbar insofern von besonderer Art, als hier das grammatische Subjekt funktionell eher dem Prädikatsnomen nahesteht; man vgl. als Gegensatz 
talo on minun mit klarer Subjektfunktion. Nun sind die Personalpronomina Wörter, die nach Form und Funktion seit alters einen ausgesprochenen "Nominativ» besitzen, es ist daher verständlich, wenn gerade sie in Situationen, wo der Nominativcharakter irgendwie verschleiert ist, Arstoss erregen, zumal die Kongruenz der Person noch das formelhafte Prädikatsverb bedroht. Als Ersatz für den Nominativ kann, solange die sprachliche Form gewahrt bleibt, nur ein "grammatischer" Kasus in Frage kommen. Anscheinend eignet sich für diese Rolle einer Art »casus constructus» der Akkusati noch am ehesten. Man vgl. schwedisch (umgangsspr.) jag är större än dig.

In der Schlussregel (S. 330) lässt Ikola - in scharfem Gegensatz zu Penttilä - die Spezies ganz unberücksichtigt.

In Penttiläs 1. Antwort auf Ikolas eben besprochene Arbeit (59, 393 ff.) interessieren uns zwei Einzelheiten. Einmal die Behauptung »Jaottomuus... on tietysti seurausta sen (sc. des vorher behandelten Wortes sanat in dem Satz Sävelmään pitää tulla sanat) puolidefiniittisyydestä; sanat on jaoton tai jaollinen siitä riippuen, mitä se merkitsee» (395). Hier wird also wiederum versucht, den Primat der Spezies über den neuen Begriff der Teilbarkeit $\mathrm{zu}$ verteidigen. Wenn wir indessen den auf S. 396 angeführten Satz "V e t $t \ddot{a}$ ('osakaan kattilaan pantavaksi aiotusta vesierästä', puolidef.) ei ole vielä kattilassa oder, um mögliche Störungen durch die Negation auszuschliessen, lieber Siros Form $(61,189)$ Vettä on kattilassa (mit der sog. "notivischen» Variante der Halbbestimmtheit) hinzunehmen, sehen wir, dass auch Teilbarkeit mit Halbbestimmtheit vereinbar ist und also die Unteilbarkeit nicht aus ihr folgen muss. Zureichende Bedingung für b e i d e Erscheinungen ist offenbar die Kontextbedeutung des Subjektwortes; diese sind somit gleichgeordnet. Ausserdem ist durch den zweiten der hier zitierten Sätze, wie Siro S. 188 hervorhebt, Penttiläs Regel über das Verhältnis von Spezies und Partialität erschüttert. Seine Beispiele S. 395 f. scheinen übrigens wieder die Bedeutung des psychologischen Prädikats zu unterstreichen: in dieser Funktion ist das (nachgestellte) Wort durchweg indefinit. Die zweite interessante Einzelheit ist der kurze Hinweis darauf 
(S. 396), dass auch die halbbestimmten Vorstellungen "ilman muuta" die Existenz des Gegenstandes voraussetzen. Demnach wäre also der Partitiv auch in nicht-existentialen Sätzen möglich (von Penttilä näher begründet 60, $42 \mathrm{f}$.). Da über die Zulässigkeit der von Penttilä gegebenen Interpretation anscheinend keine Einigkeit besteht (vgl. Ikolas Ablehnung 60, 345), muss die Frage auf sich beruhen.

Offenbar unter der Einwirkung der zuletzt erarbeiteten Ergebnisse wendet sich Penttilä in seiner 2. Antwort $(60,28 \mathrm{ff}$.) wieder mehr der Partialität zu. Er wendet den Gesichtspunkt, dass die Partialität von der Kontextbedeutung des Wortes abhängig sei (0.S. 30 ), auch auf Individuen an (Jänistä on vielä pöydässä jäljellä: S. 28) und leitet den Umstand, dass solche Vorstellungen von Individuen oder Einzelgegenständen so selten im Partitiv erscheinen, aus der Art ab, wie das im Prädikat bezeichnete Geschehen das Subjekt trifft (S. 29 f.). Diese Methode ist zugleich logisch und psychologisch und wirkt durchaus überzeugend. Das einzige Verb ausser olla, bei dem nach Penttilä ein solcher Partitiv in Frage kommt, ist näkyä und Synonyma. Ikola fügt dann kuulua hinzu. Damit wäre die Trübung des Verhältnisses von Partialität und Partitiv einigermassen überwunden. Aber Penttilä legt Wert auf übersichtliche Ergebnisse und erklärt nun die eben als unteilbar erkannten Vorstellungen "olemisen ja näkymisen kannalta katsoen jaollisiksi» (S. 30). Bei näkyä leuchtet das ein; ein Gegenstand kann als Ganzes oder nur teilweise in unser Blickfeld geraten; aber wie ein Gegenstand "olemisen kannalta" teilbar sein soll, ist schwer zu begreifen. Noch bedenklicher ist jedoch Penttiläs ebenfalls neue These, dass der Subjektpartitiv in allen verneinten und zweifelnden Sätzen ebenfalls eine teilbare Vorstellung bezeichne (also auch in Sätzen wie Mattia ei ole nyt täällä: S. 34). Diese extreme Auffassung, die Penttilä offenbar einer übersichtlichen Regelung zuliebe entwickelt hat, ist von Ikola 60, 338 widerlegt worden ${ }^{1}$. Penttiläs neue Partitivanschauung bestätigt den hier schon mehrfach geäusserten Eindruck, dass die Forscher im Interesse einer einfachen Regel

1 Vgl. noch 61, 288.

3 -- Finnisch-ugrische Forschungen 
deren Bestandteile komplizieren. So sind wir nun genötigt, mit mehreren Formen der Partialität zu rechnen: mit einer bei Individuen, wo nur in verneinten Sätzen und bei näkyä der Partitiv steht, mit einer anderen bei Einzelgegenständen in singularischer Form, wo olla hinzukommt, aber nicht in jedem Fall sondern nur da, wo die Vorstellung »olemisen kannalta» teilbar ist; es folgen die klassischen Fälle der Teilbarkeit im Singular, für die es gar keine Regel gibt; denn "olemisen kanta" ist für vesi on kattilassa und vettä on kattilassa, soweit ich verstehe, derselbe; ferner die Vorstellungen in pluralischer Form, wo wir. auch keine Richtschnur haben: die Beschaffenheit des Existentialverbs spielt ja keine Rolle mehr (auch der Typ kaatua ist möglich) usw. usw. Wäre es nicht viel einfacher, wenn wir Penttiläs früher (allerdings zur Ermittlung der Unteilbarkeit) empfohlenes Verfahren beibehielten und fragten, ob in dem betr. Kontext ein Teil oder das Ganze gemeint sei, so wie wir es bei näkyä, den Stoffnamen und Vorstellungen in pluralischer Form ohnehin tun müssen? Damit war der von Ikola 60, 335 kritisierte formalistische Standpunkt "poikaa on jaoton, koska poika on jaoton, ja poikia on jaollinen, koska pojat on jaollinen" bereits v o r dieser Kritik überwunden. Wenn man Penttiläs Ausführungen recht versteht, führen sie zu dem auch für den Nichtfinnen brauchbaren Ergebnis, dass eine Vorstellung dann teilbar ist, wenn jeder willkürlich abgegrenzte Teil ihres Gegenstandes sich auch im Verband des Ganzen ebenso verhalten kann wie das Ganze. Eine zweite Frage ist es dann, in welchen sprachlichen Zusammenhängen diese Möglichkeit aktuell wird. Der Ausschluss der nicht in Betracht kommenden Fälle ist m.E. Penttilä gelungen. Die ganze Diskussion dreht sich um diejenigen Fälle, wo der Partitiv mög li ch ist. Da die Grenzen offensichtlich fliessend sind, kann es keine logische Abgrenzung geben.

Das scheint mir besonders anschaulich bei olla und näkyä hervorzutreten, den beiden Verben, neben denen der Partitiv am weitesten verbreitet ist. Der Sprachgebrauch *Jänistä on olemassa, (?) Venettä näkyy wäre nicht unlogisch; man könnte das Existieren ebenso gut vom Teil wie vom Ganzen aussagen. Aber er ist nun einmal nicht voll realisiert. Mit Recht ist in 
der Diskussion mehrfach betont worden, dass die "Existentialsätze» ein "irgendwo-Sein" ausdrücken, was zweifellos gegen den Terminus "Existentialsatz" spricht. Dass sich aber jeder beliebige Teil eines Ganzen ebenso wie das Ganze selbst »irgendwo befinden" oder "irgendwo zu sehen sein" kann (was ja nur eine Variante des Seins ist), leuchtet ein. Das ist jedoch nicht gleichbedeutend mit dem Gedanken der Teilbarkeit "rom Standpunkt des Seins». In b e i d e n Mustersätzen Vettä on kattilassa und Vesi on kattilassa verhält sich jeder Teil der Wassermenge "vom Standpunkt des im-Kessel-Seins" wie das Ganze. Die Verwendung des Partitivs hängt nicht davon ab, dass die Subjektvorstellung durch die Einbeziehung in die Gesamtvorstellung des Satzes spezialisiert, in ihrem Umfang beschränkt, "geteilt" wird, sondern davon, ob sich der Sprecher den Subjektgegenstand als etwas aus sich heraus Existierendes, als identifizierte Einheit oder als Stoff, ungegliederte Masse, als etwas nicht als Einheit Identifiziertes vorstellt. vesi ist "Individuum" entweder als die generelle Begriffsbezeichnung (Wasser an sich) oder als durch den Gedankenzusammenhang oder den Kontext »definierte» Wassermenge; es bezeichnet eine Vorstellung, deren "tarkoitteena oleva yksilö voidaan, ainakin teoreettisesti, osoittaa muiden samanlaisten yksilöiden joukosta" (Penttilä, 59, 156). vettä dagegen ist zwar "määrätarkoitteinen" (Siro S. 189), aber für den Sprecher bleibt die Wassermenge amorph; für ihn ist die im Satz genannte Beziehung zwischen den Vorstellungen "Kessel» und "Wasser» wichtiger als weitere Individualisierung der Vorstellung "Wasser". Daher sind auch von Siros Beispielen a.O. die mit unbestimmter »quantitativer Spezies" partitivisch: kollektive und eine Mehrheit ausdrückende Vorstellungen werden eben mit Hilfe der Quantität bestimmt. Bei den "notivisch" bestimmten Vorstellungen dagegen führt die quantitative Unbestimmtheit nur zur Inkongruenz. Wenn Bezeichnungen für lebende Individuen im negierten Satz im Partitiv stehen können, im affirmativen nicht, so ist auch das Sache der Konvention, wie z.B. der Umstand zeigt, dass der Fragesatz zu den negierten gehört. Wenn die Vorstellung der Teilbarkeit z.B. mit der eines menschlichen Individuums laut Sprachgebrauch unvereinbar ist (der $\mathrm{Objekt}$ partitiv ist, 
wie man sieht, noch weit weniger von der Teilbarkeit abhängig als der Subjektpartitiv), dann dürfte das auch für den negierten Satz gelten. Ikolas feine Beobachtung, dass der Satz Mattia ei ole täällä nur unter der Voraussetzung zulässig ist, dass Matti sich nicht in Sehweite befindet $(60,338)$, zeigt, dass man den Partitiv nicht als "kein Stück vom M.» zu verstehen hat $^{1}$ sondern ähnlich wie in der deutschen Ausdrucksweise »kein M. ist hier» (für die Ikolas Bedingung ebenfalls zutrifft): das "kein" macht den Gegenstand des Eigennamens unbestimmt, nimmt ihm seine Individualität, reiht das Individuum in eine ungegliederte Masse ein, für die die Negation in gleicher Weise gilt und dadurch an Nachdruck gewinnt. Das aber ist nur möglich, wenn man den Gegenstand nicht vor sich hat. So löst sich auch der Streit um den Satz ei tullut enää Annaa m.E. ohne Schwierigkeit: "Es kam k e i n e Anna mehr".

Ikolas $^{2}$ und Penttiläs letzte Beiträge $(60,334-63)$ bringen nur noch weitere Begründungen der Standpunkte. Was zunächst die Teilbarkeit anlangt, so sind sich die beiden Forscher nun ziemlich einig darin, dass die Teilbarkeit letztlich eine im Kontext aktualisierte Eigenschaft der Gegenstände selbst ist (S. $335 \mathrm{f} ., 355)^{3}$. Mir scheint deshalb Penttiläs Verfahren zur Feststellung der Teilbarkeit leichter durchführbar als Ikolas. Die Unteilbarkeit der Subjektvorstellung in dem Satz Minulla on nyt jauhot mukanani stellt Penttilä folgendermassen fest $(59,152)$ : „Sen tarkoite on kyllä jaettavissa osiin, jotka kaikki ovat tosin jauhoja, mutta joista mikään ei ole sellainen jauhoerä, jota lauseen käyttäjä ajattelee ja joka saattaa olla esim. tarpeellinen johonkin määrätarkoitukseen". Diese Auffassung berührt sich nahe mit der oben von mir dargelegten: der Sprecher denkt im Rahmen der Gesamtvorstellung des Satzes nicht

1 Denison arbeitet a.O. S. 118 - nicht überzeugend - mit einer nur vorgestellten Teilbarkeit.

2 Ikolas Aufsatz 61, 287 ff. erhielt ich erst, als diese Arbeit schon beendeet war. Ich konnte sie daher nur noch in Anmerkungen berücksichtigen.

3 Im weiteren Verlauf der Diskussion entfernen sich die Auffassungen wieder voneinander. Ikola stellt 61, $289 \mathrm{f}$. den Unterschied zwischen "natürlicher" und "grammatischer" Teilbarkeit auf; Penttilä spricht von "latenter" Teilbarkeit (s.u.). 
an die mögliche Teilbarkeit des Gegenstandes. Ikola, der dieser Ansicht 60, 335 f. zustimmt, versteht jedoch obiges Zitat etwas anders. Er sagt S. 336 über den Satz Kattilassa on jo vesi: "Jälkimmäisen lauseen subjektin tarkoite on tarvittava, tilanteen vaatima vesierä, siis erä, joka on kvantiteetiltaan rajoitettu aivan samalla tavalla kuin äskeisen jauhot-saneen tarkoittama jauhoerä». Penttilä spricht a.O. n i c h t molemisen kannalta", sondern S. 151 heisst es von dem Satz Miehillä oli mukanaan kirveet: "tärkeintä on, että kirveitä on työn kannalta katsoen tarvittava määrä». Hier wird also nicht das Verhältnis der im Satz vorkommenden Vorstellungen zueinander untersucht sondern die Stellung der Subjektvorstellung innerhalb der Gesamtvorstellung. Wählt man nämlich den ersten Weg, dann ergeben sich ähnliche Schwierigkeiten wie sie oben für Ikolas Bestimmung der Existentialität aufgezeigt wurden. Ikolas Charakterisierung des Satzes Kattilassa on jo vesi gilt auch bei partitivischem Subjekt. Die Frage nach dem Subjektkasus darf nicht i n n e r h a l b des Satzes entschieden werden, da dieser ja in jedem Fall die Aufgabe hat, "die Quantität zu begrenzen", sondern es ist zu untersuchen, in welchem Verhältnis die begrenzte Vorstellung des Satzes zu der nicht begrenzten Vorstellung steht. Besteht im Gedankenzusammenhang eine bestimmte (also nicht durch einen Satz sondern durch eine bereits gegebene Vorstellungsverknüpfung begrenzte) Vorstellung eines Gegenstandes, und ist die im Sat $\%$ gemeinte Vorstellung mit ihr gleichen Umfangs, steht der Nominativ; ist der Umfang geringer, steht der Partitiv.

Leider wird nun diese relative Einigkeit der Forscher durch eine mir unverständliche Polemik Penttiläs $(60,355)$ wieder in Frage gestellt. Nachdem er S. 353 festgestellt hat, dass "jauhot sananmuodolla on se $\mathrm{k} \ddot{a}$ jaollisia e t $\mathbf{t}$ ä jaottomia esiintymiä» (z.B. in Ikolas Beispiel S. 335) und S. 354 erläutert hat: "Sama olio voi olla jaollinen eräältä kannalta katsoen, mutta jaoton toiselta kannalta katsoen", lehnt er S. 355 Ikolas Behauptung, dass die Subjektvorstellung des Satzes Tähän näkyy rakerinusten lomitse kirkko unteilbar sei, mit dem Hinweis ab, dass im gleichen Satz mit partitivischem Subjekt die Subjektvorstellung von beiden Forschern als teilbar erkannt 
worden sei. "Tällaiseen tulokseen on nähtävästi kummallakin taholla tultu tarkastamalla onko kirkko jaollinen näḳ̣misen suhteen". Gegen die Teilbarkeit argumentiert er dann so: "Jos kirkko, eräs rakennus siis, hetkistä aikaisemmin ymmärrettiin näkymisen suhteen jaolliseksi, niin miten samainen kirkko. eräs rakennus, voidaan seuraavassa hetkessä ymmärtää näkymisen kannalta jaottomaksi?» Hätte man also zuerst die Variante mit nominativischem Subjekt als Ausdruck einer unteilbaren Subjektvorstellung ermittelt, dann wäre die partitivische das Streitobjekt geworden. Penttiläs Gedankengang führt somit zu ganz zufälligen Ergebnissen. Anderseits schreibt er aber den Gegenständen die Teilbarkeit als wesenhafte Eigenschaften zu (vgl. S. 354), die "piilevästi» auch dann rorhanden ist, wenn sie im Satz nicht zum Ausdruck kommt (S. 355). Wenn in dem Satz vene näkyy jo die Teilbarkeit "piilevästi" im Gegenstand enthalten ist, dann fehlt uns wiederum das Verfahren, die Kasusform des Subjektworts zu bestimmen. Der Nominativ wird aber doch - darüber sind sich alle einig - dann gebraucht, wenn das Boot als Ganzes im Sehfeld des Sprechers ist, wenn sich die Subjektrorstellung mit der allgemeinen Vorstellung "Boot» deckt. Das aber hängt nicht von irgendwelchen, im Zusammenhang mit dem Erscheinen aktuell werdenden Wesenseigenschaften des Gegenstandes ab sondern von der Sachsituation.

Wenn wir also der Ansicht sind, dass der Standpunkt, von dem aus die Teilbarkeit zu bestimmen ist, nicht durch die Bedeutung des Prädikatsverbs sondern durch die Situation gegeben ist, und mit Ikola (S. 337) zugeben, dass auch die Sätze Tähän näkyy rakennusten lomitse kirkko und Oksien välistä näkyi orava existential sind, dann ist die oberste Bedingung für das Auftreten des Partitivs nicht die Existentialität sondern, wie seit alters angenommen wurde, die Partialität der Subjektvorstellung. Das gilt nach unseren obigen Darlegungen auch für die negierten Sätze des Typs Kauhaa ei ole kattilassa, wenn von "määräkauha" die Rede ist (Ikola S. 339). In diesem Sinne gemeint, kann der Satz trotz seines partitivischen Subjekts nicht existential sein (die Existenz eines "määräkauha” muss vorausgesetzt werden), aber der Partitiv erklärt 
sich eben aus der besonderen Situation des negierten Satzes überhaupt: die (fingierte) Unbestimmtheit (oder Partialität: Sadeniemi S. 13) setzt auch die bestimmte Vorstellung als Teil aller unter ihr vereinigten Einzelexemplare. Hierin mag auch Ikolas interessante Beobachtung ihre Erklärung finden, dass man nicht sagen kann Kirkko ei näy (S. 347). Er selbst nimmt zwar die Existentialität als Ursache an. "Mutta jos tahdotaan sanoa, ettei sitä näy minnekään, ettei sen näkökuvaa siis lainkaan ole olemassa, on lause pakosta eksistentiaalinen ja on käytettävä partiaalista subjektia: Kirkkoa ei näy». Diese Erklärung ist mir nicht ganz verständlich. Da man sagen kann Vene näkyy jo und - wenn vielleicht auch etwas konstruiert?1 - Venettä näkyy jo (beides Existentialsätze), schliesst doch offenbar das Fehlen einer Ortsangabe bei näkyä den Charakter der Existentialität nicht aus, weil näkyä die mögliche Existenz eines Sehenden immer voraussetzt. Also scheint die fragliche Eigenart durch die Negation bedingt zu sein. Könnte nun die Ursache nicht darin liegen, dass die Verneinung der Subjektvorstellung eine gewisse Unbestimmtheit verleiht (weil eben das Erscheinen geleugnet wird), so dass das Fehlen einer konkreten Ortsbezeichnung, das die Bestimmtheit der Subjektvorstellung noch weiter reduziert, sich einerseits mit einer bestimmten Subjektvorstellung nicht mehr verträgt, andererseits die Beziehung der Negation auf ein bestimmtes Subjekt den Geltungsbereich der Negation auf einen konkreten Gegenstand beschränkt, für den der Satz den paradoxen Sachverhalt aussagt, dass er existiert aber doch "nicht vorhanden ist»? Mit solcher starken Verneinung des Vorhandenseins (und ihrer Varianten) verbindet sich offenbar gern partitivisches Subjekt.

Penttiläs Polemik in seiner letzten Antwort $(60,353 \mathrm{ff}$.) ist bereits besprochen worden, und es sei mir nur noch eine Bemerkung dazu gestattet. Wenn in den Sätzen Vene näkyy jo und Oksien välistä näkyi orava die Subjektvorstellung, wie Penttilä S. 355 sagt, "piilevästi tai potentiaalisesti» teilbar ist, dann gilt das für a lle Subjektvorstellungen ohne Rücksicht

1 Vgl. jedoch Penttilä, 60, 357. 
darauf, ob die betr. Wörter im Partitiv rorkommen oder nicht. Wenn die Methode zur Bestimmung der Partialität, obwohl sie sich natürlich an die Vorstellungen und nicht an die Wörter halten muss, nicht auf die sprachlichen Gegebenheiten Rücksicht nimmt, ist sie für die Grammatik nicht verwendbar. Da "näkymisen kannalta” alle Vorstellungen teilbar sind, verändert sich der Gegensatz "teilbar: unteilbar» in woffen teilbar: latent teilbar». Es fragt sich, ob es nicht zweckmässiger wäre, wie früher näkyä als Sonderfall zu behandeln und, wie Penttilä es S. 356 bei Betrachtung des Satzes Minulla on jauhot mukanani selbst tut, die Teilbarkeit als eine sich aus der Situation ergebende Ans cha ung we is e aufzufassen wie auch z.B. Sadeniemi in seinem vorbildlich klaren Aufsatz Vir. 1950, 46 ff. ${ }^{1}$ Auch die "latente Teilbarkeit» kann ja erst ermittelt werden, wenn die Teilbarkeit selbst bereits feststeht; und wenn die Teilbarkeit durch die Gegebenheiten des Einzelfalles unwirksam werden kann, wie Penttilä das a.O. an dem eben zitierten Satz klar zeigt, dann ist eben d i es für die Sprachformung das allein Wichtige. Wenn jauhoja in dem Satz $\mathrm{Mi}^{-}$ nulla on j. mukanani nicht das partitivische Gegenstück zu dem vorher erwähnten jauhot ist, so beweist das nur, dass der Gegensatz "teilbar: unteilbar" sich mit dem Gegensatz "definit: indefinit» überschneidet. In dem hier verfochtenen Sinne kann ich Penttiläs Feststellung vorbehaltlos zustimmen, dass mon välttämätöntä tietää jotakin subjektin totaalisuuden ja partiaalisuuden ilmaisutehtävästä, ennenkuin voi suorittaa ratkaisun niiden kesken» $(59,44=60,358)$. In der Praxis geht Penttilä auch ganz in dieser Weise vor; man vgl. seine Ausführungen über den Satz Oppilaat tulicat opettajainhuoneeseen S. 361 , wo er, wie mir scheint, mit Recht, nochmals klar ausspricht, dass Partialität und Existentialität zwei voneinander unabhängige, gleichwertige Bedingungen des Partitivgebrauchs sind.

Die Unklarheit, die in Penttiläs Darlegungen über die Teilbarkeit trotz allem immer noch bestehen bleibt, macht sich in Siros Kritik $(61,185)$ bemerkbar. Der Umstand, dass "niiden

1 Auch Ikola vertritt jetzt ganz klar diesen Standpunkt: vgl. 61, 290. 
sanojen joukko..., jotka voivat partiaalisena subjektina tavallisessa myöntölauseessa esiintyä, on toinen kuin niiden sanojen joukko, jotka kielto- ja näkyä-lauseessa voivat subjektina esiintyä», lässt sich mit Penttiläs Auffassung der Teilbarkeit »johonkin nähden» ohne Mühe vereinbaren, nicht aber mit seiner Behauptung, eine Vorstellung könne nicht in gleicher sprachlicher Umgebung zugleich teilbar und unteilbar sein. Die Teilbarkeit kann nicht zugleich eine Eigenschaft der Dinge und ein Ausdruck ihres Beziehungsverhältnisses zu anderen Dingen sein; in diesem Fall ist sie ein an den Dingen auftretendes Merkmal, das ihnen aber nur zufällig anhaftet. Da Penttilä, wie erwähnt, in der Praxis diese letztere Auffassung teilt, hat Siro im Endeffekt Recht, wenn er fortfährt: »Tämä seikka siis vastustaa jyrkästi Penttilän ehdottamaa poikkeamaa traditionaalisesta kannasta». Andererseits ist es m.E. nicht die Relativierung der Teilbarkeit, die Penttilä zu seiner Ausweitung des Teilbarkeitsbegriffs nötigte, wie Siro meint (denn schon die klassische Auffassung hatte ihn relativ angewandt), sondern eben jene allzu logische Definition als Eigenschaft der Dinge. Siros berechtigte Kritik an der Meinung, dass alle Subjekte negierter Sätze teilbare Vorstellungen bezeichneten, wurde schon erwähnt. Aber auch Ikolas Begriff der Teilbarkeit, der im Gegensatz zu Penttiläs enger als der frühere ist, lehnt Siro ab: seiner Ansicht nach sind Sätze wie Jauhot ovat pöydällä existential (damit sind also Penttiläs Existenzsätze als die für Partialsubjekt in Betracht kommenden anerkannt) und haben teilbares Subjekt (S. 190). Er bringt die von Penttilä in die Diskussion geworfene Spezies wieder zu Ehren, indem er durch Aufspaltung des inhomogenen Begriffs "Halbbestimmtheit» in "(quantitativische" und "notivische Spezies" ${ }^{1}$ die von Ikola bemängelten Widersprüche in Penttiläs Konzeption beseitigt. Siro scheint, obwohl er das nicht ausdrücklich sagt, mit seinem leider nur sehr knappen Beispielmaterial, dessen repräsentativen Wert der Ausländer nicht sicher abzuschätzen vermag, folgende Regelung anzustreben: im affirmativen Existenzsatz ist das voll bestimmte Subjekt total und kongruiert ausser bej

1 Gebilligt von Ikola 61, 292. 
Vorstellungen, deren Mehrheit mit ihrer Beziehung auf die adverbiale Ergänzung (wohl nur lebende Wesen) von Natur gegeben ist (korrat, ranhemmat u.a.); das nur quantitativ bestimmte Subjekt ist total, kongruiert aber (wenigstens bei den schwierigen pluralischen Begriffen) nicht; das notivisch bestimmte und das unbestimmte Subjekt sind partial, jenes ist psychologisches Subjekt, dies psychologisches Prädikat.

Wenn diese Regel sich bewährt, bietet sie den grossen Vorteil, dass wir um die Bestimmung der Existentialität in Ikolas Sinne und (im Plural) der Teilbarkeit ${ }^{1}$ herumkommen, über die trotz allen Bemühungen immer noch keine volle Einigkeit erzielt wurde. Andererseits enthält sie den Gesichtspunkt des Zusammengehörigkeitsgrades, der leichter anwendbar ist und mir sehr wichtig zu sein scheint. So leuchtet z.B. der von Sadeniemi (59, 14 Fussn.) angedeutete Unterschied zwischen den Sätzen Hotellissa on hyrä ruoka (nach Sadeniemi mindefiniittinen», nach Siro quantitativ bestimmt) und Pöydässä on hyvää ruokaa (unbestimmt) durchaus ein, und man versteht, dass die Zusammengehörigkeit des Subjekts mit der adverbialen Bestimmung zufällig, mit dem "Besitzer»-Inessiv aber eine Folge von dessen Zweckbestimmung ist: das Hotel soll in erster Linie für Essen sorgen. Man sieht ferner, dass bei den im klassischen Sinne teilbaren Wörtern singularischer Form das Finnische trotz seiner weitgehenden Differenzierung auf diesem Gebiet keinen Unterschied zwischen voll und quantitativ bestimmt macht (da hier die Kongruenz nicht sichtbar werden kann); Penttiläs Beispiele $59,395 \mathrm{f}$. stehen in negierten Sätzen und müssen deshalb beiseite bleiben. Dieselbe Vermischung, aber mit umgekehrtem Ausgang, zeigen Subjektvorstellungen wie korvat. Der Unterschied zwischen notivischer und indefiniter Spezies wiederum manifestiert sich nicht an morphologischen sondern an syntaktischen Merkmalen, an Wortfolge und Betonung. Da das unbestimmte Wort hier zugleich psychologisches Prädikat ist, tritt die von Ikola bemerkte Schwierigkeit $(58,239)$ nicht herror: Hakulinens Feststellung, dass das indefinite Wort meist durch Betonung hervorgehoben wird

1 Vgl. Ikola, 61, 292. 
(SKRK II 196) und Nurmelas Beobachtung, dass im Finnischen die Betonung hauptsächlich zur Kennzeichnung des psychologischen Prädikats dient (Vir. 1934, 174 ff.), treffen hier zusammen. Ikolas Beispiele für betontes definites Subjekt (a.O. S. $240 \mathrm{f}$.) enthalten unteilbare Vorstellungen, die Betonung beruht auf einem durch den Kontext gegebenen Gegensatz. Das sind Sonderfälle, für die die Sprache keine eigenen Mittel entwickelt hat, spezielle Regelungen also, die das System nicht stören. Schwieriger zu beurteilen sind die Fälle mit unbetontem unbestimmtem Subjekt. Im 1. Beispiel (Joku tulee) ist die Unbestimmtheit lexikalisch erreicht; das Wort dürfte nur in dem einzigen, nichts beweisenden Fall als psychologisches Prädikat auftreten können, dass die Unbestimmtheit selbst dessen Inhalt ist: ainakin jok $u$ tulee. Zum 2. Beispiel (Puuroa tuli ru'nsaasti) möchte ich fragen, ob hier nicht eine leichte rhythmische Stilisierung vorliegt. Wären nicht die Varianten tuli runsaasti puuroa und t.p.r. gewöhnlicher? Ist nicht obige Form gewählt, um die Aufeinanderfolge zweier betonter Wörter zu vermeiden? Auch zum 3. Beispiel (Ihmisiä kuoli nälkään) kann ich nur Fragen stellen: hat der Partitiv wirklich auch dann besonderen Ton, wenn $\mathrm{n}$ i $\mathrm{ch}$ t das Schreckliche des Vorfalls hervorgehoben werden soll? In diesem Fall aber handelt es sich um Affektbetonung und demnach um die von A. Heusler sog. "bewegte Wortfolgen, die nicht die Norm repräsentiert. Ferner ist vielleicht zu berücksichtigen, dass das Subjekt motivisch bestimmt" ist, sowie dass in Verbindungen wie kuolla nälliään der nominale Bestandteil als psychologisches Prädikat immer den Ton trägt, so dass auch hier, wenn das Subjekt dem Verb folgte, zwei betonte Wörter nebeneinander stünden. Immerhin sieht man, dass es auch hier Berührungspunkte zwischen den Kategorien gibt. Bezeichnend für die Struktur des Finnischen ist es jedoch, dass sich die Bereiche des totalen und des partialen Subjekts anscheinend $n \mathrm{i} c \mathrm{ht}$ verwischen, dass m.a.W. der wesentlichste Unterschied nicht zwischen den Kategorien Bestimmt und Unbestimmt sondern mitten durch die früher als einheitlich behandelte Kategorie Halbbestimmt verläuft. Hier grenzen sich Partitiv und Inkongruenz gegeneinander $a b$. Darin liegt eine interessante Bestätigung für die 
bekannte Tatsache, dass im Finnischen der Unterschied zwischen quantitativer Bestimmtheit und Unbestimmtheit ein wichtiger Zug des Systems ist, die Spezies dagegen nicht.

Aus diesem Umstand könnte man - gerade unter dem von Siro bevorzugten Gesichtspunkt des Systems - einen theoretischen Einwand gegen obige Form der Regel ableiten: ist es zweckmässig, eine Regel auf einer sprachlichen Kategorie aufzubauen, die nicht zum System der betr. Sprache gehört? Eine Beantwortung dieser Frage würde den Rahmen der vorliegenden Arbeit überschreiten. Zu Siros Verteidigung kann man anführen, dass seine Regel ja nicht nur den Partitiv sondern auch die Inkongruenz berücksichtigt, da eben b e i d e Phänomene sowohl an der Teilbarkeit als an der Spezies teilhaben. Auch diese höchst interessante Verschränkung zweier so verschiedener Kategorien gehört zweifellos zum System des Finnischen. Ihr Sinn ist ja das Problem vorliegender Arbeit.

Indessen habe ich den Eindruck, dass Siro in seiner Regel gerade das Verhältnis von Teilbarkeit und Inkongruenz durch die Rückkehr zum alten Teilbarkeitsbegriff zu Ungunsten der ersteren verschleiert, ohne dass die Regel dadurch gewinnt. Als Gewinn kann ich nur die Tatsache erkennen, dass es näherliegt, eine Vorstellung wie jauhot mit ihrer pluralischen Form als teilbar aufzufassen. Dem stehen aber mehrere Nachteile gregenüber: teilbar soll andererseits auch ruoka (Hotellissa on hyvä ruoka) sein, obwohl es nicht ohne weiteres klar ist, dass ruoka als mainesana» zu gelten hat; Ikola wäre genötigt, auf die ursprüngliche Fassung seiner Regel $(58,230)$ zurückzugehen; Penttiläs Auffassung wird nur unwesentlich berührt: er müsste sich zur Anerkennung zweier Arten von Teilbarkeit entschliessen (vgl. 60, 356) niemis Ausführungen 59, 14. Siro begnügt sich damit, sie formal zu widerlegen: da in dem Satz pöydällä on jauhot das Subjekt nicht, wie Sadeniemi meint, indefinit sondern quantitativ bestimmt ist, verstösst er nicht gegen die Regel, dass im Existenzsatz nominativisches Subjekt zur Bezeichnung einer teilbaren Vorstellung immer definit sei, und es liegt daher kein

1 Ähnlich äussert sich Ikola 61, $289 \mathrm{f}$. - 
Grund vor, jauhot für unteilbar zu erklären. Aber auf Sadeniemis, aus der Struktur der Sprache gewonnene Begründung, dass in dem Satz Suomessa on kylmät talvet das Subjekt deshalb unteilbar sei, weil man ihn nur zu Suomen talvet ovat kylmät (nicht: kylmiä) umformen könne, geht er nicht ein. Sadeniemi begründet u.a. die Unteilbarkeit derartiger Vorstellungen gerade mit ihrer quantitativen Bestimmtheit ${ }^{1}$, d.h. mit demselben Argument, mit dem Siro für die Teilbarkeit eintreten will. Siro ist jedoch insofern im Nachteil, als er nur einen Einwand entkräftet, Sadeniemi dagegen positive Gründe geltend macht.

Wenn ich recht verstehe, beruht die Meinungsverschiedenheit wesentlich auf verschiedener Interpretation des Begriffs "Teilbarkeit». Siro vertritt, wie gesagt, die ältere, stärker stoffgebundene Auffassung, die letztlich ron der Zerlegbarkeit von Gegenständen in solche Teile ausgeht, deren Wesen dem des Ganzen gleich ist. Für diese Auffassung war z.B. das Verhalten paarweiser Gegenstände wie sakset eine "Ausnahme". Auf demselben Boden erwuchs auch die Inkonsequenz in Setäläs Satzlehre, wo grundsätzlich der Nominativ und Partitiv des Prädikatsadjektivs neben pluralischem Subjekt (und Objekt) für gleichwertig erklärt, aber doch Ausnahmen genannt werden, ohne dass eine Erklärung gegeben würde (vgl. etwa pojat ovat iloiset: iloisia, letzteres mit "pojkar äro glada» übersetzt). Für Sadeniemi wie auch für Ikola und Penttilä dagegen ist Teilbarkeit relativ; sie hängt vom Betrachter und vom Kontext ab. Das führt zugleich zu einer Erweiterung und zu einer Verengung des Begriffsumfangs. Paarweise Gegenstände werden als "pluralische Individualitäten" erkannt, sie sind dadurch unteilbar; ebenso die quantitativ bestimmten Torstellungen im Plural, deren Unteilbarkeit Sadeniemi a.O. aus ihrem Gruppencharakter herleitet. Dieselbe Eigenschaft hatte Sadeniemi schon in seinem Aursatz Vir. 1950, 46 ff. als Voraussetzung für

1 Da nach freundlicher Mitteilung von Dr. Sadeniemi der Partitiv des prädikativen Adjektivs Boden gewonnen hat, weisen die Fälle, wo noch jetzt der Nominativ üblich ist, deutlich auf ganzheitliche Auffassung hin; so edellytykset ovat hyvät (aber jauhot ovat hyviä); jalkani ovat kipeät (aber hänen partakarvansa alkavat olla harmaita). 
Totalität des prädikativen Adjektivs angegeben. Umgekehrt setzt die von ihm a.O. sog. "distributive» Partialität in allen ihren Spielarten teilbares, d.h. als teilbar vorge st ellt es Subjekt voraus: "... predikatiivin ilmoittama ominaisuus omistuu, .. ., jokaiselle sen todelliselle tai ajateltavissa olevalle osalle» (S. 48). Andererseits ist im Zusammenhang mit näkyä jede Subjektvorstellung teilbar, und da Penttilä dasselbe für alle negierten Sätze annimmt, sind für ihn grundsätzlich alle Vorstellungen teilbar - die weitest denkbare Ausdehnung des Begriffs. Da nun Siro durch Fassung und Unterteilung des Speziesbegriffs selbst die Möglichkeit geschaffen hat, die beiden Auffassungen von Teilbarkeit als in der Sprache verankert zu erweisen (die quantitative, stoffgebundene wird durch den Partitiv, die nur potentielle, durch Zusammenfassung der Gegenstände in Gruppen in den Hintergrund gedrängte, mehr geistige aber durch Inkongruenz ausgedrückt), wäre es m.E. systemgerechter, Vorstellungen wie das hier behandelte jauhot mit Sadeniemi als unteilbar zu betrachten, wenn anders grammatische Regeln den Bau der Sprache verdeutlichen und nicht verschleiern sollen.

Die Darlegung des bisherigen Diskussionsverlaufs musste so ausführlich geschehen um zu zeigen, wieviel Mühe und Scharfsinn auf die Aufstellung möglichst einfacher und zugleich umfassender Regeln verwandt worden ist, ohne dass das Froblem als gelöst betrachtet werden kann. Alle bishor geäusserten Standpunkte lassen sich mit guten Gründen verteidigen, gegen alle lassen sich aber auch Einwände machen. Nun lassen sich zwar besonders kompliziertere sprachliche Tatbestände öfter von verschiedenen Gesichtspunkten her in Regeln fassen; wenn aber die Verschiedenheit des Ausgangspunktes, wie das hier mehrfach der Fall war, zu widersprechenden Folgerungen und Ergebnissen führt, dann ist das ein Anzeichen dafür, dass das Fundament der Regeln nicht solide genug war. Man kann zur Ordnung grammatischer Tatsachen bekanntlich die induktive und die deduktive Methode verwenden. Jene sammelt möglichst gründlich den Stoff und stellt die gleichartigen Fälle zu Gruppen zusammen; diese geht von einem übergeordneten Prinzip aus und stellt das Verhältnis der Einzeltatsache zu ihm 
fest. Je komplizierter und vielschichtiger der zu bewältigende Stoff, desto aussichtsreicher ist das deduktive Verfahren, da die enumerativen Regeln dann zu unübersichtlich werden. Allerdings verschiebt sich dann der Erkenntniswert rom Praktischen mehr ins Wissenschaftliche, da das ständige Überwechseln von der Ebene der Erscheinungen zu derjenigen der Ordnungsprinzipien die Tatsachen aus ihrem anschaulichen Zusammenhang herauslöst. Ein Beispiel. Fasst man die Biidung des Genitiv Pluralis im Finnischen in enumerative Regeln, so kann man zwar in der Praxis die Formen richtig bilden, erhält aber eine grosse, unübersichtliche Menge ron Vorschriften ${ }^{1}$, die sich schlecht handhaben lässt. Geht man aber davon aus, dass in diesen vielfältigen Formen die Pluralcharaktere rerschiedene Verbindungen mit den Stämmen eingehen dann kann man zwar nicht alle, wohl aber die meisten Formen ableiten und besitzt ein viel handlicheres Werkzeug.

Ähnliches gilt nun auch im vorliegenden Fall. Es wurde eingangs bereits betont, dass ich als Ausländer weder das Recht noch die Absicht habe, die praktischen Regehn zu verbessern. Mir geht es um die Klärung der Grundlagen, um so womöglich eine deutlichere Vorstellung von denjenigen Momenten zu gewinnen, die die Regeln nicht erfassen können und doch zu ihrer richtigen Anwendung bereits voraussetzen, also etwa ron dem Zusammenhang zwischen Subjekpartitiv und Existenzsatz. Das ist eine rein wissenschaftliche Fragestellung, die letztlich dem Ziel dient, den Gieist der finnischen Sprache sichtbar zu machen.

Nun sind natürlich in der Praxis die beiden geschilderten Verfahren nicht so verschieden, dass man nicht aus ihrer Kombination grossen Nutzen ziehen könnte. Die eingehende Vorführung der Diskussion im "Virittäjä" hatte nicht zuletzt den Zweck, das Bemühen der Forschung um die Grundlagen aufzuzeigen. Von hier aus gesehen, gliedert sich vorliegende Arbeit organisch in den Gang der Forschung ein. Die meisten Gedinken, die ich zur Frage beitragen möchte, sind in der Diskussion bereits geäussert worden. Nur ihre Zusammenfassung und kon-

1 Vgl. Penttilä, "Suomen kielioppi» (Hels. 1957), 158-174. 
sequente Anwendung fehlte noch. Die wichtigsten dieser schon rorgebrachten Gedanken seien zum Schluss nochmals kurz angedeutet. Ahlman stellt die Bedeutung des Zusammengehörigkeitsgrades von Subjekt und prädikativer Ergänzung fest; Airila sucht einen Zusammenhang zwischen dem Subjektpartitiv und der Art des Verbgeschehens; Ikola führt diesen Gedanken durch Präzisierung des Begriffs "Existentialität» fort; Kritik an Ikola führt Sadeniemi dazu, die Teilbarkeit der Subjektvorstellung vom Kontext abhängig zu machen; aus Ikolas Erwiderung ist der Gesichtspunkt wichtig, dass die Darstellungsfunktion des Satzes für seine Form wesentlich ist: das Existieren muss mausgedrückt» werden, wenn es den Partitiv bedingen soll; Siro macht auf die Beziehung zwischen geringer Intensität des Verbgeschehens und der Unbestimmtheit des Subjekts im Existenzsatz aufmerksam, die den Partitiv erklären soll; Sadeniemi tritt mit neuem Beweismaterial für die alte These ein, dass das nachgestellte Partitivsubjekt gewöhnlich psychologisches Prädikat und betont sei; zur Erklärung des Subjektpartitivs sagt er, das Handlungsmoment trete in solchen Sätzen in der Subjektvorstellung wenig hervor; Penttilä sucht dann die Teilbarkeit ausser mit dem Kontext auch mit der Verbtätigkeit in Beziehung zu bringen, also das Satzganze auf die Form seiner Teile zur Wirkung zu bringen; ausserdem verwandelt er durch Einführung der Halbbestimmtheit den logischen Gegensatz der Spezies in einen sprachpsychologischen, von der Interpretation abhängigen; er zeigt durch Interpretation von Verba wie kaatua, wie bei gewissen Verba ihre Bedeutung den Subjektpartitiv ausschliesst; Siro fordert als Erster Einbeziehung des Systemgesichtspunktes in die Diskussion im Sinne einer grundsätzlich anderen Methode, die es gestattet, die Beziehungsverhältnisse zwischen den diskutierten Begriffen von den Zufälligkeiten des Einzelfalls frei zu machen. Damit ist der unmittelbare Anknüpfungspunkt für die nun folgenden Ausführungen gegeben. Nur möchte ich mich nicht durch den Ausdruck "System" festlegen sondern versuchen, am lebendigen Sprachmaterial das Typische in den sich aus der Wechselwirkung von Syntax und Wortbedeutung ergebenden Beziehungen der Satzteile zueinander abzulesen. 


\section{Versuch einer sprachpsychologischen Deutung.}

Die Bedeutung der soeben aufgezählten Erkenntnisse liegt vor allem darin, dass sie nicht an Einzelobjekten sondern an Beziehungsverhältnissen gewonnen worden sind. Partitiv und Inkongruenz beim Subjekt des Finnischen sind in der Sicht, wie wir sie jetzt eröffnen möchten, nicht in erster Linie semologische sondern syntaktische Probleme. Wir gehen nicht von der Eignung von Vorstellungen oder Gegenständen für Teilbarkeit oder der Möglichkeit existentieller Auffassung aus sondern von den "semodynamischen» (sit venia verbo) Beziehungen zwischen Subjekt und Prädikat. Dieses Verfahren soll dem Übelstand begegnen, dass die Wirkungsweise der für Partitiv und Inkongruenz bestimmenden Faktoren durch ihr verwickeltes Zusammenspiel in der Praxis verschleiert wird.

Wenn fast in jedem Einzelfall mehrere dieser Faktoren zur Motivierung des Subjektausdrucks zusammenwirken, dann kann keiner den letzten Grund für die gewählte Formulierung enthalten. Die Forschung hat gezeigt, dass sich die Anwendbarkeit eines der Faktoren erst aus der Interpretation des ganzen Satzes, des Kontexts oder gar der Sachsituation ergibt, d.h. teilweise sogar aus nichtsprachlichen Ursachen. Den sprachlichen und nichtsprachlichen Ursachen kommt verschiedene Bedeutung für die Formulierung des Sprachausdrucks zu, weil sie verschiedenen Bewusstseinsschichten angehören. Die rein sprachlichen Kategorien werden dem Sprecher während der Formulierung des Satzes nicht bewusst und bleiben seiner Willkür fast völlig entzogen, da sie sich nach vorgegebenen Schemata verbinden. Im stilistischen Bereich aber, dort also, wo ausser dem Was auch das Wie des Ausdrucks berücksichtigt wird, w ä h $1 \mathrm{t}$ der Sprecher zwischen mehreren richtigen Möglichkeiten. Hier ist sein Formwille primär; die Wahl erfolgt nicht, weil ein Schema es so vorschreibt, sondern weil das Schema, die Kategorie, dem Ausdrucksbedürfnis entspricht. Je mehr solcher subjektiver Ausdruckselemente eine sprachliche Äusserung enthält, desto komplizierter wird die sprachliche Leistung und desto anfälliger gegen Missverständnisse. Das bedingt eine besonders gekennzeichnete sprachliche Form, für 
die gewöhnlich das Zusammenwirken mehrerer Ausdrucksmittel und verstärkte Inanspruchnahme des Zusammenhanges charakteristisch ist.

Es ist klar, dass bei der erwähnten Komplizierung der Sprachleistung noch weniger ein deutliches Bewusstsein von dem Zusammenhang zwischen grammatischer Kategorie und Sinngehalt besteht. Wenn wir ihn nachträglich feststellen, b eschreiben wir lediglich den sprachlichen Tatbestand, v e r s t e h e n ihn aber u.U. nicht. Diese Schwierigkeit führte offenbar die finnische Forschung und mich unabhängig dazu, durch die Methode des Verstehens dem Problem näher zu kommen. Diese Methode will in erster Linie nicht Tatsachen beschreiben sondern Zusammenhänge einsichtig machen. Sie bezieht den Menschen in die Wirkursachen des Geschehens ein und zeigt, dass auch die besondere Wirkungsart menschlichen Denkens und Fühlens den Erscheinungen bestimmte Merkmale aufprägt, die sich dann verselbständigen, objektivieren können und ihrerseits wieder auf den Menschen zurückwirken. Dass diese Betrachtungsweise gerade bei dem eminent menschlichen Erzeugnis der Sprache besonders angebracht ist, leuchtet ohne weiteres ein. Die Wissenschaft von der Sprache ist ohne das Studium ihrer Abhängigkeit rom Menschen sinnlos. Dieser Ausgangspunkt hat zur Folge, dass wir einerseits über die Grenze des grammatischen Bereichs im engeren Sinne hinausgehen müssen, andererseits das Gebiet des Sprachlichen als unseres Forschungsgegenstandes nicht verlassen dürfen. Diese für alle Verstehenswissenschaft typische Spannung kennzeichnet denn auch den oben genannten konkreten Ausgangspunkt unserer Untersuchung, das "semodynamische" Verhältnis von Subjekt und Verb, das wir nun kurz beschreiben wollen.

In einer Sprache mit zweipoligem Satz und aktivischem, subjektivem Verb, wie auch das Finnische eine ist, erscheint das Subjekt unabhängig von seiner inhaltlichen Rolle als Träger des Vorganges. Das Sprachsystem teilt ihm ohne Rücksicht auf den tatsächlichen Ablauf des Gesehenen eine Herrscherrolle zu, kraft deren es dem Geschehen Form und Richtung gibt und seine Handlungsenergie in dem vom Verb bezeichneten Vorgang realisiert. Diese Energie verbindet Subjekt- und 
Prädikatvorstellung nicht allein im Denken sondern gleicltzeitig in einem emotionalen Akt, der gleichsam das Geschehen stellvertretend vollzieht, ebenso wie die entsprechenden Satzteile zn einer festen Einheit, deren formales Kennzeichen die Kongruenz ist. Liefe nicht der rationalen Nachbildung der Wirklichkeit in der sprachlichen Formulierung im Bewusstsein ein dynamisches, zur Gestaltung drängendes Ergreifen derselben Wirklichkeit parallel, dann wäre die Sprache für ihre Aufgabe untauglich; es gäbe - um nur eins zu nennen - keine Metapher, die Sprache wäre ein logisches System und könnte z.B. keine aktivischen Verba für Sinneseindrücke ("sehen", "hören" u.a.) schaffen. Solche Verba zeigen besonders anschaulich, wie stark oft die Wirklichkeit von der sprachlichen Formulierung abweicht. Unser zweipoliger aktivischer Satz ist eine Verallgemeinerung. Diese ist einerseits Zeichen für eine gewaltige Dramatisierung der Wirklichkeit, zerstört aber andererseits durch so einseitige Interpretation allen Geschehens die Voraussetzungen für viele sprachliche Leistungen, die umso schwerer zu entbehren sind, je mehr sich das geistige Leben differenziert. F. N. Fink hat das Verbum solcher Sprachen als "Tatverb" bezeichnet und ihm das "Empfindungsverb" anderer Sprachen gegenübergestellt. Er veranschaulicht den hier gemeinten Unterschied in der Wirklichkeitsauffassung durch das Paar wich sehe" und "mir erscheint".

Es leuchtet unmittelbar ein, dass die Einseitigkeit der geschilderten Satzstruktur umso fühlbarer wird, je handlungsferner der Satzinhalt ist oder je weniger in dem mitzuteilenden Tatbestand das Handlungsmoment hervortreten soll. Im Rahmen der subjektiv-aktivischen Satzform gibt es ja zahllose Abstufungen und Übergangsformen zum Typ mit Empfindungsverb je nach Temperament und Weltanschauung der Sprachgemeinschaft und des Individuums. Hier beginnt der Bereich all derjenigen sehr wesentlichen Sprachfunktionen, die über die blosse Mitteilung von Gedanken hinaus der Selbstdarstellung und Verwirklichung menschlichen Innenlebens dienen. Für diese Aufgaben schafft sich die Sprache eine Anzahl mehr oder minder deutlich gekennzeichneter Darstellungsformen, deren Existenzberechtigung oft lediglich darin besteht, 
einen Tatbestand in einer von der gewöhnlichen abweichenden Form wiederzugeben, um eben eine Besonderheit in der Einstellung des Sprechers anklingen zu lassen. Demnach hat umgekehrt der Interpret das Recht, die Ungeeignetheit einer Sprachform für eine bestimmte Nuance, für die es in der betr. Sprache einen selbständigen Ausdruck gibt, als zureichenden Grund für stilistisch-syntaktische Differenzierungen anzunehmen.

Wir haben es hier mit zwei verschiedenen, wenngleich ineinander übergehenden Schichten der Subjektivierung zu tun. Die eine ist mit der Eigenart menschlichen Seelenlebens überhaupt gegeben und bewirkt die Gliederung der Wirklichkeit in für sprachliche Wiedergabe geeignete Vorstellungseinheiten und -reihen. Bühler hat in ihr die drei Hauptleistungen der Sprache, Darstellung, Kundgabe und Auslösung, unterschieden. Für den Sprecher selbst ist natürlich diese Umgestaltung noch gar keine Subjektivierung; er empfindet sie als das natürliche Äquivalent der Wirklichkeit und bedarf deshalb neuer Mittel, um seine persönliche Einstellung zur Wirklichkeit kundtun zu können. Dadurch entsteht die im engeren Sinne subjektivierende Färbung der Sprache. Sie ist unendlich mannigfaltiger, schwerer fassbar und weit weniger konsequent durchgeführt als die zuerst erwähnte Art. Es lässt sich ein Beziehungsverhältnis zwischen den beiden Formen der Subjektivierung erkennen: die Stärke, mit der sie sich im Einzelfall realisieren, steht gewöhnlich in umgekehrtem Verhältnis. Die Auslösung und die Kundgabe sind unmittelbare sprachliche Objektivierungen subjektiver Stellungnahme; diese selbst ist ein Stück Wirklichkeit und braucht nicht "nebenbei», durch Färbung des anderen Zwecken dienenden Sprachgebildes zum Ausdruck gebracht zu werden. Dies letztere ist dagegen bei der Darstellung der Fall. Sie verwirklicht sich umso reiner, je weniger spontane, triebhaft gebundene subjektive Reaktion auf die Merkwelt ihr beigemischt ist und muss deshalb, sofern es sich nicht um Wiedergabe objektiver Tatbestände handelt. wieder subjektiv gefärbt werden.

Auf dem Gebiete der Darstellung manifestieren sich die Fortschritte der geistigen Entwicklung am deutlichsten. Mit 
zunehmender Differenzierung des sprachlichen Ausdrucks wächst das Bedürfnis, für die mannigfachen Spielarten geistiger Bewältigung der Wirklichkeit durch Sprache eigene Ausdrucksformen zu schaffen, so etwa für Erzählung, Schilderung, Mitteilung, Feststellung ua. Bei aller gegenseitigen Überlagerung brauchen sie doch, um für den Sprecher ein jederzeit verfügbares Ausdrucksmittel zu werden, ein Minimum von unverwechselbaren - meist wohl syntaktischen - Kennzeichen, die u.U. die durch den sachlichen Inhalt des Satzes geforderte Sprachform verändern können (vgl. etwa die sog. "Attraktion des Tempus"). Je s t a t i s c h e r nun die Variante der "Darstellung" (als Sprachleistung gemeint), je ausschliesslicher sie der Konstatierung eines Sachverhalts ohne subjektive Färbung dient, ohne dass z.B. eine Behauptung aufgestellt wird oder der Akt der Verbindung der Einzelvorstellungen selbst einen Mitteilungswert erhält, je klarer sie sich also auf die Aussage beschränkt, dass die im Prädikat genaunte Vorstellung im Bereich des Subjekts gültig ist, ohne einer der beiden Vorstellungen einen wie immer gearteten Vorrang einzuräumen, desto weniger eignet sich der zweipolige Satztyp mit subjektivischem, aktivischem Verb zur Wiedergabe dieser Aussage. In diesem Fall muss nicht nur, wie das in jeder Sprache selbstverständlich ist, vieles aus dem Zusammenhang verstan de n sondern auch vieles im Zusammenhang ü berhört werden; so etwa das Handlungmoment in dem deutschen Satz "Er bekam einen Brief», wo die formal festgelegte Aktivität und Subjektivität des Verbs den Vorgang eindeutig als Handlung des Subjekts erscheinen lässt.

Fragen wir uns nun, welche Mittel in einer Sprache mit zweipoligem Satz und subjektivisch-aktivischem Verb zur Verfügung stehen, um dem Handlungsmoment entgegenzuwirken, so wird, da das Handlungsmoment wesentlich ein Ausdruck der im Verb realisierten Energie des Subjekts ist, die Antwort in der Hauptsache in einer Modifikation der Beziehung von Subjekt und Verb zu suchen sein. Je mehr diese Beziehung inhaltlich und formal gelockert wird, desto wirksamer ist der zwischen beiden Satzteilen fliessende Energiestrom unterbrochen, desto statischer wird der Satz. 
In den idg., besonders in den germanischen Sprachen lebt der Satz so eindeutig aus diesem Energiepotential, dass wir wenig Möglichkeiten zur Abschwächung besitzen. Im Deutschen und in skandinavischen Sprachen wäre die Inversion zu nennen: in der Satzfrage z.B. wird eine Feststellung aufgebaut, die der Gefragte bestätigen soll; sie enthält lediglich das sprachliche Gerippe, das durch die Mitwirkung des Gesprächspartners erst zum Leben erweckt wird. Es wäre daher ganz unzweckmässig, wenn die innere Form eigenes Leben verriete, indem etwa vom Subjekt ein Handeln angedeutet würde. Schon die blosse Assoziation mit der entsprechenden syntaktischen Form (eben die Wortfolge Subjekt-Verb) wird vermieden. Ähnlich in den Sätzen mit Scheinsubjekt ("Es zogen zwei Burschen wohl über den Rhein»): die Burschen und ihr Tun sind dem Hörer unbekannt und daher gleichermassen Gegenstand der Mitteilung; nicht in den Zusammenhang dagegen würde eine Schilderung des Rheinüberganges selbst passen. Im nicht invertierten Satz wäre wiederum das Handlungsmoment zu stark betont. Noch deutlicher wird der Mitteilungscharakter solcher Sätze und damit der störende Einfluss der geraden Wortfolge, wenn ein Wort wegen seiner subjektiven Wichtigkeit aus dem Satzinnern an den Anfang gezogen wird: $M$ or ge $n$ gehe ich in die Stadt (: nicht heute). Hier tritt die Beziehung von Subjekt und Verb überhaupt an Wichtigkeit zurück, da sie im allgemeinen für den Hörer nichts Neues bringt. Ein anderes Mittel veranschaulicht der Satz Mein Freund und ich liefen um die Wette. Die Zerlegung des Subjekts und die Inkongruenz schwächen die Energie im Handlungsausdruck; die adverbiale Bestimmung wirkt in derselben Richtung: sie ist dem Verb gegenüber "psychologisches Prädikat” (vgl. o. S. $37 \mathrm{zu}$ Ihmisiä kuoli nälkään). Ein letztes Beispiel: Eine Menge Menschen strömte(n) herbei: die Kollektivierung des Subjekts lässt die einzelnen Individuen, die allein Handlungsträger sein können, in den Hintergrund treten; kollektives Vorgehen ist ein V o r g a $\mathrm{n} g$, keine Handlung mehr.

Anders im Finnischen. Hier gibt es mehr Möglichkeiten, die Subjekt-Prädikatverbindung zu lockern, und ich glaube, nebenbei gesagt, dass sie sehr alt sind, da sie sich aus dem unter- 
ordnenden Sprachtypus ergeben, dem das Finnische angehört. Das attributive Verhältnis ist hier wichtiger als das prädikative. Damit ist natürlich über die Chronologie ihrer Entstehung im einzelnen nichts ausgesagt.

Solange das Finnische nach alter fgr. Weise statt des Plurals noch den kollektiven Singular verwendete, bestand in dieser Konstruktion Inkongruenz zwischen Subjekt und Verb, die vermutlich noch eine Zeitlang andauerte, als schon ein Pluralkennzeichen am Nomen bestand, das sich möglicherweise dann entwickelte, wenn das Subjekt die Aufmerksamkeit in besonderem Masse auf sich zog, oder wenn es der Spezies nach "bestimmte» Gegenstände bezeichnete, ähnlich wie der acc.sg. auf - $m$ neben dem endungslosen Akkusativ.

Dass die Beschaffenheit der Subjektvorstellung nicht allein auf die Entstehung des nominalen Plurals sondern auch zumindest auf die Anwendung des verbalen Plurals von Einfluss gewesen ist, zeigt noch heute die Syntax des Zahlworts. Die blosse Vervielfachung genügt offenbar nicht, um in der Vorstellung des Sprechers das Handeln des Subjekts so zu verändern, dass er die Notwendigkeit empfände, auch dem Handlungsausdruck selbst das Kennzeichen der Mehrheit beizulegen. Hakulinen betont SKRK II 241 ff. mit Recht mehrfach, dass die Erscheinung der Kongruenz vom logischen Standpunkt aus überflüssig sei. Gerade darin aber erblicke ich einen Fingerzeig für die psychologischen Entstehungsgründe: je mehr der Plural als Summe von an demselben Geschehen beteiligten Individuen aufgefasst wurde, desto mehr Bedeutung erlangte die Mehrheit für den Satz als Ganzes und drängte zum Ausdruck auch am Verb. Sobald sich diese Anschauung durchgesetzt hat, wird die Konstruktion mit attribuiertem Kardinale, der früher nichts Besonderes angehaftet hatte, zum Sonderfall, zum Glied des neu entstandenen Gegensatzes »individueller Plural: kollektiver Singular".

Ravila hat Vir. 1944, 123 ff. einen Weg angedeutet, wie aus vorauszusetzendem *kolme poika im Urfinnischen kolme poikaa geworden ist. Er betont mit Recht, dass kolme nicht von Anfang an das Bestimmungsglied der Gruppe gewesen sein kann, da es sonst dem Substantiv folgen müsste. Es sei deshalb 
eine Zwischenstufe etwa des Typs *kolme tuli poikaa mes kamen drei aus einer Knabenschar» zu vermuten. Man müsste also annehmen, dass die Wortgruppe, die ursprünglich und heute als zusammengehörig empfunden wird, eine Zeitlang im Bewusstsein getrennt worden sei, was natürlich denkbar ist. Vielleicht wäre aber daneben $\mathrm{zu}$ berücksichtigen, dass das Zahlwort als reines Formwort ohne materielles Gegenstück in der Wirklichkeit eine Sonderstellung einnimmt: *kolme poika ist seiner Struktur nach nicht ohne weiteres mit iso poika gleichwertig. So ist z.B. im Deutschen die Verbindung aus Masswort und Gemessenem die einzige, deren syntaktisches Abhängigkeitsverhältnis heute konsequent unbezeichnet bleibt: bei einem Glas(e) Wein u.ä., wo das Sprachgefühl Wein nicht sicher in das Kasussystem einzuordnen vermag. Es wäre deshalb denkbar, dass wenigstens in manchen Fällen die Glieder kolme und poika ihren syntaktischen Zusammenhang bewahrt hätten. Es wäre z.B. sonst eigenartig, dass sie in allen Kasus ausser Nom. und Akk. heute kongruieren, während Nom. und Akk. ein Subordinationsverhältnis zeigen. Zur Herausbildung des Partitivs könnte dann der Umstand beigetragen haben, dass sich bei Entstehung der Numeruskongruenz das Gefühl für die Unbestimmtheit bloss gezählter Gegenstände vom Standpunkt der Individualität aus geschärft hätte. Das Gezählte erschien nun als blosse Masse, als unbestimmtes Ganzes. Besteht jedoch das Gezählte aus individuell bestimmten Einheiten, so setzt sich dieser Umstand wenigstens in der Form des Prädikatsverbs durch. Da auch das Objekt ein Bestandteil der Handlung ist, greift der Partitiv auch hierauf über, während die vielfach $\mathrm{zu}$ beobachtende Abneigung gegen Ausdrücke, wo das Bestimmungsglied selbst weder Subjekt noch Objekt ist, im Falle der übrigen Kasus den Adjektivcharakter des Kardinale durch Einführung der Kongruenz weiter verstärkt hat: nicht *kolmesta poikaa sondern kolmesta pojasta.

Trifft diese Erklärung zu, dann haben wir hier ein Beispiel für die Wichtigkeit der Beziehung von Subjekt und Verb für die Satzgestaltung. kolme poikaa meni ohitsemme ist weniger subjektiv-aktivisch als k.p. menivät o. oder pojat menivät ohitsemme, was äusserlich an der vom Subjekt aufs Verb über- 
greifenden Endung sichtbar wird. Die Numeruskongruenz zeigt hier an, dass das Handeln jedes der drei Knaben gleich wichtig genommen wird, weil der Hörer alle drei kennt und deshalb die im Zusammenhang mit ihnen berichteten Vorgänge nicht als bloss statische Mitteilung sondern als Teil ihrer selbst, als dynamisches Erlebnis in sich aufnehmen soll; das Vorbeigehen ist gleichsam nur eine durch aktive Selbstverwirklichung umgestaltete, spezialisierte Erscheinungsform der Knaben. Wenn jetzt das Verb in die mit der subjektrorstellung gegebene Mehrheitsvorstellung nicht einbezogen wurde, dann bildete diese Konstruktion eine Opposition mit der durch dic Kongruenz ausgezeichneten, die sich zudem durch ihre klar umrissene Funktion im Bewusstsein deutlich abzeichnete. Eine solche Sachlage ist aber immer ein günstiger Ausgangspunkt für die Ausbildung einer irgendwie gegensätzlichen Funktion auch für die andere Oppositionsvariante.

Durch den Einbau in die Opposition wurde also aus dem alten partitivus quantitatis ein Ausdruck für die Unbestimmtheit der Subjektvorstellung. Da sich die Kongruenz - wie uns schien, infolge eines Wandels im subjektbegriff - am stärksten zwischen Subjekt und Prädikat durchsetzte, blieben die attributiven Verbindungen mit Kardinale davon unberührt. So entsteht ein konstitutiver Gegensatz zwischen Vielheit und Masse, dessen morphologischer Ausdruck die Kongruenz ist. Die Zahl als typischer Ausdruck der Quantität verbindet sich gewöhnlich mit unbestimmten subjektrorstellungen. so vereinigen sich in den Verbindungen mit Kardinale - von del Syntax des Partitivs und der Inkongruenz aus: zufällig Partitiv, Inkongruenz und Unbestimmtheit an demselben Modell. Beide syntaktischen Grössen dienen letzten Endes demselben Zweck, nämlich eine Subjektrorstellung auszudrücken, die infolge ihrer Rolle im Kontext nicht genügend Aufmerksamkeit beanspruchen kann, um sie als durch ihr Handeln bestimmt erscheinen zu lassen. In diesem Lmstand liegt für uns die Berechtigung, Partitiv und Inkongruenz zusammen zu behandeln. Für das gegenseitige Verhältnis der hier betrachteten Kategorien ist es wichtig, dass Partitiv und Inkongruenz Vollbestimmtheit nicht ausdrücken kömnen, dass aber Nomi- 
nativ und Kongruenz neben Vollbestimmtheit auch Teil- und Unbestimmtheit wiedergeben. Hieraus ergibt sich mit wünschenswerter Deutlichkeit, dass Partitiv und Inkongruenz heute nur für solche Subjektrorstellungen zuständig sind, deren Gegenstände nicht als Agens im engeren sinne auftreten. Partitiv und Inkongruenz erscheinen hier somit als Mittel, die psychologische Beziehung zwischen Subjekt und Prädikat auch syntaktisch zu schwächen. Auch hier gilt wie in obigen deutschen Beispielen, dass ein Kollektiv nicht handelt sondern funktioniert.

Die Kardinalzahlverbindungen führen uns indessen noch einen Schritt weiter. Bekanntlich verlangen sie Kongruenz, wenn das Gezählte bestimmt ist: kolme poikaa menivät ohitsemme. Dieser Sonderfall zeigt sehr anschaulich, welche Bedeutung der Stellung einer syntaktischen Erscheinung im System zukommt. Der Partitiv war ursprünglich als Ausdruck der unbestimmten Menge eingedrungen. An dieser Auffassung änderte sich, wie der gleichbleibende Singular des Prädikatsverbs zeigt, auch dann nichts, als sich das syntaktische Abhängigkeitsverhältnis zwischen den beiden Bestandteilen änderte (dass dies geschah, scheint u.a. daraus hervorzugehen, dass der Partitiv neben Kardinalia sich ohne Rücksicht auf die Teilbarkeit der Subjektvorstellung behauptet). Diese Verdunklung ist die Voraussetzung für die Verwendung von Kardinalzahlverbindungen in kongruenten Sätzen: die Auffassung, dass das Gezählte ein Ausdruck für eine unbestimmte Menge sei, muss ebenso zurücktreten wie die, dass das Kardinale das Bestimmungsglied der Gruppe sei. Der Anstoss dafür aber, dass die gleiche Kardinalzahlverbindung auch zur Bezeichnung einer bestimmten Mehrheit diente, und dass in den betr. Sätzen eine zu deren Wesen nicht passende Kongruenz einzog, konnte nicht aus der Konzeption der Kardinalzahlverbindung selbst sondern nur aus den Sätzen mit bestimmtem Subjekt ohne Kardinale mit kongruierendem Verb kommen. Erst als der kategoriale Gegensatz bestimmt: unbestimmt soweit geklärt war, dass für Vollbestimmtheit Kongruenz notwendig war, konnte die fragliche Ausdrucksvariante geschaffen werden.

Dass es sich jedoch hier nicht um logische sondern um psy- 
chologische, vielleicht genauer: um phänomenologische Bestimmtheit handelt, d.h. um solche, die sich aus dem Wesen der Erscheinung als eines Anschaumnggegenstandes ergibt, zeigt sich darin, dass auch ein vom logischen Standpunkt unbestimmtes Attribut des Kardinales Kongruenz bedingt: jotkut kaksi tämän luokan oppilasta orat särleneet ikkunan. Solche Fälle verhindern, dass sich Vollbestimmtheit und Kongruenz völlig decken. Hier kommt es nicht auf die Identifizierbarkeit der Täter an sondern darauf, dass der Hörer sie sich als solche v orstelle n kann, dass das Subjekt durch irgendeine Besonderheit individualisiert wird, die es zum Träger der Handlung geeignet macht. Gerade solche Beispiele zeigen deutlich, dass die Kongruenz letztlich psychologische Gründe hat. Aus derselben Ursache erklären sich Sadeniemis Beispiele (S. $11 \mathrm{f}$.) $J$ o $k$ in avain on naulassa. Bei Gegenständen aber, die ausserdem pluralisch gekennzeichnet sind, sind zwei Varianten möglich: (Muutamia) mitaleja on pöydällä oder Muntamat mitalit ovat pöydällä. Ist aber die Unbestimmtheit durch die Rolle als psychologisches Prädikat unterstrichen. scheidet die Inkongruenz aus: es heisst also nicht ${ }^{*}$ Pöydällä ocat (on) muutamat mitalit sondern $P$. on (muutamia) mitaleja (muutama mitali).

Ein anderer interessanter Spezialfall ron Inkongruenz sind die Entsprechungen der deutschen Sätze mit "haben". olla kann hier bekanntlich nur im Singular auftreten. Auf den besonderen Charakter dieser Konstruktion wir schon 0. S. 28 hingewiesen worden. Schon Setälä hatte in ihr eine erstarrte Ausdrucksweise gesehen. Das grammatische Subjekt ist hier psychologisches Prädikat und hat so wenior subjektcharakter, dass man versucht hat. es als eine Art Objekt zu verstehen. Tatsächlich ist das "Subjekt" hier nicht "Satzgegenstand" sondern eher Satzaussage, das, worauf der Satz hinzielt, angelegt ist, das, was $\mathrm{mitg}$ e t e il t werden soll. Der Satz ist ganz statisch; zwischen Subjekt- und Verbvorstellung besteht keinerlei "semodynamische" Verbindung, kein Energiestrom des Subjekts setzt sich im Verbrorgang in Handlung um. Das Verb dient lediglich dem formalen Aufbau des Satzes; in der entsprechenden russischen Konstruktion ist es giar nicht vorhanden. Hier würde die Kongruenz geradezu das W e s e n der 
Konstruktion aufheben, sie würde Mitteilung zu Vorgangsdarstellung rerfälschen. Durch seine reine Nennfunktion ist das Subjekt im Vorstellungsverband seines Satzes so stark isoliert, dass selbst der Nominativ, der hier die logische und zugleich die situationsbedingte Bestimmtheit ausdrückt, keinen Einfluss auf den Numerus der Verbform ausübt. Die ungewöhnliche Passivität des Subjekts bewirkt hier demnach sogar eine Ausnahme von der sonst streng geltenden Regel, dass Vollbestimmtheit mit Inkongruenz unvereinbar ist. Es ist also nicht die Bestimmtheit schlechthin, die individualisiert; darüber hinaus muss die Voraussetzung gegeben sein, dass die Individualisierung sich auf die Beziehung von Subjekt und Verb im Sinne der Aktivierung auswirken kann. In der "haben»Konstruktion kann das Subjekt nicht als Handlungsträger fungieren sondern bleibt Kern der Aussage. Auch hier entscheidet somit nicht das Vorhandensein der logischen sondern das Fehlen der psychologischen "Bestimmtheit" über die Form des Satzes. Die fragliche Konstruktion nimmt in allen bisher vorgeschlagenen Regelungen eine Ausnahmestellung ein.

Ehe wir sie jedoch verlassen, wollen wir noch einen Augenblick bei einer ihrer Eigentümlichkeiten verweilen, deren Bedeutung für unsere Betrachtungsweise hier besonders klar zutage tritt. Das grammatische Subjekt ist in der "haben»-Konstruktion psychologisches Prädikat und folgt gewöhnlich dem Verb. Diese Wortfolgeregel scheint mir wesentlich zu sein. Schon Rosenqvist hat (Lehrbuch ${ }^{2}$ S. 85) darauf aufmerksam gemacht, dass Inkongruenz mit Vorliebe bei nachgestelltem Subjekt eintritt. Wemn für die Satzgestaltung wirklich der Umstand von Belang ist, dass die Sprache ein Abbild der wirklichen Vorgänge ist, dann liegt es auf der Hand, dass Umstellung von Subjekt und Prädikat die Dynamik des Handlungsausdrucks aufhebt. Primär ist also bei der "haben"Konstruktion die handlungsferne Mitteilung, der stereotype sprachliche Ausdruck, nachgestelltes Subjekt und singularisches Verb. Da Kongruenz bei pluralischem Subjekt hier gar nicht möglich ist, kann man hier auch nicht von Inkongruenz sondern eher ron Unipersonalität und, wenn man will, von 
Subjektlosigkeit sprechen. Daraus ziehen wir den methodischen Gewinn, dass wir diejenigen Züge, die die Inkongruenz mit der "haben"-Konstruktion gemein hat, als ursächlich von der inneren Form ihrer Sätze bedingt erkennen. Demnach kann man die Inkongruenz nicht z.B. als zufälligen Rest einer früher weiter verbreiteten Sprachgewohnheit oder als willkürliche Differenzierung aus der Kongruenz ansehen, sondern sie ist der einheitliche Ausdruck für zwei miteinander zusammenhängende Eigenschaften der inneren Form ihres Satzes. Die eine ist die semodynamische Verbindungslosigkeit von Subjekt und Verb, die für beide Satzteile einen Verlust an syntaktischer Konkretheit bedeutet: das Subjekt verliert als psychologisches Prädikat (bei Inkongruenz scheint es in "Ruhestellung» - Gegensatz »bewegte Stellung»: 0. S. 25 nur so vorzukommen) an Fähigkeit, Ausgangspunkt der Darstellung und Initiator des Geschehens zu sein; das Verb verliert an Fähigkeit, die Energie des Subjekts als durch dessen Individualität geprägten Anstoss (z.B. als Handlungswillen einer Mehrheit) in Geschehen umzusetzen; es nähert sich dem nominalen Prädikat und stellt seinen Aussageinhalt einfach neben den des Subjekts. Die andere Eigenschaft betrifft die Aussageweise des Satzes. Da Subjekt und Prädikat nicht ihre volle Kraft entwickeln können, muss der Satz statisch bleiben, d.h. seine Aussage beschränkt sich auf blosse Mitteilung von Inhalten, ohne gleichzeitig die Form zu vermitteln, in der der Inhalt realisiert oder geistig angeschaut worden ist. In den meisten einschlägigen Fällen tritt zur Inkongruenz noch ein weiteres Kennzeichen unterstützend hinzu: das Subjekt steht entweder im Partitiv, wodurch, wie ausgeführt, der Subjektcharakter schon fast in Frage gestellt ist, oder als Prädikat tritt das inhaltlich blasseste Verb, d.h. olla, auf. Dass die Beschaffenheit des Subjekts der wichtigere der beiden Faktoren ist, ersieht man daraus, dass im ersten Fall das Subjekt, weil weitgehend seiner Eigenart beraubt, nicht psychologisches Prädikat sein muss: tuli oppilaita. Suomessa on kylmät talvet. Oppilaita tuli opettajainhuoneeseen (wenn mich mein Sprachgefühl nicht täuscht, muss im letzten Fall eine adverbiale Er- 
gänzung hinzukommen ${ }^{1}$. Das Vorbild der Sätze mit gerader Folge ist hier so stark, dass man die Statik des Satzes als unbefriedigend empfindet. Erst die Ortsbestimmung rundet den Satz zur Mitteilung.). Wir können somit feststellen: die Inkongruenz ist der organische Ausdruck für einen statischen, der blossen Mitteilung dienenden Satz mit funktionsgeschwächtem Subjekt und Prädikat.

Zur Veranschaulichung des hier Ausgeführten seien Beispiele aus den Diskussionsbeiträgen angeführt. I k o la 58, 228: Pojalla on vaaleat hiukset. Säkissä on saappaat. Heille syntyi kiaksoset. Mieheltä loppui rahat. - Vaaleat hiukset on pojalla ja tu'mmat tytöllä. Dass Sätze des zuletzt angeführten Typs wegen ihrer bewegten Wortfolge die Geltung der Normalform nicht beschränken, wurde bereits gesagt. Ikola kommentiert die Beispiele so: "Asian ydin on tässäkin se, että on kysymys jostakin lokaliteetista tai olotilasta, jonka sisällöstä lause ilmoittaa jotakin». Diese Erklärung soll die Sätze als Existentialsätze erweisen. Ich bin mit Ikola darin einig, dass das Prädikatsverb hier möglichst "blass", handlungsfern, am liebsten also olla sein muss - aus den oben angeführten Gründen. Die Funktion solcher Sätze möchte ich dagegen etwas anders umschreiben; hierüber unten bei den Existentialsätzen.

S a d e n i em i (S. 13 f.): Pihalla juoksee poikia. Ohjelmassa seuraa iltauutiset. Siihen on olemassa hyvät edellytykset. Lapissa on epäedulliset ilmastosuhteet. Miehillä oli mukanaan kirveet. Näissä alioikeuksissa toimi tuomareina etupäässä muulalaiset miehet. Siellä on nyt johdossa uudet miehet. Helsingissä on kaduilla nykyään kaikkialla sähkölamput. Kissalla on poikaset. Koulussa on huonot opetusvälineet. Koivussa on tänä vuonna isot lehdet. Suomessa on kylmät talvet. Minulla on mukanani ne mitalit, joita halusit nähdä. Akkunaan ilmestyi kalpeat kasvot. Der Satztyp ist überall derselbe, die Funktion reine Mitteilung in Form der Nebeneinanderstellung der Vorstellungen mit dem Nachdruck auf dem Subjekt. Einige Fälle sind von besonderem Interesse. So sagt Sadeniemi S. 13, der Satz *Pihalla juoksee Niemelän lapset sei nicht üblich. Wir

1 Vgl. auch Penttilä, 60, 33 . 
wissen jetzt, dass der syntaktische Grund die Bestimmtheit des Subjekts ist. Von unserer Sicht aus wäre derselbe Sachverhalt so zu formulieren: durch die Bestimmung ist die Subjektvorstellung so konkret geworden, dass sie trotz ihrer Rolle als psychologisches Prädikat über die blosse Nennfunktion hinaus Handlungsträger wird. In den 3 folgenden Sätzen gibt es keine genaue singularische Entsprechung zur Subjektform; die Vorstellungen meinen einen einheitlichen Sachverhalt und sind zudem unanschaulich. Pluralisches Verb würde die Einheitlichkeit zerstören und entgegen dem Sinn jede einzelne »Voraussetzung», »Klimaverhältnis» usw. zu einem selbständig wirkenden Faktor isolieren. Miehillä oli mukanaan kirveet; wenn man die »haben»-Konstruktion hier nicht gelten lassen will, ergibt sich die Form aus der Halbbestimmtheit: den Partitiv schliesst die quantitative Bestimmtheit aus, die Kongruenz der Gruppencharakter der Subjektvorstellung. Die beiden folgenden Beispiele haben lebende Wesen zum Subjekt (miehet); sie zeigen besonders klar, wie Kongruenz die Subjektvorstellung sofort in einzeln handelnde Individuen zerlegen würde. Zu beachten auch das wenig zum Existentialsatz passende Verb toimia. Koulussa on huonot opetusvälineet: wenn ich nicht irre, würde der gleiche Satz mit pluralischem Verb bedeuten "in der Schule befinden sich die schlechten Unterrichtsgegenstände», d.h. der Plural wäre hier vom Inhalt her primär notwendig, während er im inkongruenten Satz eine unbeachtete, durch den Kontext selbstverständliche Eigenschaft der Subjektvorstellung ist. Das letzte Beispiel zeigt, dass selbst eine so nachdrückliche lexikalische Bestimmung wie Demonstrativpronomen und erklärender Relativsatz die "psychologische" Unbestimmtheit nicht aufheben kann. Alles in allem kann man sagen: bei distributiver Auffassung der Subjektvorstellung herrscht Kongruenz, bei kollektiver (also u.a. immer beim Subjektpartitiv) Inkongruenz. Vielleicht lässt sich dies Ergebnis als brauchbare Ergänzung der bereits erarbeiteten verwenden. Auch so käme man um das heikle Problem der Teilbarkeit herum.

Der - soweit ich sehe - einzige Typ, der sich obiger Betrachtungsweise nicht fügt, sind Sätze mit gewissen pluralia 
tantum als Subjekt: einerseits zwar regelrecht Akkunaan ilmestyi kalpeat kasvot, andererseits aber Akkunaruudun takaa näkyivät tyttölapsen kalpeat, kauhistuneet kasvot. Vgl. auch Rehtorilla oli kaulassaan yliopiston rehtorinketjut. Oliko sinulla mukanasi nuo sakset? Pojalla oli jalassa parhaat kenkänsä. (Penttilä 59, 158 nach Ikola, 58, 228). Penttilä bemerkt, dass in Sätzen wie Mieheltä paleltui korvat auch pluralisches Prädikat möglich sei. Die beiden Varianten, deren Subjekt bestimmt ist, entsprechen rein formal den beiden ersten Beispielen. Den Plural paleltuivat könnte man sich so erklären, dass er darauf hinweisen soll, dass b e i d e Ohren unabhängig das gleiche Schicksal traf. Nach Ikolas Beispielen zu schliessen, setzt sich aber bei solchem Subjekt die "Konstruktion nach dem Sinn» erwartungsgemäss durch. Vgl. auch Sadeniemis Beispiel Pöydällä ovat ne mitalit, joita halusit nähdä. Auch Penttilä hat Schwierigkeiten mit derlei Sätzen (a.O. S. 159 f.). Er begnügt sich mit dem Hinweis, dass kasvot sich als plurale tantum anders verhalte. Als Gegensatz bringt er das "halbbestimmte" Akkunaan ilmestyi pienet kädet mit "normaler" Inkongruenz. Dagegen aber steht wieder das (nach Penttilä) gleichwertige Variantenpaar Akkunaruudun takaa näkyi (: näkyivät) tyttölapsen vaaleat kiharat mit bestimmtem Subjekt, dessen Spezies aber "leksikaalisin keinoin" bezeichnet sei. Auch Sadeniemi S. 16 erklärt den fraglichen Unterschied aus der Spezies. Penttilä ergänzt seine Erklärung 59, 396 damit, dass kasvot heute nicht mehr halbbestimmt auftreten könne, d.h. in unsere Terminologie übersetzt, dass die entsprechende Vorstellung keinen Gruppencharakter annehmen könne. Alle diese Lösungen sind indessen für uns nicht verwendbar, weil sie dem psychologischen Gesichtspunkt nicht genügen. Daraus lässt sich wohl nur schliessen, dass dieser Gesichtspunkt hier keine Geltung hat. Da bei pluralia tantum aus der üblichen Variantendreiheit die partitivische ausscheidet (kasroja ist Plural), muss die Inkongruenz die Unbestimmtheit bezeichnen, und da zudem Bestimmtheit sonst überall Kongruenz fordert, wird sie auch hier durchgeführt. Das wäre also eine rein grammatische Regelung.

Unsere Ermittlungen über die Inkongruenz stehen in vollem Einklang mit den Ergebnissen der finnischen Forschung. Die 
übliche Nachstellung des inkongruenten subjekts folgt aus dessen Nennfunktion; die geringe Dynamik des Verbinhalts aus dem Mitteilungscharakter des Satzes; die Unteilbarkeit der pluralischen subjektvorstellung aus deren kollektiven Sinn; ihre nur quantitative Bestimmtheit aus der syntaktischen und psychologischen schwächung der Subjektfunktion. Alle diese Kennzei،hen haben einen mehr oder minder deutlich hervortretenden negativen Zug gemeinsam. Der inkongruente Satz unterscheidet sich in seiner inneren Form vom kongruenten durch eine gewisse Vagheit und Passivität, deren morphologischer Ausdruck eben die mangelnde I'bereinstimmung von Subjekt und Prädikatsverb ist.

Auf dieser Grundlage können wir weiterbauen. Als wesentliche Kennzeichen der Inkongruenz hatten sich inhaltliche Farblosigkeit des Verbs und durch Nenn- oder Mitteilungsfunktion bewirkte Isoliertheit des Subjekts ergeben. Nun sind sich alle finnischen Forscher darüber einig, dass Inkongruenz von Subjekt und Verb einschl. der Fälle mit Subjektpartitiv nur im Existential- bzw. Existenzsatz vorkommt. Oben ist versucht worden, für diese Beschränkung eine phänomenologische Begründung zu geben und damit zwischen den genannten sprachlichen Erscheinungen einen inneren Zusammenhang zu finden. Ohne mich auf eine Diskussion über die verschiedene Abgrenzung der beiden Termini einzulassen, möchte ich doch die Frage aufwerfen, ob die Termini das Wesen der fraglichen Sätze kennzeichmen. "Existenz" ist ein Begriff der Philosophie, sie wird dem Objekt absolut, ohne Rücksicht auf dessen Erscheinungsform in der Erfahrungswelt beigelegt; die hier gemeinte Existentialität aber soll das Sein an einem Ort, also das veränderliche Sein in der Erfahrungswelt, bezeichnen. Gelegentlich fallen beide Formen des Seins zusammen (Beispiele bei Ikola, 59, 322). Aber einmal geschieht das nur ausnahmsweise, und damn zeigt gerade in solchen Fällen, wo vom Subjekt wirklich nur das Sein ausgesagt wird, der Umstand, dass Vorbedingung für ihre Anwendung die Teilbarkeit der Subjektvorstellung ist, besonders klar, dass nicht die Prädizierung des Seins an sich den Partitiv bedingt. Gerade hier drängt sich nur zu leicht der Einwand auf, dass jedes Handeln, jeder $\mathrm{Zu}-$ 
stand usw. das Existieren der Beteiligten voraussetze, der ja in der Diskussion bis zuletzt eine grosse Rolle gespielt hat und Ikola 61, 293 zu der nachdrücklichen Feststellung nötigte, es sei ein örtlich und zeitlich genau bestimmtes Sein gemeint. Hinzukommt schliesslich noch, dass neben olla = "existieren» der Anwendungsbereich des Nominativs grösser ist als neben olla = "sein" (Penttilä, 60, 47 f. $\left.{ }^{1}\right)$.

Tiefer dringt indessen ein anderer Einwand. Die Bezeichnung "Existentialsatz» (bzw. „Existenzsatz») richtet die Aufmerksamkeit auf eine Eigentümlichkeit, die zwar wichtig ist aber nicht die zureichende Bedingung für die zu deutende Erscheinung enthält. Zu den oben bereits geäusserten Bedenken kommt nun noch ein weiteres von dem im Vorstehenden entwickelten Standpunkt aus hinzu. Ikola definiert den Existentialsatz, um seine letzte Formulierung $(61,295)$ zu gebrauchen, so: "Lähtökohtana on lokaliteetti, ja ilmoitetaan, että siihen ilmestyi jotakin». Es handelt sich somit nicht um Sein sondern darum, dass durch die im Satz vollzogene Verbindung von Subjekt- und Ortsvorstellung $\mathrm{mittelbar}$ auch das Sein zum Ausdruck gebracht wird, weil eben der Subjektgegenstand in der Wirklichkeit mit dem Ort nicht ohne das Prädikat des Vorhandenseins verbunden auftreten kann. Der Terminus erhebt somit eine Begleiterscheinung zur Hauptsache. Auch die Bestimmung, in Existentialsatz werde die Existenz "nicht vorausgesetzt", gibt, wie sich gezeigt hat, zu Missverständnissen Anlass, weil sie zu rationalistisch formuliert ist: der Sprecher reflektiert. gewöhnlich nicht über die Existenz des Subjektgegenstandes. Ich möchte daher die Formulierung vorschlagen, die Existenz des Subjektgegenstandes an einem anderen Ort (oder zu einer anderen Zeit) wird in der Aussage unberücksichtigt gelassen.

Ich darf an obige Darlegungen über die Mitteilungsfunktion des Satzes erinnern. Jede Aussage hat einen Schwerpunkt, um den sich ihre Bestandteile herumgruppieren, und kann nur voll verstanden werden, wenn dieser Schwerpunkt als solcher er-

1 Ist es wirklich so, dass neben olla = mexistieren" nur definites Subjekt auftreten kann, wie Penttilä a.O. sagt? Kann man nicht einem Atheisten entgegenhalten: Jumala on? 
kannt wird. Der Schwerpunkt der "Existentialsätze» ist nun nicht das Sein, auch nicht die Ortsangabe sondern m.E. die Summe von Subjekt- und Prädikatvorstellung. Wenn Ikola 58, 225 sagt: "Lause Po $i$ ki a juolsee pihalla ilmoittaa, että. piha sisältää juoksevia poikia, kun taas lauseessa $M u$ u $a^{-}$ m. at pojat juokserat pihalla on kysymys pojista ja siitä, missä he nyt ovat», so scheint mir der Inhalt der Sätze nicht genau wiedergegeben zu sein. Im 2. Satz ist zwar die Rede von den Knaben; aber es wird nicht nur gesagt, "wo sie jetzt sind» (wenn auch der rein stoffliche Inhalt damit erschöpft sein mag), sondern dass sie durch die Tätigkeit des Laufens individualisiert sind, und dies Laufen spielt sich auf dem Hof ab. Das Subjekt ist hier zugleich Ausgangspunkt der Darstellung und der Handlung; seine Energie setzt sich im Verb in Geschehen um und wird in der Bestimmung lokalisiert. Schwerpunkt der Mitteilung ist dies konkrete Handeln, nicht das Sein des Subjekts, das ausserhalb des Rahmens der Sprechsituation bleibt. Ebensowenig kommt zum Ausdruck, dass die Existenz der Knaben ror diesem Lauf (also ein Gesichtspunkt, den Ikola für die echten Existentialsätze ausdrücklich ausschliesst) vorausgesetzt ist. Anders der 1. Satz. In dieser Form (also mit vorangestelltem Subjekt) scheint er mir nur in bestimmten Situationen möglich zu sein, z.B. in einer Milieuschilderung, wo mehrere derartige Beobachtungen aufzählend nebeneinandergestellt werden. Das sind komplexe Wahrnehmungen, die als Ganzes übermittelt und aufgenommen werden. Hier wird nicht Handlung wiedergegeben, Energie umgesetzt, sondern selbst das Geschehen wird zum Zustand, gleichsam auf seine Substanz reduziert. Das Subjekt ist nicht durch Tätigkeit individualisiert, es erscheint als Kollektiv, und dadurch verliert auch der Verbinhalt seine Konkretheit. Das Subjekt ist auch hier Ausgangspunkt der Darstellung aber nicht des (xeschehens, denn ein solches wird gar nicht mitgeteilt. Während im 2. Satz das Subjekt den übrigen Satzteilen gegenübersteht, bilden im 1. Subjekt und Prädikat die Einheit: auf dem Hof findet Knabenlaufen statt. Dieselbe Gliederung herrscht, wemn das Subjekt dem Verb folgt, nur dass es dann noch deutlicher den Schwerpunkt des Satzes bildet. In beiden Fällen aber ist 
die Subjektvorstellung viel zu unselbständig, als dass man an die Existenz ihrer Gegenstände dächte, und auch die Ortsangabe bleibt zu sehr Bestimmung, als dass man als Inhalt der Aussage angeben dürfte, was sie enthält. Schwerpunkt der Aussage ist auch hier der Subjektkomplex: das kollektivierte, versachlichte Subjekt und das statische, fast an ein Attribut erimnernde Verb (vgl. Ikolas obige Umschreibung). Die Aussage hat also nicht wie im 2. Satz die Schaffung des Kontakts zwischen subjekt- und Prädikatrorstellung zum Gegenstand, da der Kontakt bereits gegeben ist. Dadurch fehlt dem Satz die eindeutige Terichtetheit, der klar parallele Verlauf der Energie vom subjekt durch das Verbum zur Ortsbestimmung und der sprachlichen Wiedergabe dieses Vorgangs; er hat vielmehr etwas Schwebendes, Unbestimmtes, der Schwerpunkt ist. hier nur durch den Inhalt, nicht gleichzeitig durch den Geschehensablauf bestimmt. Aus dieser Konstellation entsteht die oben S. 15 angedeutete Schwierigkeit: wenn die Lokalvorstellung des Satzes schon als integrierender Bestandteil der Subjektvorstellung mitgedacht werden soll ("kattilassa oleva konkreettinen vesierä»), dann wird dem Satz die einzige Spannung genommen, kraft deren sich seine Vorstellungen zu einer Aussage konstituieren können, er wird gegenstandslos.

Den gleichen Unterschied wie die hier analysierten Sätze zeigt das S. 13 zitierte Paar Ihmiset juoksevat (: Ihmisiä juoksee) täällä asioimassa pyhinälin. Auch Penttilä erklärt den Unterschied aus der eigentlichen und der uneigentlichen Bedeutung des Verbs. Nur möchte ich das Wesentliche in der Bedeutungsänderung nicht in der wachsenden Entfernung von olla sehen sondern darin, dass das Verb umso mehr von der Fähigkeit einbüsst, Handlung darzustellen und damit das Subjekt zu individualisieren, je unanschaulicher seine Bedeutung wird: im 1. Satz wird das Laufen vieler einzelner Menschen vorgeführt, im 2 . wird mitgeteilt, dass es selbst an Feiertagen hier von Menschen wimmelt.

Hier sei an Airilas bereits erwähnte feine Beobachtungen über die "Existentialsätze" erinnert: bei partialem Subjekt dürfe das Prädikat nichts über das Wesen und die Tätigkeit des Subjektgegenstandes aussagen, und deshalb dürfe es auch 
keine näheren Bestimmungen erhalten. Es solle nur das Sein des Subjektgegenstandes ausdrücken. Airila bemüht sich also, genau wie es hier versucht wird, das Wesen der fraglichen Sätze aus der Art der Verbindung von Subjekt und Prädikat zu deuten. Er leitet, m.E. mit vollem Recht, die Existentialität aus der Partialität her, nicht umgekehrt. Denn, da nach der offiziellen Lehrmeinung jeder Satz mit partitivischem Subjekt existential ist, aber nicht jeder Existentialsatz partitivisches Subjekt hat, so ist Partialität zureichende Bedingung der Existentialität. Das zeigt Ikolas Existentialsatzpaar Oksien välistä näkyi orava: Tuolla oksien välissä näkyi oravaa. Deshalb kann man nicht aus der Existentialität die Partialität mit Sicherheit folgern noch erklären. Es wäre daher sachgemässer, wenn man in Airilas These das Sein als notwendige Bedingung der Partialität etwas abwandelte und ihre positive Seite mehr zur Geltung brächte: das Subjekt wird umso bestimmter, je deutlicher es als Ausgangspunkt der Darstellung und des Geschehens hervortritt und je dentlicher der Verbinhalt Aktivität des Subjekts voraussetzt. Je unbestimmter aber die Subjektvorstellung, je blasser, statischer der Verbinhalt (Extremfall: Sein), desto gemässer das Partialsubjekt.

Diese Betrachtungsweise führt, wie öfter betont, unvermeidlich zu einer umständlicheren, unbestimmteren Formulierung als die frühere. Das ergibt sich aber zwingend aus der komplexen Natur des Phänomens und daraus, dass es keime scharfen Grenzell aufweist. Andererseits bietet die Betrachtungsweise den Vorteil, dass man den Einzelfall aus der Interpretation des Satzes entscheiden kamn und nicht auf die vage und nicht umbedingt zuverlässige Existentialität angewiesen ist. Man braucht z.B. auch nicht näkyä (und kuulua) zu Sonderfällen zu machen $(60,345 \mathrm{f}$.), wodurch übrigens für den Lernenden die Schwierigkeiten immer noch nicht behoben sind. Wenn wir dem oben zitierten Beispielpaar das folgende gegenüberstellen: Kirkko ei näy tänne: Kirkkoa ei näy tänne, und wenn wir erfahren, dass in diesem Fall nur derjenige mit Partialsubjekt existential sei (a.0. 347), dann sehen wir, dass bei näkyä ausser der Existentialität die (durch die Situation gegebene) Partialität und die Spezies des Subjekts zu berïcksichtigen ist. 
Später (61, 290) fügt Ikola die wichtige Bemerkung hinzu, dass man bei näkyä auch dann den Nominativ verwenden kann, wenn nur ein Teil des Gegenstandes im Blickfeld ist, weil man in Gedanken schon das Ganze vor sich sieht. Wenn man auch hier an dem Gesichtspunkt der Existentialität festhalten will, muss man sagen: es wird nicht die Existenz des Gegenstandes, auch nicht die seines Abbildes in der Wirklichkeit sondern seiner Vorstellung im Sprecher ausgedrückt. Ist aber nicht jede Vorstellung im Geist des Sprechers vorhanden, die er in sprachliches Gewand kleidet?

Bevor wir den Gegenstand verlassen, muss noch einem Einwand begegnet werden. In der Hauptmasse der Existentialsätze ist das Prädikat olla. Dies Verb kann seiner Bedeutung wegen der obigen Forderung, Handlung auszudrücken, auch im nicht existentialen Satz nicht genügen. Wie soll man also hier die beiden Typen unterscheiden? Zunächst bestätigt die Tatsache, dass olla sich anders als die übrigen Existentialverba. verhält, dass man es nicht ohne weiteres mit ihnen gleichstellen darf. Es ist zuzugeben, dass die Semodynamik bei olla sehr gering ist, besonders wenn das Subjekt im Singular steht und ein nomen materiae oder collectivum ist, also etwa in dem Satz Vesi on kattilassa. Andererseits war oben ausgeführt worden, dass es auch einige Schwierigkeiten macht, die Existentialität des Satzes Kattilassa on vettä zu erweisen. Das Dilemma entsteht dadurch, dass beide Beispielsätze der Definition des Existentialsatzes genügen, da sie ja nichts anderes besagen, als dass der Subjektgegenstand an dem genannten Ort ist. Deshalb fügten Airila und Ikola die Bedingung hinzu, dass die Existenz im Existentialsatz nicht vorausgesetzt sonderm ausgesagt werde. Diese beiden Angaben schliessen sich aber nicht aus: auch im 1. obigen Satz wird das Sichbefinden des Subjekts ausgesagt. Dass die Existenz des Subjektgegenstandes a u ss e r d e m noch vorausgesetzt wird, ist nur eine sekundäre, aber keineswegs notwendige Folge der Bestimmtheit. Bestimmtheit und Existenz können im Rahmen der blossen Vorstellung bleiben. Einen Gegenstand aber, der in der Vorstellung $\mathrm{n}$ i c h t existiert, kann ich nicht sprachlich bezeichnen. Weiter ist zu bedenken, dass die Aussage über den Aufenthaltsort des 
Subjektgegenstandes und die Voraussetzung seiner Existenz an einem anderen Ort nicht gleichzeitig gültig sein kann. Sie beziehen sich auf verschiedene Zeitstufen und stellen somit eine andere Methode dar als die, welche bei der Diagnose des Existentialsatzes angewandt werden soll (61, 293 f). Wird auf beide Satztypen dieselbe Methode angewandt, dann verschwindet, soweit ich sehe, der hier diskutierte Unterschied zwischen ihnen, und wir kommen zu Penttiläs Existenzsätzen.

Auch Ikolas Bemerkung, im nicht existentialen Satz werde nur etwas ïber den Aufenthaltsort des Subjekts ausgesagt, hilft uns m.E. nicht weiter. Denn dasselbe gilt ebenso für die Existentialsätze: beide obigen Sätze sagen aus, dass Aufenthaltsort des Wassers der Kessel ist. Der Unterschied liegt aber darin, das Vesi z u g l e i c h Ausgangspunkt der Darstellung u n d der Aussage, vettä dagegen n u r der (sprachlichen) Darstellung ist. Dort ist die Subjektvorstellung so selbständig, dass es einen Sinn hat, mit Beziehung auf sie eine Ortsangabe zu machen, etwas über ihren Aufenthaltsort zu sagen, sie zu lokalisieren; hier aber bezeichnet sie nur die Materie, die den Inhalt des Kessels bildet. Hier ist das (grammatische) Subjekt Bestimmung des Adverbials, nicht umgekehrt wie im 1. Satz: "Wasser" gibt es ausser im Kessel an zahllosen Orten, aber der gemeinte Kessel wird durch den Wasserinhalt näher bestimmt, ebenso wie das bereits bestimmte Vesi durch die Ortsangabe kattilassa. Mir scheint deshalb, auch bei olla ist der hier gemeinte Unterschied noch hinreichend deutlich. Auch hier steht in der nominativischen Variante das Subjekt als selbständige "Substanz", Ausgangspunkt der sprachlichen Darstellung und der Aussage dem übrigen Satz gegenüber, der, da. das Verb statisch ist, lediglich der Bestimmung des Subjekts dient, diesem also ganz untergeordnet ist; die partitivische Variante dagegen besitzt keinen "Ausgangspunkt der Aussage», da sie keine "Substanz" im psychologischen sinne hat. Beide Vorstellungen sind nicht selbständig: die Ortsangabe nicht, weil sie ohne das zu Lokalisierende gegenstandlos ist, die Subjektvorstellung nicht, weil sie durch die Ortsangabe erst zum Gegenstand der Darstellung wird. Im Existentialsatz wird die Subjektvorstellung durch die Verbindung mit der Orts- 
angabe überhaupt erst als solche konstituiert. So kann man abschliessend vielleicht formulieren: im Existentialsatz werden Subjekt- und Ortsvorstellung $m$ it e i n a n d e r verbunden (das Prädikat reine "Kopula»), im nicht existentialen Satz wird die Subjektvorstellung mit der Ortsvorstellung verbunden, das Prädikat durch das Subjekt beschränkt, individualisiert; dadurch konkreter als das reine Formwort des Existentialsatzes.

Das Gemeinsame zwischen olla und sonst in unserem Satztyp verwendbaren Verben liegt somit nicht in erster Linie in dem Seinselement sondern darin, dass das Prädikatsverb hier den äusserst möglichen Grad an inhaltlicher und funktioneller Abstraktheit und Statik erreicht. Es baut nur die Beziehung von Subjekt und Bestimmung in die Zeitdimension ein und weist ihr damit ihren Platz in der Wirklichkeit an; es hat keinen individuellen Ausdruckswert, man kann olla ohne wesentliche Änderung des Sinnes durch näkyä, esiintyä, u.U. sogar durch juosta ua. Bewegungsverben ersetzen, weil der dynamische Gehalt des Prädikats unausgenutzt bleiben soll. Solcher Entleerung sind aber nur bestimmte Verben fähig, und hierin sehe ich den Hauptgrund für die eigentümliche Beschränkung von Partitiv und Inkongruenz auf den hier behandelten Satztyp.

Die enge Wesensverwandtschaft der "Existentialsätze» mit der Inkongruenz ist aus dem Vorstehenden deutlich geworden. Wo sie auftreten, ist das Eigenleben des Satzes herabgesetzt, weil er kein Geschehen nachbilden sondern Tatsachen oder nur eine einzige Vorstellung übermitteln soll und es eine Ablenkung des Hörers bedeuten würde, wenn man zu diesem Zweck das sprachliche Bild eines Geschehensablaufs wählte. Wenn wir deutsch sagen auf dem Tisch liegen die Handschuhe, so ist das zwar dem Sinne nach dasselbe wie pöydällä on käsineet; aber um den Satz so zu verstehen, müssen wir den störenden Plural les Verbs überhören, der uns schon auf eime Eigenschaft del subjektvorstellung hinweist, die in der Aussage gar keine Rolle spielt, bevor wir die Vorstellung selbst erfahren, und wir müssen mit Hilfe des Kontexts den ursprünglichen anschaulichen Sinn des Verbs bis zur Funktion des Formworts entleeren. Und wenn im Finnischen käsineitä entspricht, dann müssen wir diese Nuance überhaupt dem Zusammenhang überlassen. 
Die Vielfalt der finnischen Ausdrucksformen bei derartigen Sätzen ist offenbar aus der Kategorie der Quantität herausgewachsen, deren Wichtigkeit der Partitiv seine überragende Rolle im heutigen Finnischen zu verdanken hat. Daher ist im Singular die Differenzierung gering. Inkongruenz kann nur bei partitivischem Subjekt und dieses - wenn man von dem Sonderfall näkyä (und kuulua?) sowie den negierten Sätzen ${ }^{1}$ absieht - nur bei quantitativer Unbestimmtheit auftreten, die ihrerseits naturgemäss auf die seit alters bekannten Fälle (nomen materiae, collectivum, abstractum) beschränkt ist. Diese Vorstellungsgattungen bilden den Gegenpol zu den durch nomina propria bezeichneten lebenden Wesen, und die F o lg e hiervon ist Abstraktheit der Verbbedeutung, der "sein" am besten entgegenkommt (vgl. aber auch das weiter oben zitierte puuroa tuli runsaasti 11.a.). Dass aber auch hier eine Art Inkongruenz empfunden wird, scheint aus dem - freilich zur shaben»-Konstruktion gehörigen - Typ minulla on sinut hervorzugehen. Bei quantitativer Bestimmtheit wird der Unterschied zwischen "notivischer» Bestimmtheit und Unbestimmtheit gewöhnlich durch ein anderes, nicht in den gleichem Systemzusammenhang gehörendes Mittel, durch die Wortfolge, ausgedrückt. Dass die Sätze mit notivisch umbestimmtem Subjekt im System mit den partitivischen gleichwerliy sind (den Unverschied in der Form berdingt lediglich die "Teilbarkeit» der Subjektvorstellung), ergibt sich daraus, dass im Plural eben diese beiden Typen durch die Inkongruenz gegenüber demjenigen Init quantitativ bestimmtem Subjekt zusammengeschlossen werden; vgl. pöydällä on käsineitä käsineet : pöydällä ovat käsineet. Nun kann aber in dem Nitz pöydällä orat läsineet las Subjekt auch voll bestimmt sein, It.zw., wenn ich nicht irre, auch dann, wenn keins der Nomina durch die Wortfolge besonder's stark hervorgehoben werden soll. Während im Singular die Wortfolgetypen mehrdeutig sind, weil die Zweiheit der Stellungsmöglichkeit für die Vielheit der Aufgaben nicht ausreicht, zeigt die Vielheit der pluralischen Ausdrucksweisen, dass blosse Nachstellung des Subjekts noch nicht ausreicht,

1 Für definites Partialsubjekt im Existentialsatz sind m.W. bisher nur negierte Beispiele angeführt worden. 
IIm dip semodynamische Verbindung zum Verb aufzuheben. pöydällï on lautanen ist Gegenstück zu pöydällä ovat käsineet und $p$. on $k$. und kann eine (voll oder quantitativ) bestimmte Subjektvorstellung enthalten und kongruent seil. Die Wortfolge hat hier somit nur akzessorische Bedentung, sehr wahrscheinlich nach Analogie der Sätze mit partitivischem Subjekt. Der Unterschied in der notivischen Spezies ist also schwächer gekennzeichnet als der in der quantitativen.

Im Plural überschneiden sich die Funktionsbereiche: der Kasus unterscheidet quantitative Bestimmtheit und Unbestimmtheit; die Kongruenz Vollbestimmtheit von Teil- und Unbestimmtheit; die Wortfolge nur volle und notivische Unbestimmtheit ron quantitativer (?). Nachstellung eines voll bestimmten Wortes erscheint unter diesem Gesichtspunkt als Sonderfall. Die Funktion des Kasus ist dieselbe wie im Singular. Die Inkongruenz dagegen, die im Singular als blosse Begleiterscheinung der Differenzierung durch Kasus den gleichen Funktionsbereich hatte wie jene, gewinnt erheblich an Boden: sie bezeichnet die volle Unbestimmtheit unteilbarer Vorstellungen, die im Singular nicht vorkommen kann (auch im Numerus), und die nur quantitative Bestimmtheit, die, weil an den Nominativ gebunden, in Singular ebenfalls unausgedrückt bleiben muss. Das verschiedene Verhalten der Inkongruenz in den Numeri ist somit nicht Zeichen für mangelnde Symmetrie des Systems sondern durch dessen Eigenart bedingt. Die Wortfolge endlich hat sicher nachweisbar nur die Aufgabe, andere Ausdrucksformen zu unterstützen. Ob der Unterschied der Typen poikia on pihalla und pihalla on poikia durchgehend derselbe ist wie bei Tettä on kattilassa und Kattilassa on rettä, kann ich nicht beurteilen. Während also für die nur quantitative Bestimmtheit als besonderes Ausdrucksinittel die Inkongruenz zur Verfügung steht, gibt es für die unr notivische nur das Unsichere der Wortfolge. Aber an einem Punkt leistet die Wortfolge einen wichtigen Dienst. Wenn ich nicht irre, steht dem Paar Saappaat ovat sälissä: säkissä orat saappaat nur die eine Möglichkeit Säkissä on saappaat gegenüber. Daraus ersieht man, dass bei gerader Wortfolge die Verbindung von Subjekt und Verb enger als bei ungerader ist. 
Das nur schwach bestimmte Vettä on kattilassa ist deshalb offenbar nur darum möglich, weil der Partitiv an sich die Verbindung zum Verb auflebt. Andererseits scheint der Sonderfall Pöydällä ovat käsineet sozusagen eine zufällige Lösung zu sein: die inkongruente Variante war vergeben, im Singular aber bestand das Paar lautanen on pöydällä: pöydällä on lautanen als Vorbild. Partitiv wie Inkongruenz zerstören den semodynamischen Einfluss des Subjekts auf das Verb, und diesem Umstand muss sich dessen Inhalt anpassen.

Nach dem neuesten Stand der Forschung sind die Gegensätze "teilbar: unteilbar" und "quantitativ unbestimmt: quant. bestimmt) gleichwertig. Letzterer überschneidet sich also mit dem deutschen Gegensatz "unbestinumt: bestimmt»: poika on huoneessa kann im Deutschen mit bestimmtem oder unbestimmtem Artikel übersetzt werden (wenn auch der bestimmte das Üblichere ist). Daraus ist zu ersehen, dass die grössere Konkretheit und Handlungsnähe des nominativischen Satzes nicht an die Vollbestimmtheit des Subjekts gebunden ist. Entscheidend ist hier der Unterschied zwischen Individuum und Masse. Eine Zwischenstufe, die des "psychologischen Singulars", wird mit Hilfe der Inkongruenz bei Subjekten pluralischer Form geschaffen. Die Existentialsätze beruhen also auf derselben Anschauung wie die "haben"-Konstruktion und die Sätze mit, Kardinalzahlen: wo das Subjekt als Masse vorgestellt wird, fehlt die Individualisierung, und der Partitiv Sing. ist dem Part. Plural bezüglich seiner phänomenologischen Rolle gleichwertig. Für die Form des $S$ a t $z$ e s ist es gleichgültig, ob die Masse aus einer unbestimmten Anzahl von Individuen oder Partikeln eimes Stoffs u.ä. besteht. Die grosse Bedeutung der Quantität im Finnischen hat zur Folge, das bei pluralischem Subjekt das Verhältnis zum Deutschen anders ist als bei singularischem: »ein Blatt» entspricht im Plural »Blätter»; fi. nicht voll bestimmtem lehti entspricht aber sowohl lehtiä als lehdet mit singularischem Verb.

Wenn es hiernach auch so aussehen könnte, dass die Kategorie der quantitativen Bestimmtheit zum morphologischen System des Finnischen gehöre, so scheinen mir doch solche wenngleich seltenenen Fälle wie pojalta kuoli vanhemmat. 
Mieheltö palelui (paleltuivat) korvat. Akkunaruudun takaa näkyi (näkyivät) tyttölapsen vaaleat kiharat dagegen zu sprechen. Es ist zwar deutlich, dass in Fällen wie Koulussa on huonot opetusvälineet die durch Subjekt und Adverbial ausgedrückten Vorstellungen enger zusammengehören als in der entsprechenden partitivischen Variante. Die Nennfunktion ist immer noch Hauptaufgabe des Subjekts; aber die Vorstellungen stehen nicht mehr so beziehungslos nebeneinander, wie es oben als für die partitivische Variante bezeichnend ermittelt worden ist. Der Subjektgegenstand erscheint hier vom Standpunkt der Aussageform nicht als blosse Bestimmung des Adverbials sondern als dessen Bestandteil und kann daher nicht als Masse behandelt werden. Daher sind Sätze wie ${ }^{*}$ Koivussa on pienet linnut falsch. Andererseits zeigen obige Gegenbeispiele, dass dieses inhaltliche Verhältnis zwischen Subjekt und Adverbial nicht die ausschliessliche Bedingung der Inkongruenz ist. In einem Satz wie Akkunaan ilmestyi pienet kädet ist das Verhältnis der beiden Satzteile dasselbe wie in dem eben abgelehnten Beispiel; hier entsteht die für die Inkongruenz entscheidende Gruppenbildung aus dem Subjektgegenstand selbst. Der Unterschied zwischen den beiden Sätzen ist mithin lexikalisch bedingt. Der (anscheinend allein mögliche) Singular bei vanhemmat wiederum zeigt, dass selbst Vollbestimmtheit nicht unbedingt Kongruenz verlangt. Hier erzwingt die (lexikalisch bedingte) Quantität die Form des nur quantitativ bestimmten Subjeks, offenbar weil der Plural des Verbs die Subjektgegenstände zı stark individualisiert hätte. In dem Beispiel mit korrat ist diese Gefahr nicht so gross, weil es sich hier nicht um lebende Wesen handelt und die Gruppenbildung weniger stark hervortritt. Dasselbe gilt in verstärktem Masse bei kiharat, obwohl hier eindeutig Vollbestimmtheit vorliegt. Demnach verlangt bei pluralischem Subjekt weder die Vollbestimmtheit ausnahmslos Kongruenz noch die nur quantitative Bestimmtheit ausnahmslos Inkongruenz; auch hier entscheidet letzten Endes wie bei der Partialität die Subjektvorstellung und der Kontext. Eine fest zu einem Individuum gehörige Mehrheit erhält offenbar deshalb die Form der nur quantitativ bestimmten Ausdrücke, weil die beiden anderen 
Lösungen, die Form der Voll- und Unbestimmtheit, als noch weniger geeignet empfunden werden. Das ist somit der bekannte Fall, dass eine morphologische Grösse dadurch eine neue Funktion erhält, dass sie mangels eines besonderen Ausdrucks etwas unter Vernachlässigung seiner spezifischen Kennzeichen annäherungsweise wiedergibt. Ins morphologische System des Finnischen gehört deshalb die fragliche Kategorie nicht, wohl aber in die tresamtheit der durch die finnische Sprache erfassten g e istigu e n Beziehungen. Dann aber muss, da die Sprache selbst die fraglichen Sonderfälle nicht scharf als solche charakterisiert (mehrere Individuen können als Einheit, ein Kollektiv dagegen als Mehrheit bezeichnet werden), ein gemeinsames psychologisches Kennzeichen vorhanden sein, an dem man sie erkennen kann. Dies ist, wie mir scheint, in dem singularischen Verb gegeben. Psychologisch ausschlaggebend ist weder die nur quantitative Bestimmtheit noch der Zusammengehörigkeitsgrad von Subjekt- und Adverbialvorstellung sondern das Bestreben, die Subjektgegenstände nicht als selbständige einzelne Grössen hervortreten zu lassen. So kann dasselbe Mittel zum gleichen Zweck die Individualität der Subjektvorstellung sowohl schwächen als verstärken. Individualität und Kollektivität sind in der Inkongruenz kombiniert.

Vielleicht kann die hier befolgte Subjektbetrachtung auch bei der Frage nach der semologischen Abgrenzung der Existentialverba einige Dienste leisten. Ikola wendet $60,340 \mathrm{f}$. gegen Penttiläs Existenzsätze ein, dass sie sich nicht als Kriterium für partitivisches Subjekt eigneten, da in ihnen auch nominativisches Subjekt möglich sei. In ihnen könnten nach Penttiläs Definition Prädikate wie vanheta, valjeta, tulla märäksi, kumartua, hypätä, pyöriä vorkommen. Ikola will der Schwierigkeit in der oben referierten Art begegnen. Penttilä gibt, wie erwähnt, 60, 360 die Berechtigung des Einwandes zu, glaubt jedoch, dass er sich auch gegen Ikolas Methode kehren lasse. Dass auch hier keine scharfe Grenze besteht, ist von vornherein klar. Es fragt sich aber, ob es nicht möglich ist, die Eignung einer Verbbedeutung für partitivisches Subjekt annähernd aus dessen semodynamischem Gehalt zu bestimmen. Penttilä ver- 
gleicht a.O. die Sätze Lapsia sairastui. Miehiä haavoittui. Veneitä kaatui. Ihmisiä kuoli. mit: *Ihmisiä vanheni. *Vaatteita tuli märäksi. *Poikia hyppäsi ilmaan riemusta. An den nicht existentialen Sätzen fallen zwei Kennzeichen auf: ihr Prädikatsverb ist entweder rein translativ oder ausgeprägt aktivisch. Dass sich die letzgenannte Nuance mit dem Existentialsatz nicht verträgt, ist oben ausführlich auseinandergesetzt worden. hypätä ist ein so unverkennbarer Handlungsausdruck, dass die sprachliche Bezeichnung für den Träger dieser Handlung eben keine Masse wiedergeben darf. Von etwas anderer Art sind die translativischen Fälle. Hier kann natürlich von Handlung nicht die Rede sein; es handelt sich ja nur um das Übergehen in einen anderen Zustand. Die Ähnlichkeit mit den Existentialverba ist hier viel grösser. Die Translativität scheint hier jedoch reiner hervorzutreten als dort: der alternde Mensch bleibt im Grunde, was er ist, nur einige äussere Kennzeichen an ihm ändern sich. Ebenso verändern nass gewordene Kleider grundsätzlich weder ihre Qualität noch ihre Form; die Veränderungen sind äusserlich und vorübergehend. Dagegen darf man, wenn ich nicht irre, wohl sagen Vaatteita tuhoutui. Hier kommt es also anscheinend auf die Erhaltung, nicht auf die B e tät ig u n g der Individualität an, an sich zwei völlig verschiedene Prinzipien, aber wohl vereinbar unter dem Gesichtspunkt des Gegensatzes zur Massenbezeichnung. Sobald ein Gegenstand seine individuelle Erscheinungsform verliert oder für seinen Gebrauchszweck untauglich wird, ist er kein Gegenstand im engeren Sinne mehr sondern nur noch Material oder »Gerümpel». Dass das Sterben kein Handeln ist, bedarf keines Beweises (vgl. auch oben zu pojalta kuoli vanhemmat.). Dasselbe gilt von kaatua; sairastua und haavoittua dagegen kann man zwar als translativisch auffassen; aber die Veränderungen, von denen hier die Rede ist, werden von aussen an das Subjekt herangetragen, sozusagen von ausserhalb des Subjekts wirkenden selbständigen Kräften mit eigenen Handlungsgesetzen. Das Subjekt gerät in den Wirkungsbereich dieser Kräfte hinein ${ }^{1}$, nicht nur

1 Vgl. die ganz ähnliche Konzeption des lappischen $j$-Passivs UAJb. $1953,187$. 
eine äussere Eigenschaft an ihm ändert sich. Zwar kann auch Krankheit und Verwundung eine nur äusserliche, vorübergehende Veränderung bewirken; aber das Alt- und Nasswerden u.ä. lässt sich nicht als selbständiger Wirklichkeitsbereich darstellen, wie es bei partitivischem Subjekt der Fall sein müsste. Nur wenn sich die Ursache der Veränderung so weit vom veränderten Gegenstand ablösen lässt, dass das Charakteristische ihres Einflusses gerade in der Verdinglichung, Verstofflichung des Individuellen liegt, sind die Voraussetzungen für partitivisches Subjekt gegeben. Bei blossen Veränderungen a m Subjekt dagegen bleibt die Vorstellung vom Gegenstand als Einzelgrösse ebenso erhalten wie bei Handlungsdarstellung.

Wir wollen versuchen, diese Hypothese am Beispielmaterial zul prüfen. Von den oben genannten Verba verhält sich valjeta wie vanheta, kumartua und pyöriä wie hypätä. Setäläs Beispiel (bei Penttilä a.O.) poikia juoksee pihalla enthält denselben abstrakten Sinn des Verbs wie Penttiläs 0 . S. 22 zitierter Satz; juosta gibt hier nicht Handlung wieder. Penttilï bildet a.O. noch 3 unzulässige Sätze: Yskäisiä rykii luokassa (hier müsste Vorgang, nicht Handlung Einzelner gemeint sein, die dadurch ins Blickfeld rücken). Ihmisiä tyytyy kohtaloonsa (solche moralische Leistung kann nur die Persönlichkeit vollbringen). Miehiä vithastelee työssään (auch diese Tätigkeit setzt absichtsvolles menschliches Handeln voraus). - Die Hauptmasse der Beispiele enthält das Verb olla, was die Überbewertung der Existenz und die Gefahr zur Folge hat, dass die ermittelten Kennzeichen der Sätze der »haben»-Konstruktion zugehören könnelı. Ikola nennt 58, 225 den Satz pöydällä on ruokaa. Oben ist dargelegt worden, dass das Subjekt hier fast wie ein Attribut wirkt. Nun können wir hinzufügen, dass das Sein weder ein Handelı noch eine dem Subjekt von einem selbständigen Bereich her aufgeprägte oder eine am Subjekt geschehende, dessen Identität voraussetzende Veränderung sondern ein lokalisierter Zustand ist, der auf den Subjektgegenstand bezogen wird, also keinerlei "individuelle Fähigkeiten» von ihm verlangt: das da-Sein äussert sich bei Stoff und Individuum in gleicher Weise. Entsprechend sagt näkyä die Eigenschaft der Sichtbarkeit aus: dienen da-Sein und sichtbar-Sein 
zur Individualisierung von Gegenständen oder (bei lebenden Wesen) zur Darstellung ihrer Lebensumstände von ihrem eigenen Standpunkt aus (z.B. pojat ovat - juoksevat - pihalla), steht nominativisches Subjekt; erscheint aber der Subjektgegenstanci nur als Masse, die lokalisiert oder als im Blickfeld befindlich bezeichnet wird, dann steht partitivisches Subjekt. I'enettä näkyy jo lässt sich auf deutsch passend mit mein Stück Boot ist schon zu sehen» übersetzen, während bei T'ene näkyy jo die Eigenschaft des Sichtbarseins wie das Altwerden als am Individuum haftende Eigentümlichkeit aufgefasst ist, so dass - rom Standpunkt der Logik aus - die Existenz des Gegenstandes wirklich vorausgesetzt wird. Sind olla und näkyä verneint, damn enthalten ihre Sätze, wie die Forschungen ergeben haben, bei nominativischem subjekt implicite eine positive Behauptung und sind dann mit den nicht verneinten Sätzen gleicher Bauart grundsätzlich gleichwertig; bei partitivischem Subjekt werden die durch die Verba ausgedrückten Kennzeichen am Subjektgegenstand als nicht vorhanden bezeichnet, und dadurch bleibt unentschieden, ob sie es als Individuum oder als Stoff charakterisiert hätten. Kirkkoa ei näy tänne: weder ein Stück Kirche sieht man, noch weiss man, ob überhaupt eine Kirche da ist. Talossa ei ole isäntää: der Hof ist herrenlos, und man weiss nicht, ob er überhaupt einen Herrn hat.

Weitere Beispiele: Kirjeitä oli tullut: der Subjektgegenstand trotz der Anfangsstellung nicht individualisiert, das Verb gibt keine Handlung; oli tullut = oli saapunut. Interessant das von Ikola 58, 226 erwähnte Paar *Ihmisiä kävelee: Ihmisiä kävelee kadulla. Im 1. Fall wird die reine Tätigkeit ausgedrückt, daher der Nominativ notwendig; der 2. spricht vom Leben auf der Strasse, dessen Träger bleiben im Hintergrund, daher der Partitiv angemessen. Ihmisiä syntyy ja kuolee $=$ "Leben und Tod regieren die Welt». Ruusuun ei ole vielä tullut nuppua: man weiss noch nichts von der Substanz, an der sich die Veränderung vollzieht. Täällä ei kasva ruohon korttakaan: die gleiche Situation, jedoch mit der für negierte Sätze so wichtigen Nuance des verstärkten Ausdrucks: aus dem Kontext oder anderen Voraussetzungen ist dem Hörer der Subjektgegenstand oft 
recht wohl bekannt; der Partitiv enthält also eine emotionelle İbertreibung. Ei kuole rikasta noitaa eikä viisasta vanhaapiikaa: die durch die Adjektiva individualisierten Subjektgegenstände existieren gar nicht; deshalb kann das Nichtsterben nicht von ihmen wie von lebenden Wesen ausgesagt werden. Sinun ääntäsi ei ole moneen aikaan kuulunut: in Hörweite geraten kann auch Materie; "zu verstehen sein» aber setzt den Akt der Verständigung und damit Individuen voraus. Häntä on täällä harvoin näkynyt (aber nicht: ollut: Ikola, 59, 325): das hier-Sein lässt sich nicht von einem lebenden Wesen in seiner Eigenschaft als Stoff aussagen; es gibt sprachliche Situationen, wo die Belebtheit selbstverständlich den Vorrang hat. Das "Zusehensein" jedoch kann man mit der eben erwähnten Übertreibung auch ron Personen gebrauchen. Vgl. den von Ikola als dialektisch bezeichneten Satz Eikö sitä Tiinaa tullu' sinne Heikkalaan päin? Deutsch kann man umgangssprachlich sagen "Hast du was von Paul gesehen?" Paul wird hier unbestimmter vorgestellt als in der Variante "hast du Paul gesehen?" Man sagt aber nicht "Ist was von Paul hier gewesen?" - offensichtlich aus demselben Grunde wie im Finnischen.

(Sadeniemi S. 10 ff.): Ruotsalaisväestöä asuu Ahvenanmaalla sekä Pohjanlahden ja Suomenlahden ramikolla: die Verbindungslosigkeit zwischen Subjekt und Verb kommt bei Kollektiva und Stoffbezeichnungen in dem verschiedenen Geltungsbereich der beiden Vorstellungen zum Ausdruck. Bei nominativischem Subjekt gilt die Prädikatsaussage so weit wie die Subjektvorstellung reicht, bei partitivischem nur für einen Teil des Gebietes. Hier kann man sich nicht mehr vorstellen, dass jeder einzelne Finnlandschwede durch die Angabe seinen Wohnplatz erhält; nicht das Wohnen jedes Einzelnen wird ins Auge gefasst sonılern eine generelle Feststellung getroffen. Ähnlich bei dem Paar Vieraat eivät tule: vieraita ei tule: der 1. Satz gibt einen Vorgang wieder, der von verschiedenen Subjekten gleichzeitig ausgelöst wird (d.h. in diesem Falle: nicht ansgelöst wird); im 2. Satz wird die Möglichkeit des Handelns einzelner Subjekte gar nicht in Betracht gezogen sondern nur das negative Resultat festgestellt. In solchen Beispielen tritt natürlich infolge der Verbbedeutung das Handlungsmoment als

6-Finnisch-ugrische Forschungen 
Kriterium weniger hervor; es ergibt sich aus der Konkretheit der Subjektvorstellung: je deutlicher diese als Ausgangspunkt des Vorgangs und damit als dessen Träger erscheint, desto mehr wird der einzelne Gegenstand individualisiert, umso deutlicher wirkt das durch das Verb ausgedrückte Geschehen als Summe einzelner, willensbestimmter Handlungen, jede einzelne Komponente des Verbvorgangs ist auf ihren Urheber bezogen. Der Unterschied zu den nicht existentialen Verben bleibt jedoch bestehen: Verba wie asua, tulla lrücken nicht schon selbst Handlungen aus sondern nur deren lesultat.

(Penttilä 60, 32): Oppilaamme erehtyivät tässä tehtärässä: Oppilaamme erehtyivät opettajainhuoneeseen: Oppilaitamme erehtyi o.: in der übertragenen Verbbedeutung des 1. Satzes ist die translativische Färbung der Grundbedeutung (zu erä, vgl. Etym. Sanak.) erloschen: die Schüler taten etwas Falsches. Im 2. und 3. Satz dagegen weist die mit tulla analoge Konstruktion geradezu darauf hin. Andererseits felılt hier sowohl die sselbständige Sphäre" von haavoittua u.ä. als das Kennzeichen des Typs vanheta, die sich am Subjekt herausbildende Eigenschaft. erehtyä scheint der Gruppe haavoittua näher zu stehen, so dass auch von hier aus die Berechtigung der beiden letzten Beispiele nicht ausser Zweifel steht. Untereinandel' zeigen sie den gleichen Unterschied wie die vorherigen Beispiele: der 2. Satz sagt etwas über die schüler und ihr Tun aus, der 3. über ein Ereignis, das sich im Lehrerzimmer abspielte und mit Schülern zu tun hatte. Penttiläs Feststellung a.O., dass myöntyä und suostua kein Partitivsubjekt zu sich nehmen können, stimmt zu unserer Betrachtungsweise: sie passen zu erehtyä im 1. Satz, bezeichnen geistige Tätigkeiten, die das Individuum voraussetzen. Autoja vilahteli olitsemme. Tyttöjä lymyilee viidakossa: Lintuja laulaa puiden oksilla. Koiria haukkuu pihalla. Siusia ulvoo järcen jäallä: Airila lehnt die 4 letzten Sätze ab, Penttilä nur die mit laulaa und haukkua unter der Begründung, diese könnten auch transitiv gobraucht werden. Er fügt noch als möglich hinzu Leipiä paistuu uunissa. Oraviı on kesyyntynyt kaupunkimme puistoissa. Die nur von Penttilä gebilligten Sätze scheinen uns den Charakter von Grenzfällen zu haben, über dic das Sprachgefühl des Einzelnen zu entschei- 
den hat. Nur das 1. Beispiel eignet sich fraglos zur Situationsschilderung, wo die Einzelgegenstände ohne Interesse bleiben. Die an sich ähnlichen Beispiele mit Tieren als Subjekt sind insofern von anderer Art, als die Verba hier so deutlich auf das Subjekt berechnete Tätigkeiten ausdrücken, dass man sich unwillkürlich die einzelnen Träger vorstellt. Aber es ist zuzugeben, dass man den Satzinhalt auch anders fassen kann: "Es erklang Vogelgesang in den Bäumen, es erscholl Wolfsgeheul auf dem Eise" usw., besonders wenn das Subjektwort ans Satzende tritt. Der Rest wirkt auf den Ausländer fremdartig. Das Sichverbergen ist zweifellos eine Handlung; kesyyntyä bezieht das Mit- oder Gegenspiel des Tieres ein; leipiä betont, da daneben auch der Singular möglich wäre, die Mehrheit so stark, dass man die einzelnen Brote vor sich sieht und das Backen sozusagen als ihr Schicksal, ihren »Lebensweg», nicht aber das Ganze als Situationsschilderung auffassen möchte. paisua und kesyyntyä gehören zudem zu der obigen Grupp: haavoittua. Klare Situationsschilderung enthalten dagegen wieder Omenapuita kasvaa puutarhassa. Sorsia ui selällä. Vedessä kelluu tukkeja. Ob das Schwimmen oder das Heulen ein Tier mehr indiridualisiert, ist wohl Sache des Betrachters. Vielleicht ist aber nicht bedeutungslos, dass die Unterschiede im Schwimmen nicht so auffallen wie die im Heulen. Dass ein hinzutretendes Adverb den Verbinhalt konkretisiert und zur Handlung macht, so dass *Koiria juoksee nopeasti pihalla zu verwerfen ist, leuchtet ein.

Ikola ist zweifellos im Recht, wenn er 60, 341 Matti on nyt opettajainhuoneessa und tulin juuri opettajainhuoneeseen für Existenzsätze in Penttiläs Sinne hält. Dass jedoch deshalb nicht die ganze Kategorie wertlos für die Bestimmung des Subjektkasus wird, ohne dass man sich ganz auf Ikolas Standpunkt stellen muss, lässt sich auch mit der hier durchgeführten Betrachtungsweise veranschaulichen. Für Ikolas Existentialsätze ist es charakteristisch, dass ein inhaltschwaches Verb zwei vom Standpunkt der Mitteilıng aus wichtige (d.h. im Kontext unerwartete) Gegenstandsvorstellungen verbindet. In den nicht existentialen Sätzen dagegen dürfte überwiegend die Subjektvorstellung im Kontext nicht fremd, d.h. für die Mitteilung 
nicht wichtig sein, wohl aber die nominalen Ergänzungen, u.zw. in den Sätzen mit "Existentialverba» nur diese: die Aussage konzentriert sich nicht auf den Inhalt der Lokalität sondern deren Einführung in den Kontext, so wie im Existentialsatz die Subjektvorstellung eingeführt oder doch zum Mittelpunkt der Aufmerksamkeit gemacht wird. Als solcher kann der Subjektgegenstand nicht gleichzeitig zum Träger einer Handlung gemacht werden; daher der Feststellungscharakter der Existentialsätze. Da es nun in der Natur des subjektiv-aktivisch konzipierten Satzes liegt, dass lebende Wesen, besonders Menschen, wenn sie Subjekt sind, nicht zur blossen Substanz einer Feststellung gemacht werden, so wird selbst eine so statische Aussage wie die des 1. obigen Beispiels, obwohl das Verb nicht Handlung ausdrïckt und die Bestimmung das Subjekt lokalisiert, so aufgebaut, als ob das Subjekt dabei etwas täte. Dadurch dass diese Sprachauffassung sich auf alle "unteilbaren" oder "quantitativ bestimmten» Subjektvorstellungen ausdehnt, kann das Kriterium der "Handlungsfähigkeit" allein bei der Bestimmung des Subjektkasus nicht ausreichen; hinzukommen muss die Art der Verbindung von Subjekt- und Prädikatvorstellung. Daraus ergibt sich auch bei einem Satz wie Vesi on lattilassa mit seinem einzigen Aussageschwerpunkt trotz seines farblosen Verbs der Nominativ als Subjektkasus mit Sicherheit.

Finden diese Ausführungen Zustimmung, dann wäre der von der Forschung bisher abgesteckte Kreis der „Existentialverba" in der Weise einzuschränken, dass diese nicht reine Translativa (Bezeichmungen für Veränderung von Eigenschaften am Subjekt) und nicht Bezeichnungen für Handlungen (auch wenn diese Bewegungen sind) sein dürfen.

Am Phänomen der Inkongruenz liess sich der für unseren Zusammenhang zentrale Begriff der Verbindungslosigkeit ron Subjekt und Verb besser klarlegen als am Partitiv, obwohl er m.E. auch hier entscheidende Bedentung hat. Denn im Grunde sind die Konstruktionen mit Partitiv die gleichen wie die inkongruenten. Ein wesentlicher Unterschied besteht freilich darin, dass die Partialität der Subjektvorstellung, die Voraussetzung für den Partitiv, überwiegend von der Art der Vorstellung, also von stofflich-inhaltlichen Faktoren bedingt ist, die Inkongruenz aber mit wenigen Ausnahmen zu den syntak- 
tischen Formungselementen gehört. Partialität und Existentialität sind aussersyntaktische Voraussetzungen ihres Satzes und müssen deshalb vor dessen sprachlicher Formulierung geklärt werden. Die İbersetzung in die sprachliche Sphäre geschieht wesentlich durch Semologie (ein formaler Faktor ist z.B. die Spezies, ein stofflicher der Zusammengehörigkeitsgrad von Subjekt- und Adverbialvorstellung) und Semodynamik (Art der Verbindung zwischen Subjekt- und Verbvorstellung). Es sind also nicht Existentialität und Teilbarkeit, die ihren Sätzen ihre charakteristische Form verleihen, sondern die Tatsache, dass ein schwach (Inkongruenz) oder gar nicht (Partitiv) individualisiertes und daher semodynamisch mehr oder minder isoliertes Subjekt neben einem Verb mit fast formaler Funktion Kernvorstellung eines konstatierenden oder mitteilenden Satzes ist. Die Verbindungslosigkeit zwischen Subjekt und Verb wird noch durch die häufige Nachstellung des Subjekts unterstrichen, die die gleiche Folge hat wie in dem 0 . S. 54 zitierten deutschen Satz mit Scheinsubjekt. Ein Vorgreifen der Subjektpluralität auf das Verb würde die Aufmerksamkeit des Hörers rom Schwerpunkt der Mitteilung auf einen sachlich nicht vorhandenen Kontakt zwischen Subjekt und Verb ablenken.

Bekanntlich kann neben partitivischem Subjekt unabhängig ron dessen Numerus nur singularisches Prädikat vorkommen. Hier tritt, könnte man sagen, zur Inkongruenz des Numerus noch eine solche der Pers o ll. Latent findet sie sich allerdings auch bei der Inkongruenz im engeren Simne; lort ist sie nur schwerer zu erweisen. Die wichtige Rolle des Partitivs im Finnischen beruht, wie bereits erwähnt, auf der Bedeutung des Fegensatzes quantitativer Bestimmtheit und Unbestimmtheit. Dass es bei dieser Spezies nicht, wie etwa in den germanischen Sprachen, in erster Linie auf verschiedene Grade der Identifizierbarkeit ankommt sondern auf die Quantität, zeigt der Umstand, dass sie bei unteilbaren singularischen Vorstellungen keinen formalen Ausdruck findet. Die Beschränkung des finnischen Subjektpartitivs auf sog. "teilbare» Vorstellungen zeigt klar, dass es sich hier um den Gegensatz von Einzelexemplar und Gruppe, von Individuum und Masse handelt. Nur so ist auch die Einbeziehung der Inkongruenz in diesen Komplex zu 
hegreifen. Erst durch die Verquickung der logisch verschiedenwertigen Begriffe der Identifikation und Quantität konnte der konträre Gegensatz "bestimmt: unbestimmt" nochmals in "quantitative" und mnotivischem Spezies unterteilt werden. I)ass auch bei dieser Regelung dem Partitiv die Wiedergabe be id e r Formen quantitativer Unbestimmtheit zufällt, ergibt sich aus seiner Stellumg im Kasussystem. Sobald eine Vorstellung ihrer Natur nach der Umwandlung in eine solche der Masse widerstrebt, kann sie nicht durch den Subjektpartitiv ausgedrückt werden. ${ }^{1}$ Hieraus erklärt sich ungesucht der unveränderliche Singular des Verbs beim Subjektpartitiv: dieser bezeichnet immer ein (quantitativ) unbestimmtes Subjekt, und es fehlt ihm infolge der mit ihm gegebenen Umwandlung der Vorstellung ins anonym-Stoffliche die Fähigkeit, das Subjekt eines nach den Grundsätzen der Subjektirität und Aktivität infgebauten Satzes auszudrücken. Wenn neben ihm das Prädikatsverb in der 3. Person steht, so ist das, streng genommen, ebenso sinnlos, wie wenn man bei pluralischem Partialsubjekt das Verb in den Plural setzen wollte. Das ist der sprachliche Aspekt der Verbindungslosigkeit von subjekt und Verb. Das Prädikat ist hier sozusagen nicht der "verlängerte Arm des Subjekts", von ihm geprägt nach Form und Funktion, sondern cin isolierter, rein sachlicher, (munpersönlicher") Ausdruck, ein $\mathrm{N}$ a m e für einen Vorgang. ${ }^{2}$

1 Ein interessantes Licht auf das Verhältnis von Quantität und Bestimmtheit wirft die Behandlung des prädikativen Adjektivs. Dr. Sadeniemi teilte mir auf meine Fragen u.a. folgendes mit. Wörter wie vesi, 'oi, jauhot haben das präd. Adj. immer im Partitiv, auch in Sätzen wie 'esi on sinistä (obwohl mblau" gar keine Eigenschaft des Wassers ist; dagegen meri on sininen); tämä vesi on kylmä̈a (obwohl es sich um eine vollbestimmte Wassermenge handelt): huoneisto on kylmä (nicht Part., obwohl das Subjekt ein Kollektiv bezeichnet; dagegen huoneet ovat kylmiä oder kylmät); jauhot ovat hyviä (auch wenn jauhot $=$ ".Mehl im allgemeinen"), aber edellytykset $\sim$ hänen mahdollisuutensa ovat huonot usw. Auch Kollektiva werden - je nach der Beschaffenheit des Materials - u.U. als Ganzheiten und "bestimmte Quantitäten" als Masse aufgefasst.

2 Es wäre interessant zu untersuchen, ob in Sätzen mit partitivischem Subjekt die Aktionsarten seltener zur Geltung kommen als in Sätzen mit nominativischem Subjekt. 
Bei der Inkongruenz liegen die Verhältnisse grundsätzlich ähnlich, aber die Unterschiede sind unverkennbar: die Möglichkeit zum Gebrauch aller "Existentialverba" im inkongruenten Satz dürfte in der Umgangssprache, von s(trenzfällen" der oben behandelten Art abgesehen, viel seltener ausgenutzt werden als beim Partialsubjekt. Das Verb ist hier noch unpersönlicher, seiner Funktion nach formaler. Es unterwirft die Subjektvorstellung ebenfalls dem Quantitätsbegriff, indem es deren Pluralität entwertet (beim Partitiv bleibt die Quantität gegenïber der Anzahl ohnehin im Vordergrund). Aber andererseits ist im inkongruenten Satz die mehrheitliche Subjektvorstellung durch ihre semologische Beziehung zur Satzergänzung zur Gruppe und damit zu einer Art "Individuum" zusammengefasst, die zwar die Unpersönlichkeit des Verbs nicht aufhebt aber doch Subjekt und Prädikat auf gleiche Ebene stellt und die Anwendung der "3. Person» als Verbindung einer Gegenstandsund einer Vorgangsvorstellung als sinnvoll erscheinen lässt.

Auch beim Partitiv macht sich die Semodynamik natürlich nicht am Inhalt der Vorstellung geltend. Lebende Wesen werden, wenn ihre Vorstellung durch den Partitiv ausgedrückt wird, genau so behandelt wie Gegenstände, und andererseits kann auch eine Gegenstandsvorstellung, wenn ihr ein Nominativ entspricht, Träger einer »Handlung» sein (vgl. Der Sand verschütete die Mauer). Wie bei Inkongruenz und Existentialität entscheidet auch hier die phänomenologische Interpretation der Wirklichkeit. In dem Satz poikia juoksee pihalla handelt es sich zwar un mehrere menschliche Individuen; aber die sprachliche Formulierung sieht von ihrer Erscheinungsform als Individuen ab, weil es ihr nur auf den Stoff ankommt, an dem sich das Laufgeschehen auf dem Hof realisiert. Daraus wird gleichzeitig klar, dass in derartigen Sätzen nur Verben mit so allgemeiner Bedeutung vorkommen können, dass kein individualisierter Urheber des Vorgangs vorausgesetzt werden muss. Insbesondere Bewegungen, die ja in der Natur häufig so zur Anschauung kommen, als ob das Bewegte ihr Objekt, das Bewegende aber ein ungreifbares Es wäre, sind hier geeignet: die Bewegung ist die allgemeinste Form des Geschehens. Ist aber einmal die Subjektvorstellung so ausschliesslich als 
Quantum angesehen und verstofflicht, dann liegt sie ausserhalb der Zählbarkeit, und ein pluralisches Verb wäre neben ihr ganz unmotiviert. Folglich verliert auch der Singular seinen üblichen Sinn. Er ist, wie die 3. Pers. des Verbs solcher Sätze, durch die Form bedingte Leerlauffunktion der Einzahl, in Wirklichkeit Kollektiv, für das das Finnische keinen morphologischen Ausdruck besitzt. Die weitgehende Ähnlichkeit zwischen den Sätzen mit partitivischem und inkongruentem Subjekt im engeren Sinne berechtigt m.E. zu dem Schluss, dass auch in einem Fall wie Säkissä on saappaat "Inkongruenz der Person", also eine Art Unipersonalität vorliegt. ${ }^{1}$ Der Partitiv sowohl als die Inkongruenz in Sätzen dieser Art sind Widerstandsversuche einer Sprache, die sich gegen allzu schematische Uniformierung ihrer Darstellungsmittel durch die zweipolige, subjektiv-aktivische Satzstruktur zur Wehr setzt.

Partitiv und Inkongruenz verändern somit die Subjektfunktion in derselben Richtung, und auch die Ursache ist dieselbe, nämlich Schwächung des individualisierenden Elements in der Subjektvorstellung im Interesse abstrakterer Verbfunktion in Sätzen statischen Charakters. Das Finnische hat jedoch diese Regelung nicht mechanisch durchgeführt. Sobald sich eine Vorstellung der soeben geschilderten Verstofflichung entzieht, wird die Opposition von Nominativ und Partitiv als Subjektkasus je nach der Art der Vorstellung entweder ganz zugunsten des Nominativs aufgehoben oder durch die von Nominativ mit Inkongruenz und Partitiv ersetzt. Auch diese Doppelheit des 2. Oppositionsgliedes beruht offenbar auf der beherrschenden Stellung der Quantitätskategorie. Gerade weil das Sprachgefühl in dieser Beziehung so empfindlich war, musste sich innerhalb der quantitativ bestimmten, pluralisch ausgedrückten

1 Ich würde aber nicht so weit gehen wie Denison, der a.O. \$. $113 \mathrm{f}$. das partitivische Subjekt im Anschluss an Jespersen als "prädikativ" bezeichnet und doch das Verb dann als sunpersönlich" ansehen will. Das finnische Phänomen tritt m.E. umso klarer hervor, wenn man bei den herkömmlichen Termini bleibt. Partitiv und Inkongruenz sind Kennzeichen einer speziell finnischen Möglichkeit, die Verbindung von Subjekt und Prädikat zu unterbrechen. Die "Unpersönlichkeit» bezieht sich nur auf den Numerus. 
Vorstellungen ein Unterschied herausbilden zwischen denen, die eine echte Mehrheit bezeichneten, und denen, in welchen eine Mehrheit in eine Gruppe zusammengefasst und dadurch der Masse einen Schritt näher gerückt war. Wie die Beispiele auf S. 45 Fussn. 1 zeigen, ist diese Auffassung auch für die Form des Prädikativs massgebend: edellytykset ovat hyıät; jauhot orat huonoja. Doch selbst mit Hilfe des Begriffs "psychologischer Singular" entsprechen sich Partitiv und Inkongruenz im engeren Sinne im Plural noch nicht genau. Sadeniemi betrründet mir brieflich den Nominativ des Satzes edellytylset. orat hyvät damit, settä edellytykset ajatellaan yhtenäisenä kokonaisuutena - sitä ei eritellä eri edellytyksiin . ...; trotzdem aber steht das Verb im Plural. Ebenso bei jalkani ovat kipeät. Von anderer Art wieder jauhot ocat hyviä: das pluralische Verb (und der Partitiv) zeigt, dass bei Kollektiva, deren Einzelteile ohne Interesse sind, die Vorstellung nicht als Einheit gedacht wird. Wenn also kongruentem jalkani ovat kipeät inkongruentes Mieheltä paleltui korvat ${ }^{1}$ gegenübersteht; wenn der psycholngische Singular edellytykset nur bei quantitativer Bestimmtheit der Vorstellung syntaktisch wirksam wird; wenn nur unter derselben Bedingung das pluralische Kollektiv jauhot singularisch gewertet wird, so lässt dieser Unterschied in der Behandlung derselben Vorstellungen kaum einen anderen Schluss zu, als dass die Inkongruenz hier einst auch bei voll bestimmter Subjektvorstellung geherrscht hat, dass es also hiess *jauhot edellytykset on hyiät. Die I'bermacht der kongruenten Fügungen hat hier der Inkongruenz Gebiet abgewomnen. Es ist nun hesonders lehrreich für das psychologische Verständnis des Finnischen, dass die dem äusseren Ablauf nach mechanische analogische Veränderung, vom synchronischen Standpunkt aus hetrachtet, zur Verdeutlichung eben derjenigen Züge des Systems beigetragen hat, die durch sie seltener zur Wirkung kamen. Indem nämlich nun dem Gegensatz von voller und nur quantitativer Bestimmtheit derjenige von Kongruenz und Inkongruenz zur Seite trat, erhielt einesteils die Kategorie der Quan-

${ }^{1}$ Sadeniemi möchte die Variante mit pluralischem Verb nicht als gutes Finnisch anerkennen. 
tität einen neuen, nur ihr vorbehaltenen Ausdruck; andernteils wurde die Verbindungslosigkeit zwischen Subjekt- und Verbvorstellung, die sich in der Nennfuktion kundtat, auf diejenigen Fälle beschränkt, wo Pluralität des Verbs sinnstörend wirken konnte.

Eine Vorstellung, die sich unter dem Gesichtspunkt der Quantität nicht modifizieren lässt, heisst in der finnischen Forschung »unteilbar». Der Begriff der Teilbarkeit ist nun derjenige, der durch die neuen Forschungen wohl die stärkste Umgestaltung erfahren hat. Zwar ist das Prinzip der quantitativen Differenzierung eher noch mehr zur Geltung gekommen als früher; aber man hat erkannt, dass die Sprache nicht in primitiver Anschaulichkeit stecken geblieben ist sondern - vermutlich als Ergebnis geschichtlicher Entwicklung - ihr Prinzip dem subjektiven Ausdruckswillen dienstbar gemacht hat. Auch Vorstellungen von unteilbaren Einzelgegenständen wie jänis können, wie Penttilä gezeigt hat, als Quantitäten behandelt werden, und andererseits lässt die Zusammenfassung mehrerer Vorstellungen unter einem einheitlichen Gesichtspunkt die so entstehende Gruppe als unteilbar erscheinen (Sadeniemi). Es steht also im Belieben des Sprechers, durch einen geistigen Akt die Gegenstände zur blossen Materie zu machen. Da nun Teilbarkeit Voraussetzung für den Gebrauch des Partitivs als Subjektkasus ist, so enthüllt sich die Möglichkeit zur Verstofflichung der Vorstellungen als letzte Ursache all der komplizierten Regeln, um die sich die Diskussion bemüht.

Auch unter diesem Gesichtspunkt ist Sadeniemis und Ikolas Auffassung der Teilbarkeit der früheren vorzuziehen. Die pluralischen Nominativsubjekte der inkongruenten Sätze gehören nicht allein wegen ihres Nominativs zu den unteilbaren sondern auch deshalb, weil das singularische Verb, das ihnen mit den partitivischen Sätzen gemeinsam ist, nach den obigen Ausführungen eine andere Art von Inkongruenz hervorruft. Während der Verlust der Individualität dort die Vielheit zur homogenen aber gestaltlosen und deshalb auch syntaktisch nicht mehr als Mehrheit wirkenden Masse umprägt, macht er hier aus ihr eine inhomogene aber deutlich abgegrenzte Einheit, die den Singular des Verbs verlangt. Dieser ist somit dort zu- 
fällig, insofern sich die unbestimmte Menge weder durch die Einzahl noch durch die Mehrzahl charakterisieren lässt, hier aber notwendig, insofern die quantitative Bestimmtheit, die mit der begrifflichen Unbestimmtheit erkauft ist, eben in Form der Zusammenfassung, also der Einheit erfolgt, so dass nun die tatsächliche Mehrheit, die Voraussetzung der "Teilbarkeit», belanglos wird. Demnach ist die Teilbarkeit in erster Linie gar nicht ein semologisches sondern ein phänomenologisches und syntaktisches Problem.

Damit ist eigentlich der Bezeichnung "Teilbarkeit" der Boden entzogen. Denn einerseits ist z.B. in Verbindung mit näkyä j e d e Vorstellung teilbar, andererseits neben Verba wie kaatua nur die pluralisch ausgedrückte Vorstellung. Pluralische Vorstellungen sind, wenn nicht quantitativ bestimmt, a $11 \mathrm{e}$ teilbar; die Teilbarkeit ist somit von der quantitativen Unbestimmtheit abhängig und nur eine Begleiterscheinung der Mehrheit, nicht aber eine Eigentümlichkeit der Vorstellungen, und sei es durch subjektive Betrachtung gewonnen. Bei pluralischen Vorstellungen gilt das früher angeführte Kennzeichen der 'Teilbarkeit nicht, dass der Teil im Wesen mit dem Ganzen identisch sein muss (dies entkräften Sadeniemi und Penttilä). Der Partitiv ist im Plural gar nicht Ausdruck eines Teilverhältnisses oder doch nur in Ansnahmefällen. Gewöhnlich fasst der Satz gar kein Ganzes ins Auge, von dem der durch den Partitiv bezeichnete Gegenstand ein 'T'eil wäre; dies Verhältnis kann man nur nachträglich hineininterpretieren, um die betr. Sätze gegen die mit "totalem» Subjekt abzugrenzen. Tatsächlich bezeichnet der pluralische Partitiv nur eine unbestimmte Quantität, ${ }^{1}$ und dasselbe gilt, wie Penttiläs Beispiel .Jänistä on vielä pöydällä jäljellä zeigt, auch im Singular: auch das Individuum wird, wenn durch den Partitiv ausgedrïckt, zur Materie. Dass die negierten Sätze mit voll bestimmtem Subjekt m.W. die einzigen, in denen der Partitiv auftreten kann - nur scheinbare Ausnahmen darstellen, ist 0. S. 38 zu zeigen ver-

1 So unterscheidet die Sätze Miehillä oli mukanaan kirveet und poikia juoksee pihalla die quantitative Unbestimmtheit; denn poikia wird durch juoksee ebenso zur Einheit zusammengefasst wie kirreet durch den Rest seines Satzes. 
sucht worden. So aufgefasst, lässt sich die Funktion des Subjektpartitivs fül beide Numeri einheitlich als Bezeichnung einer unbestimmten Quintität definieren. Damit tritt auch hier die Rolle der Quantitätskategorie klar hervor.

Auch unter dem Gesichtspunkt der Verstofflichung lassen sich Erscheinungen wie die "Teilbarkeit" aller Vorstellungen bei näkyä oder die Unvereinbarkeit von Verba wie kaatua mit dem Part. Sg. verstehen. Was "zu sehen ist", ist nur insofern Gegenstand sprachlicher Verarbeitung, als es Material für Bilder auf der Netzhaut abgibt. Ausgangspunkt des Vorganges selbst ist nicht der erscheinende (Tegenstand sondern der Sehende, das Erscheinende sein Objekt. Der Aussagewert des betr. Satzes ist der einer blossen Mitteilung des Sichtbarwerdens, nicht Handlung oder Schilderung. Andererseits ist der Vorgang des Fallens eine Bewegung und sollte also Partitivsubjekt zulassen. kaatua gehört indessen zum Typus des oben behandelten haavoittua. Es gehört unverkennbar zum Erlebnis des Fallens, dass man wins Fallen gerät», davon überrascht wird wie von einem tückischen (Yegner. kaatua repräsentiert eine selbständige Geschehenssphäre, in die der Fallende hineinkommt, ebenfalls selbständig, entweder als Erlebender oder - im Falle eines Gegenstandes - als etwas aus seiner gehörigen Lage Gebrachtes, seinem Zweck Entfremdetes. Wo diese Interpretation nicht anwendbar ist, dürfte allch bei Verben des Fallens der Partitiv möglich sein: man könnte doch, denke ich, sagen jänistä putosi pöydältä. Wenı andererseits pluralische Vorstellungen neben kaatua unbeschränkt möglich sind, so bestätigt das, wie verschieden die Numeri interpretiert werden müssen, wenn man von der Partialität ausgeht.

Neben dem Unterschied ron Individuum und Masse ist immer der Umstand im Auge zu behalten, dass partitivischem und inkongruentem Subjekt das singularische Verb gemeinsam ist. Daraus erhellt eine weitere wichtige Anschauung, die in der finnischen Sprache zum Ausdruck kommt: dass die Pluralformen des Verbums eine individualisierte Mehrheit von Subjekten voraussetzen, dass also die Kongruenz in diesem Fall klarer Ausdruck einer inneren Beziehung von Subjektund Verbvorstellung ist, d.h. die Übersetzung der Subjekt- 
mehrheit und ihres Handlungswillens in die Zeitdimension. Das singularische Verb dagegen lässt es unentschieden, ob es sich um eine Vorstellung handelt, die ein Individuum oder ein Kollektiv bezeichnet. Da das Finnische von den beiden Numeri den Singular zur Bezeichnung des Prädikats bei einer Vorstellung der Masse als Subjekt gewählt hat, ist dieser Numerus \%weideutig. Die volle Bestimmtheit bezieht die Mehrheit der Subjektvorstellung als so wesentlichen Faktor ein, dass auch das vom Subjekt Ausgesagte, insbesondere sein Handeln, unter diesem Gesichtspunkt formuliert werden muss. Die nur quantitativ bestimmte Vorstellung wiederum erscheint, wie ausgeführt, als Einheit und verlangt deshalb den Singular. Die quantitative Unbestimmtheit endlich kommt im Numerus des Subjekts genügend zum Ausdruck: rettä und poikia sind rom Standpunkt des in Verbindung mit ihnen ausgesagten Vorgangs gleichwertig, zumal ein poikaa, das vom Nominativ Sing. zu differenzieren wäre wie poikia von pojat, ja nicht vorkommt. Diese Funktion der pluralischen Verbformen kennzeichnet den Zug zur Individualisierung im Finnischen noch erheblich stärker als die blosse Abneigung gegen die Verstofflichung bei Verben wie kaatua.

Es bedeutet dann nur weitere Ausgestaltung des schon über seine Grenzen erweiterten Begriffs der Teilbarkeit, wenn neben ler Beziehung des Vertss zum subjekt auch diejenige der adverbialen Bestimmung zum subjekt als wichtig erkannt wurde, indem sie ein fest mit der Bestimmung zusammengehöriges Subjekt als »unteilbar» erwies. Auch darin zeigt sich wieder die Quantitätskategorie, num aber ganz in die stilistische Sphäre verlagert und damit weitgehend ins Belieben des Sprechers gestellt. Die Partialität ist nun grossenteils eine Angelegenheit der Ausdrucksfunktion, als die wir sie hier, von der L e is $t$ " $\| \mathrm{g}$ der Sprache ausgehend, zu begreifen versuchten. Wenn eine adverbiale Bestimmung sich auf den wesentlichen Vorstellungsinhalt des subjekts bezieht, dann wird gewöhnlich nicht dies Verhältnis (regenstand der Aussage sein sondern eine Besonderheit des Subjekts. Dadurch ist es individualisiert und muss im entsprechenden Kasus stehen (z.B. Koirussa on suaret lehdet), auch wenn es (notivisch) unbestimmt ist. Da es sich 
dabei aber meist um Feststell u $\mathrm{ng}$ handelt, wird der Satz trotzdem inkongruent geformt (Helsingissä on nykyään kaiklialla sähkölamput).

Der Ausländer hat somit bei Bildung eines hier einschlägigen Satzes folgendes zu untersuchen:

1. Partialität. Dazu muss er feststellen, ob der Satz verneint (fragend oder zweifelnd) ist; ferner die Art der Bestimmtheit der Subjektvorstellung, besonders ob sie als Masse oder als Individuum fungiert, sowie die Beziehung von Subjekt und adverbialer Bestimmung.

2. die Wirkungsart des Subjektgegenstandes in dem durch das Verb bezeichneten Vorgang: es darf nicht von Handlung die Rede sein. Damit fallen alle transitiven Verben aus und von den intransitiven diejenigen, die das Subjekt als Einheit, d.h. als gleichbleibende Substanz, an der sich nur eine zufällige Eigenschaft ändert, oder als Erlebnisträger, der in ein selbständig wirkendes Kraftzentrum gerät, erscheinen lassen.

3. Den Aussagewert des Satzes. Er darf nicht Erzählung oder Schilderung sondern nur Feststellung enthalten (was natürlich nicht ausschliesst, dass er in einem schildernden Kontext steht). Das Subjekt, (las überwiegend psychologisches Prädikat ist, hat reine Nennfunktion, d.h. das betr. Wort hat nur die Aufgabe, im Hörer die entsprechende Vorstellung wachzurufen, nicht aber Nebenvorstellungen, die es in eine andere als rein sachliche Beziehung zu den übrigen Satzteilen bringen könnten. Dem Subjekt gegenüber bilden Verb und Bestimmung eine festere Einheit, u.zw. so, dass der Mitteilungswert der Bestimmung grösser ist als der des Verbs. Zwischen Verb und Subjekt besteht keine semodynamische Verbindung, das Verb ist ein mehr oder minder formales, statisches, sachlich wenig bedeutungstolles Verbindungsglied zwischen den Nomina, für das pluralische Form bereits eine zu starke Konkretisierung bedeutet. Die Bestimmung bleibt zwar, was sie ist, so dass das Subjekt nicht bloss als ihr Inhalt ausgesagt werden kann, aber als für den Kontext wichtige Angabe zur Lokalisierung des Subjekts unterstreicht sie den statischen Charakter des Satzes.

Diese phänomenologische Beschreibung des Tatbestandes ist, wie man sieht, weder kürzer noch einfacher als die bisher vor- 
gelegten, und sie enthält auch keine grundsätzlich neuen Wirkursachen. Ihr Vorteil - zumindest für den Nichtfinnen, wahrscheinlich aber auch für die wissenschaftliche Erkenntnis besteht $m$.E. darin, dass sie die Tatsachen von einer einheitlichen Mitte aus nach ihrem inneren Zusammenhang ordnet. Sadeniemi schreibt mir anlässlich der Beantwortung meiner Fragen, man müsse den Gebrauch des Subjektpartitivs im einzelnen aus der Praxis lernen. Das bedeutet, die bisherigen Regeln nützen nur dem Muttersprachler. Obige Beschreibung versucht nun, dem Xichtfinnen das psychologisch Tỵpische derjenigen syutaktischen und Kontextsituationen klarzumachen, die Partitiv und Inkongruenz bedingen, damit er wenigstens bis zum gewissen Grade selbst entscheiden kann, wann diese beiden syntaktischen Erscheinungen im konkreten Einzelfall am Platze sind. Darüber hinaus aber ist es eine der vornehmsten Aufgaben der Sprachwissenschaft überhaupt, neben der Ermittlung der Sprachtatsachen und ihrer systematischen (jliederung auch die psychologischen und geistigen Grundlagen zu erforschen, die das Sprachgebilde als Werk des Menschen erweisen und ihm jeweils seine eimmalige, unverwechselbare Form geben. Erst dann ist der Kreis weit genug abgesteckt, um der Sprache eine ihrem Charakter entsprechende Untersuchung zuteil werden lassen zu können, um sie als autonome (restalt im Gesamtbereich geistiger Tätigkeit beurteilen zu können.

Wolfgaxg SChlachter. 